\title{
Población, enfermedad y cambio demográfico, 1537-1636. Demografía histórica de Tunja: Una mirada crítica
}

\author{
J. Michael Francis \\ University of North Florida \\ jfrancis@unf.edu \\ Traducción de \\ Víctor Albarracín
}

Fecha de recepción: 24 de mayo de 2002

Fecha de aceptación: 1 de octubre de 2002

\begin{abstract}
Resumen
Este artículo analiza el desarrollo demográfico de la provincia de Tunja durante el primer siglo de la dominación española. Se intenta estimar el tamaño de la población indígena en el momento de la Conquista, evaluando al mismo tiempo las proporciones del descenso poblacional que se dio durante los cien años siguientes. El autor examina detalladamente las investigaciones de demografía histórica que se han realizado hasta el momento sobre el altiplano de la Cordillera Oriental colombiana, aportando nuevas fuentes y consideraciones metodológicas al debate. A partir de estas reflexiones, se argumenta que mientras la población nativa de otras regiones de América Latina logró recuperarse de su crisis inicial a partir de las primeras décadas del siglo XVII, en la provincia de Tunja esto nunca sucedió y continuó disminuyendo a lo largo de este siglo, debido al impacto de las enfermedades contagiosas, los malos tratos, el exceso de trabajo y las migraciones.
\end{abstract}

Palabras clave: POBLACIÓN, ENFERMEDAD, DEMOGRAFÍA HISTÓRICA, TUNJA, SIGLO XVI, SIGLO XVII.

\begin{abstract}
This article analyzes the demographic development of the Province of Tunja during the first century of Spanish domination. An effort is made towards estimating the size of the indigenous population at the time of Conquest, while at the same time evaluating the decrease in population for the following hundred years. The author carefully examines the studies on historical demography for the Colombian Eastern Highlands, adding new sources and methodological considerations to the debate. It is argued that while native populations from other parts of Latin America were able to recover from this initial crisis during the first decades of the $17^{\text {th }}$ century, this never happened in the province of Tunja and the population continued to diminish during this century due to the impact of contagious diseases, harsh treatment, excessive work and migration.
\end{abstract}

Key words: POPULATION, DISEASE, HISTORICAL DEMOGRAPHY, TUNJA, $16^{\mathrm{TH}}$ CENTURY, $17^{\mathrm{TH}}$ CENTURY.

Fronteras de la Historia 7 (2002)

(C) ICANH 


\section{Introducción}

[...Usando] ingeniosos métodos, y con una valentía extraordinaria, los historiadores contemporáneos han establecido el tamaño [estimado] de la población indígena americana en la víspera de la conquista. Ningún argumento de peso ha sido esgrimido en contra de sus resultados, y aquellos que... continúan rechazándolos, lo hacen simplemente porque, si [el cálculo] es correcto, les resulta profundamente perturbador ${ }^{1}$.

El 15 de septiembre de 1559, Juan de Penagos, juez y magistrado en Santafé de Bogotá, envió un mensaje de alarma al Consejo de Indias en España. Allí describía los efectos catastróficos de una peste mortífera, recién aparecida en la Audiencia de la Nueva Granada. Según Penagos, la enfermedad, o enfermedades, ${ }^{2}$ fue traída al puerto de Cartagena por un grupo de esclavos, comprados en la isla de La Española por el obispo de Santafé. El reporte del magistrado describe detalladamente el horror de la epidemia:

Fue esta pestilencia tan grande que vinieron los naturales en tanto trabajo y angustia, que los padres desamparaban los hijos y los hijos a los padres sin poderse valer unos a otros. Y era por el grande hedor que entre ellos andaba que no había quien lo pudiese sufrir. ${ }^{3}$

Penagos afirmaba que más de 40.000 indios de las provincias de Santafé y Tunja habían muerto, y que muchos miles estaban aun infectados. ${ }^{4}$ De hecho, el número de víctimas siguió creciendo hasta el año siguiente, convirtiendo a esta epidemia de 1558-1559, en la más severa del siglo XVI, y probablemente, en la más mortífera de todo el periodo colonial.

Trágicamente, otras epidemias siguieron. Para el tiempo en que Juan de Valcárcel conducía su inspección general en 1635-1636, hubo, tan sólo en la Provincia de Tunja, otros seis brotes epidémicos que redujeron en casi un ochenta por ciento la población nativa de la región, pasando en apenas cien años, de más de 200.000 indios, a menos de 50.000. Aunque una parte de la caída poblacional puede ser atribuida a las guerras de conquista, el escape, la migración, el tratamiento indígena de las enfermedades y el mestizaje, la causa más importante y dramática de ésta fue la irrupción de las enfermedades del Viejo Mundo.

\footnotetext{
${ }^{1}$ Tzvetan Todorov, The Conquest of America (New York: Harper \& Row, 1934), 132.

${ }^{2}$ Es posible que la región hubiera sufrido epidemias de viruela y sarampión en 1559.

${ }^{3}$ Archivo General de Indias, Sevilla (en adelante citado como AGI), Audiencia de Santafé 188, Carta de Juan de Penagos, fol. 226v.

${ }^{4}$ Ibídem, 226r.
} 
El tamaño de la población nativa americana en la víspera de la conquista española ha sido el tema de una gran cantidad de textos académicos. La naturaleza del cambio demográfico en el Nuevo Mundo ha atraído el interés de historiadores, antropólogos, arqueólogos, geógrafos históricos, demógrafos, y recientemente, virólogos y epidemiólogos. También ha sido fuente de un controvertido, y algunas veces, acalorado debate académico. ${ }^{5}$ La demografía histórica de Colombia no es la excepción. Desde 1954, cuando Angel Rosenblat estimaba, aunque sin el uso de material de primera mano, que la población de Colombia en la preconquista no excedía los 850.000 habitantes, el asunto ha recibido una considerable atención académica, sobre todo a nivel regional. En las últimas cuatro décadas se han publicado excelentes estudios demográficos, que cubren diversas áreas del territorio colombiano, entre ellas, Vélez, Pamplona, Cartago, Pasto, Popayán, Santafé, y especialmente, la Provincia de Tunja. ${ }^{6}$ Estos estudios regionales han ido, sucesivamente, haciendo dramáticos reajustes de los estimativos iniciales de Rosenblat. Hoy en día es ampliamente aceptado que la población prehispánica en Colombia alcanzaba al menos los 3’000.000 de habitantes; académicos más audaces sugieren que esta cifra podría subir hasta los cinco o seis millones. ${ }^{7}$ Aunque se ha ido haciendo evidente que la población colombiana anterior al contacto excedía de lejos los 850.000 calculados por Rosenblat décadas atrás, nuestro conocimiento del cambio demográfico en la Nueva Granada es aún insatisfactorio y necesita exploraciones más profundas. ${ }^{8}$ Basta con mirar de cerca los reportes demográficos de la Provincia de Tunja, sin duda la región más y mejor documentada de Colombia, para darse cuenta de que nos falta andar un largo camino para alcanzar algún consenso sobre la naturaleza del cambio poblacional durante el periodo colonial.

\footnotetext{
${ }^{5}$ Los cálculos sobre la población americana en 1492 fluctúan en un rango que va de los 8.4 millones de habitantes estimados por A.L. Kroeber en 1934, a la ligeramente exagerada cifra dada por Henry Dobyns, que oscilaba entre 90 y 112.5 millones. Para un estudio más detallado sobre este debate, se puede consultar: Linda A. Newson, "Demographic Collapse of Native Peoples of the Americas, 1492-1650", en Warwick Bray, ed., The Meeting of Two Worlds: Europe and the Americas, 1492-1650 (Oxford: Oxford University Press, 1993), 247-250.

${ }^{6}$ Aquí, me refiero a los estudios de Darío Fajardo, James Parsons, Kathleen Romoli de Avery, Hermes Tovar Pinzón, Juan y Judith Villamarín, Germán Colmenares y Juan Friede. Para la Provincia de Tunja, la región más estudiada de la Colombia colonial, remitimos a los textos de Jaime Jaramillo Uribe, Juan Friede, Julián Ruiz Rivera, María Ángeles Eugenio Martínez, Germán Colmenares y Hermes Tovar Pinzón.

${ }^{7}$ Para más detalles, remitirse a: Jorge Orlando Melo, Historia de Colombia (Bogotá: La Carreta, 1978), 1: 63-69, y especialmente a: Hermes Tovar Pinzón, "Estado actual de los estudios de demografía histórica en Colombia", Anuario Colombiano de Historia Social y de la Cultura, no. 5 (1970), 65-140. Tovar ha calculado que hacia 1560 quedaban aún, por lo menos, un millón y medio de indios en Colombia, a pesar de que habían pasado ya más de 30 años desde la fundación del primer poblado español en Santa Marta, y más de dos décadas desde la llegada de Gonzalo Jiménez de Quesada y sus hombres a la Cordillera Oriental (es importante anotar que los estimativos de Tovar se basan en las listas de tributo, con lo cual, sólo estarían incluidas en su cálculo las zonas bajo control administrativo de España). Para este efecto, ver: Hermes Tovar Pinzón, No hay caciques ni señores (Barcelona: Sendai Ediciones, 1988), 15. Estas cifras también son citadas en la reciente investigación de McFarlane sobre la Colombia colonial, ver: Anthony McFarlane, Colombia Before Independence: Economy, Society and Politics Under Bourbon Rule (Cambridge: Cambridge University Press, 1993), 16.

${ }^{8}$ Germán Colmenares, por ejemplo, sugiere que la población colombiana anterior al contacto estaba alrededor de los tres millones. Ver: Germán Colmenares, Historia económica y social de Colombia, 1537-1719 (Medellín: Editorial La Carreta, 1975). También citado en: William M. Denevan, ed., The Native Population of the Americas in 1492 (Madison: University of Wisconsin Press, 1976), 154.
} 
Por supuesto, la mayoría de los estudiosos que han intentado calcular el tamaño de la población -precolombina y de la temprana colonia- reconocen que nunca sabremos a ciencia cierta la magnitud del descenso poblacional en la Nueva Granada, y de igual forma, en el resto del Nuevo Mundo. Censos confiables de las comunidades nativas eran raros durante el periodo colonial temprano, y en muchas zonas de América Latina, inexistentes hasta el último siglo. A pesar de los sofisticados, y algunas veces "ingeniosos" cálculos sobre los que algunos investigadores han basado sus estimativos, las cifras de población para el siglo XVI permanecen, a lo sumo, como "suposiciones informadas" (informed guesses) ${ }^{9}$. Pero, ¿qué constituye con exactitud una suposición informada? ¿Estamos resignados, como sugiere Nancy Farris, a "escoger cualquier cifra (poblacional) que impacte (nuestro) capricho o prejuicio"? ${ }^{10}$

El propósito de este estudio es llegar a una suposición informada sobre el tamaño de la población nativa de Tunja en la víspera de la conquista española, y evaluar el descenso poblacional ocurrido durante el siglo que siguió a ésta. No reclamo tener cálculos poblacionales precisos sobre Tunja durante la colonia temprana; esa nunca ha sido mi intención. Tal conteo, dada la naturaleza dispersa, y algunas veces dudosa, de las fuentes disponibles, se convertiría en un ejercicio engañoso y frustrante. Tampoco me propongo sugerir o proponer nuevas aproximaciones metodológicas a la historia demográfica. En cambio, este estudio examina detalladamente la historiografía de los estudios de población enfocados en la Cordillera Oriental colombiana, y especialmente en la Provincia de Tunja, introduciendo a los lectores en la evolución demográfica de ésta durante el primer siglo de gobierno español y, por medio de un exhaustivo análisis de evidencia documental hasta ahora abandonada, provee estimativos generales sobre el tamaño de la población, desde la víspera de la conquista hasta mediados del siglo XVII. Esta aproximación nos ayudará a cerrar el amplio espectro de cálculos de población que existen para la región, y al mismo tiempo, plantea dudas considerables sobre la validez de los estudios poblacionales aplicados a ésta. Lo que se evidencia es que, a diferencia de otras regiones latinoamericanas, donde la población nativa comenzó a recuperarse hacia el primer cuarto del siglo XVII, y en algunos casos ya en la década de 1590, la población indígena de la Provincia de Tunja nunca logró vencer la persistente acometida de la enfermedad, y el dramático descenso demográfico se perpetuó hasta la llegada, e incluso durante la totalidad, del siglo XVII ${ }^{11}$. A pesar de las inherentes dificultades metodológicas a las que uno se enfrenta cuando se examinan registros de censos de la temprana colonia, sugiero que las cifras de población recogidas en la Provincia de Tunja no fueron infladas por avaros encomenderos $u$ oficiales reales, en un intento de expropiar tantas riquezas de las comunidades Muisca como fuera posible, sino que, más bien, corresponden a reflexiones precisas, y aún conservadoras, sobre el tamaño de la población.

\footnotetext{
${ }^{9}$ Nancy Farris, Maya Society Under Colonial Rule: The Collective Enterprise of Survival (Princeton: Princeton University Press, 1984), 57.

${ }^{10}$ Ibídem.

${ }^{11}$ Aquí, me refiero específicamente a la recuperación reportada en el norte ecuatoriano. Para más información al respecto ver: Newson, "Demographic Collapse", 253.
} 


\section{Demografía histórica de Tunja: Una mirada crítica}

Hace veinticinco años, Charles Gibson publicó un provocador ensayo sobre las últimas tendencias en la historiografía del Méjico colonial. En el artículo, Gibson advierte a los lectores sobre el examen crítico de todos los textos históricos, aún (y tal vez, sobretodo) aquellos que parecen estar más allá de cualquier reproche.

Los libros que perduran, generalmente, lo hacen por falta de competencia, $y$ como no estimulan posteriores investigaciones, dominan la bibliografía por defecto y, por consiguiente, nadie sabe cuán vulnerables son en realidad ${ }^{12}$.

En muchos aspectos, durante los últimos veinticinco años, nuestra comprensión de la historia demográfica colonial colombiana ha sufrido una falta de "competencia" académica. Por supuesto, la escasez de estudios poblacionales detallados sobre la Colombia de la temprana colonia no ha pasado inadvertida. Hace más de tres décadas, el historiador colombiano Hermes Tovar Pinzón criticaba el estado de la demografía histórica en Colombia, y pedía a los académicos un nuevo examen de las evidencias de archivo disponibles, para lograr una reconstrucción más exacta de la historia poblacional colombiana. Tovar se quejaba de que en los estudios demográficos existentes faltaban los detalles necesarios para sentar conclusiones fiables sobre el tamaño de la población indígena colombiana del pre-contacto y la colonia temprana. Un examen cuidadoso del material secundario revela que la crítica de Tovar se refleja claramente en el amplio rango de estimativos para el territorio Muisca. Por ejemplo, en 1949, A.L. Kroeber sugería que la población total de las provincias de Tunja y Santafé estaba, en la preconquista, alrededor de los 300.000 habitantes $^{13}$. En un libro publicado ese mismo año, Guillermo Hernández Rodríguez afirmaba que la población de esa misma región era significativamente mayor, oscilando entre 800.000 y un millón ${ }^{14}$. ¿Quién tenía razón? Desafortunadamente, ninguna de estas cuentas se sostiene ante un cuidadoso escrutinio, ya que ni Kroeber ni Hernández explican cómo obtuvieron sus cifras.

Quince años más tarde, Jaime Jaramillo Uribe conduce uno de los primeros estudios detallados de población en el territorio Muisca, y concluye que los cálculos de Kroeber no sólo eran adecuados, sino que, de ninguna manera la población combinada de Tunja y Santafé podría haber excedido los 300.000 habitantes durante la preconquista ${ }^{15}$. Aunque Jaramillo confiesa, al

\footnotetext{
${ }^{12}$ Charles Gibson, "Writings on Colonial México", Hispanic American Historical Review 55, no.2 (1975), 299.

${ }^{13}$ A.L. Kroeber, "The Chibcha" en Handbook of South American Indians, ed. Julian H. Steward (New York: Cooper Square Publishers Inc., 1963), 2:660. Las provincias de Santafé y Tunja corresponden aproximadamente a los actuales departamentos de Cundinamarca y Boyacá.

${ }^{14}$ Guillermo Hernández Rodríguez, De los chibchas a la colonia y a la república (Bogotá: Universidad Nacional de Colombia, 1949), 11.

${ }^{15}$ Jaime Jaramillo Uribe, "La población indígena de Colombia en el momento de la conquista y sus transformaciones posteriores", Anuario Colombiano de Historia Social y de la Cultura 1, no.2 (1964), 284. Jaramillo Uribe fue uno de los primeros historiadores en proveer evidencia documental como soporte de sus conclusiones, que el basaba principalmente en dos fuentes, la Geografia y descripción universal de las Indias, de Juan de Velazco (1574), y la
} 
final de su artículo, que aún es muy temprano para intentar sacar conclusiones convincentes sobre el tamaño de la población indígena de la preconquista y la colonia temprana, se muestra convencido, a partir de la evidencia demográfica aportada por la visita de Angulo de Castejón, en 1562, de que una población de 300.000 habitantes debía ser considerada como el máximo posible. Sin embargo, si Jaramillo Uribe estaba en lo cierto, y la región no podía soportar una población mayor de 300.000, ¿por qué el reputado antropólogo Gerardo Reichel-Dolmatoff sugiere para esta misma zona la cifra de $500.000 ?^{16}$

No pasó mucho tiempo para que las conclusiones de Jaramillo Uribe fueran puestas en tela de juicio. El año siguiente, Juan Friede publica un breve informe sobre el cambio demográfico en la Tunja de la colonia temprana ${ }^{17}$. Friede concluye que sólo la población de Tunja en la preconquista alcanzaba los 560.000, una insinuación asombrosa cuando se considera que los estimativos de Jaramillo incluían a la provincia de Santafé, una región de tamaño similar, y probablemente, con una similar distribución poblacional en el momento de la conquista. En otras palabras, las conclusiones de Friede sobre la Provincia de Tunja implican que el tamaño de la población en el territorio Muisca de la preconquista pudo exceder fácilmente el millón de habitantes, muy lejos del límite de 300.000, establecido apenas un año atrás. Una controversia nacía entonces. ¿O tal vez no?

Treinta y cinco años después de haberse publicado su estudio sobre Tunja, las hipótesis y metodologías de Friede ameritan un escrutinio cuidadoso, especialmente porque sus cifras continúan siendo ampliamente aceptadas. Friede adoptó aproximaciones metodológicas muy similares a las utilizadas por Jaramillo Uribe. Sin embargo, en lugar de intentar un cálculo poblacional razonable basado en los datos recogidos durante la visita de Angulo de Castejón en 1562, optó por enfatizar en las más exactas y detalladas cifras, recogidas setenta y cuatro años más tarde, durante la visita realizada por Juan de Valcárcel en 1635-36. La decisión de Friede de reconstruir la población de Tunja en el siglo XVI mediante el uso de una fuente del siglo XVII se basó en el hecho de que Valcárcel ofrecía cifras poblacionales para comunidades enteras, y no sólo listas de indios tributarios, como era característico en las inspecciones anteriores.

Basado en la información demográfica recogida por Valcárcel, Friede encuentra que la población tributaria de Tunja, en 1636, era de 9.272, mientras la población total alcanzaba los

visita de Angulo de Castejón a la Provincia de Tunja (1562). Ibídem, 251-255. Jaramillo sospechaba de la afirmación de Velazco, según la cual había 92.000 indios tributando en las provincias de Santafé y Tunja al momento de la conquista, y basaba sus sospechas en las cifras recogidas por Angulo de Castejón durante su visita de 1562, según las cuales calculaba una población tributaria de 33.386 para la Provincia de Tunja. Jaramillo multiplicó esta cifra por tres, para alcanzar una población total de 111.158. Así concluía, entonces, que era altamente improbable, si no imposible, que la población combinada de Santafé y Tunja excediera los 300.000 al momento de la conquista.

16 Gerardo Reichel-Dolmatoff, "Colombia indígena”, en Manual de Historia de Colombia (Bogotá: Instituto Colombiano de Cultura, 1984), 1:97.

${ }^{17}$ La provincia colonial de Tunja corresponde aproximadamente a lo que es hoy el departamento de Boyacá, abarcando un área ligeramente menor a la de Bélgica, o aproximadamente la misma del estado norteamericano de Maryland. 
44.691 ${ }^{18}$. A partir de estas cifras, Friede adapta un coeficiente de 4,82:1, que representa el número total de habitantes frente al de indios tributarios. Luego, utiliza el mismo coeficiente para calcular la población del siglo XVI. Aquí, Friede regresa a una de las primeras visitas a la Provincia de Tunja.

El primer registro de censo del siglo XVI, encontrado por Friede, era una retasa de 1564 (basada en la visita que Angulo de Castejón hizo en 1562). En aquel censo, Friede cuenta 34.946 indios tributarios, que al ser multiplicados por 4,82, resultan en una población total de 168.440 , para el año de 1564. Luego Friede se propone calcular la población posible para la preconquista, una tarea intimidante, considerando que la visita de Angulo de Castejón tuvo lugar casi veinticinco años después del primer contacto español con el territorio Muisca. En el intento por alcanzar su meta, Friede desarrolla un método creativo, algo confuso y bastante sospechoso.

Usando los datos de la retasa de 1564, y los de la visita de Juan de Valcárcel en el siglo XVII, Friede encuentra que entre los años 1564 y 1636, la población de Tunja tuvo una caída del $73,5 \%$; luego, asume que ésta fue constante, y de una magnitud similar a la ocurrida entre el momento del arribo español a la región y el año de la retasa. Por lo tanto, concluye que en los veintisiete años transcurridos entre 1537 y 1564, la población indígena de la región pudo haberse reducido en un $27,54 \%$. Friede multiplica por este porcentaje el total de 168.440 censados en 1564, para obtener una población estimada, al momento del primer contacto, de 232.407 habitantes ${ }^{19}$. No obstante, sabía que la población de Tunja en la preconquista era mucho mayor, y estaba convencido de que la retasa de 1564 no había incluido a los habitantes de los cacicazgos de Duitama y Sogamoso, dos de los más grandes e importantes de la provincia en el siglo XVI.

Para probar su hipótesis, Friede acude a una pequeña y muy cuestionable inspección de los cacicazgos de Duitama y Sogamoso, conducida por el fiscal Antonio de Luján, en 1543, apenas seis años después del arribo español al territorio Muisca ${ }^{20}$. Friede usa la evidencia recogida en el reporte de Luján para calcular con más exactitud, según cree, la población de Tunja al momento del contacto. Sin embargo, debe tenerse en cuenta que las cifras de Lujan se basaban en el testimonio de dos personas. Por ejemplo, para el cacicazgo de Duitama, Friede hace el cálculo de la población basado en el testimonio del cacique Sytimoso. Según él, en el momento de la llegada de los españoles, Duitama ejercía el control político sobre cincuenta y siete capitanías, pero en la retasa de 1564, descubre Friede, sólo veinte son censadas. Las otras habían desaparecido, y su ausencia en el reporte de Castejón se debía, según asume Friede, a que sucumbieron ante la enfermedad. Pero, ¿cuántos indios pudieron morir entre 1537 y 1564 ?

\footnotetext{
18 Juan Friede, “Algunas consideraciones sobre la evolución demográfica en la Provincia de Tunja”, Anuario Colombiano de Historia Social y de la Cultura 2, no.3 (1965), 12-13.

${ }^{19}$ Ibídem, 13.

${ }^{20}$ Ibídem, 15. Según Friede, el propósito de los datos de población recogidos en la zona era la posterior distribución de encomiendas, que Lugo haría entre sus seguidores.
} 
Friede retoma las cifras del censo de 1564 para calcular la población tributaria de las veinte capitanías incluidas en la visita, y encuentra que había 12.120 indios obligados al tributo, un promedio de 601 indios por capitanía. Luego aplica esta cifra a cada una de las treinta y siete capitanías "desaparecidas", obteniendo, para Duitama, una población tributaria de 34.257. Luego, incrementa esta cifra en un $27,54 \%$ y multiplica el resultado por 4,8 (el número de habitantes por cada indio tributario), llegando a 227.875 el total de la población indígena de Duitama en $1537^{21}$.

Adopta luego el mismo método para calcular la población de Sogamoso en 1537. El censo de 1564 incluye listas tributarias de apenas veintiuna de las treinta y cuatro capitanías que, según varios testigos, dependían del cacique de Sogamoso en el momento de la conquista. Estas veintiún capitanías tenían una población tributaria de 9.650 indios, un promedio de 460 por cada una. Friede aplica esta cifra a las trece capitanías restantes, con lo que obtiene una población de 15.650 indios (tributarios) en 1564. Incrementa este número en $27,54 \%$, multiplica por 4,8, y concluye que la población total de Sogamoso, al momento del contacto, era de 104.035 indios ${ }^{22}$. Luego añade las cifras de Duitama y Sogamoso a las obtenidas en su primer cálculo, con lo que el total de la Provincia de Tunja alcanzaría los 562.510 habitantes al momento de la conquista ${ }^{23}$. Curiosamente, a pesar de tan cuestionable aproximación metodológica, las cifras aportadas por Friede son ampliamente aceptadas ${ }^{24}$. De hecho, algunos estudios recientes insinúan cifras de población aún mayores para el territorio muisca de la preconquista ${ }^{25}$.

Sin embargo, a pesar de la aceptación general de los cálculos de Friede, hay muchas razones para poner en tela de juicio la exactitud de sus conclusiones. La aproximación de Friede fue, sin duda, original. Su planteamiento de que la población de Tunja en la preconquista era mucho mayor que la asumida por académicos anteriores es una teoría aceptable, especialmente cuando se considera lo que ahora sabemos sobre la magnitud de la caída demográfica entre los indios del Nuevo Mundo. Sin embargo, hay algunos errores serios en su trabajo, siendo el más importante el que Friede inventara poblaciones, o más exactamente, capitanías, que simplemente no existieron. El resultado de esta falla es que Friede terminó contando dos, y hasta tres veces, los mismos indios.

Por ejemplo, Friede asume arbitrariamente que cada una de las cincuenta capitanías de Duitama y Sogamoso que no se incluyen en el censo de 1564 tenía el mismo número de indios que las registradas allí. Por lo tanto aplica el mismo promedio de indios tributarios por capitanía (601 para Duitama y 460 para Sogamoso) a cada capitanía ausente en la retasa de 1564. Friede aborda cada capitanía como un ente separado, cuando en la realidad Muisca éstas formaban parte del mismo pueblo o cacicazgo. En otras palabras, es probable que, en muchas de las

\footnotetext{
${ }^{21}$ Ibídem, 15-17.

${ }^{22}$ Ibídem, 16-17.

${ }^{23}$ Ibídem, 17.

${ }^{24}$ Los cálculos poblacionales de Friede han sido citados en: Armando Suescún Monroy, La economía chibcha (Bogotá: Ediciones Tercer Mundo, 1987), 19-20.

${ }^{25}$ Melo, Historia de Colombia, 59.
} 
capitanías, Friede no reconociera que las claras divisiones políticas que implicó a partir del reporte de Luján no reflejaban lo que era una realidad en extremo confusa. Registros coloniales revelan docenas de ejemplos de encomiendas con más de un capitán. El resultado es que Friede, probablemente, agregó población que ya había sido incluida en la retasa de 1564.

Germán Colmenares, tal vez el mejor historiador de la Colombia colonial, fue igualmente crítico con el mal uso que dio Friede al reporte de Luján de 1543. Según Colmenares, las listas de capitanías perdidas utilizadas por Friede, deben ser rechazadas, ya que no hay ninguna evidencia que sugiera la existencia de ellas, especialmente, añade, cuando se considera las dificultades que han enfrentado los historiadores para ubicar y nombrar con exactitud los pueblos muisca. Los nombres de los lugares cambiaban constantemente, y a menudo se dificulta saber si cierto nombre referido en un documento alude a un pueblo, una parcialidad, el nombre de un cacique o capitán, o una combinación de los cuatro ${ }^{26}$. No sólo eso, sino que, frecuentemente, los nombres de los pueblos cambiaban cuando los caciques eran reemplazados, cuando comunidades grandes se dividían o, algunas veces, cuando las pequeñas se congregaban.

Igualmente cuestionable es el coeficiente, planteado por Friede de 4,8 habitantes por cada indio tributario. Aunque la evidencia documental recogida durante la visita de Juan de Valcárcel sugiere que había de hecho 4,8 personas por tributario en 1636. Friede no ofrece ninguna evidencia adicional de que ese fuera el caso en otros periodos del siglo XVI y comienzos del XVII. De hecho, el alto porcentaje de indios en 1636, podría indicarnos que la población nativa se había hecho más resistente a las enfermedades del Viejo Mundo. También podría ser un reflejo del número creciente de hombres adultos, quienes, al prestar sus servicios personales a los encomenderos, se hacían merecedores de la exención tributaria y, por consiguiente, no contaban como indios tributarios.

Sin embargo, hay evidencia documental dispersa sobre el territorio muisca, donde se indica que el tamaño de las familias era considerablemente menor al sugerido por Friede. Por ejemplo, en 1595, el visitador Juan de Ibarra reportó 19.161 indios tributarios para la provincia de Santafé, frente a una población total de 42.224. Esto significa que había apenas 2,2 personas por indio tributario, un porcentaje significantemente menor al calculado por Friede para 1636. En todo caso, las cifras de Ibarra deben ser analizadas con cautela, ya que sus listas tributarias incluían tanto a caciques y capitanes como a ancianos, mientras que las recopiladas durante la visita de Valcárcel sólo incluyen a los adultos que pagan tributo; esto es, a hombres con edades entre los diecisiete y cincuenta y cuatro años, quienes eran responsables del tributo anual (excluyendo de ese modo a los caciques, capitanes y ancianos, al igual que a otros grupos de adultos, eximidos, por motivos diversos, de la tributación). No es sorpresivo entonces que el porcentaje poblacional por tributario sea mucho más alto en la inspección de Valcárcel que lo encontrado por Ibarra cuarenta y un años atrás. Es claro que no se puede aplicar el mismo porcentaje

\footnotetext{
${ }^{26}$ En su detallado estudio de la encomienda en la Nueva Granada durante el siglo XVII, Julián Ruiz Rivera dice haber tenido problemas similares en la identificación exacta de los lugares muisca. Ver: Julián Ruíz Rivera, Encomienda y mita en Nueva Granada en el siglo XVII (Sevilla: Escuela de Estudios Hispano Americanos de Sevilla, 1975), 213
} 
poblacional de 1636 a las visitas anteriores de $1562,1571,1600$ o cualquier otra realizada durante el periodo colonial. Los estándares, simplemente, no son los mismos ${ }^{27}$.

Tal vez el estudio demográfico más influyente sobre la Tunja colonial venga del historiador colombiano Germán Colmenares. Hasta la fecha, Colmenares es el único investigador que ha analizado a largo término el cambio poblacional en la provincia. En todo caso, la aproximación de Colmenares es más cauta que la de Juan Friede, su predecesor, ya que termina por concluir que la evidencia documental del siglo XVI es muy escasa e insuficiente para alcanzar cualquier tipo de cálculo informado sobre la población de Tunja en la preconquista. De hecho, le da poco crédito a todas las cifras poblacionales recogidas con anterioridad a la visita de Valcárcel en 1635-36. Colmenares concluye que una reconstrucción exacta del tamaño de la población indígena en la Nueva Granada debe ser confinada al siglo XVII, ya que no es posible hacer en Colombia el mismo tipo de análisis demográfico que Sherburne Cook y Woodrow Borah hicieron en $\mathrm{Méjico}^{28}$. O no hay fuentes, o aún deben ser descubiertas. Por lo tanto, debido a la aparente escasez de fuentes confiables, Colmenares escoge no intentar el cálculo de la población de Tunja en la preconquista. En cambio, ofrece sólo un cálculo tentativo para el año 1551, más de una década después de la llegada de Gonzalo Jiménez de Quesada a territorio muisca, y a casi cincuenta años del primer contacto europeo con población nativa colombiana; como sea, 1551 es la fecha más temprana sobre la que Colmenares aporta cifras de población ${ }^{29}$.

Usando una rica variedad de material de archivo, especialmente evidencia de las visitas de Angulo de Castejón, en 1562, y de Juan de Valcárcel, en 1635-36, Colmenares llega a cálculos de población en Tunja para siete años distintos entre 1551 y la mitad del siglo XVIII (ver Tabla 4, más adelante). Por supuesto, el libro de Colmenares La Provincia de Tunja en el Nuevo Reino de Granada, no es solamente el mejor estudio poblacional sobre la Tunja colonial escrito hasta la fecha, sino que se mantiene como una de las obras más completas sobre la demografía de cualquier región de la Nueva Granada ${ }^{30}$. Aún a pesar de su contribución a nuestro entendimiento de los patrones demográficos en la Tunja colonial, el estudio de Colmenares está lejos de ser exhaustivo. Por ejemplo, las listas tributarias de la visita anónima de 1560 no habían sido descubiertas aún, y Colmenares encuentra sólo pequeñas muestras de población recogidas durante las visitas de Juan López de Cepeda, Egas de Guzmán y Luis Enríquez.

\footnotetext{
${ }^{27}$ Estudios sobre la familia colonial en Tunja también han sugerido que el coeficiente de Friede, al menos en lo que respecta al siglo XVII, debería ser mucho menor. Por ejemplo, Jaime Jaramillo Uribe calculó un coeficiente de tres personas por tributario. Si bien concede que su cifra es conservadora, Jaramillo afirma que su cálculo está soportado en evidencia de archivo disponible. También encontró que el promedio de hijos por familia era de apenas dos, y que un alto porcentaje de matrimonios, casi el cincuenta por ciento en algunas comunidades, no tenía hijos. Según Jaramillo, las familias con cuatro hijos eran realmente raras. Ver: Jaime Jaramillo Uribe, Ensayos sobre historia social colombiana (Bogotá: Universitaria de Cultura Colombiana, 1968), 89-150.

${ }^{28}$ Germán Colmenares, Encomienda y población en la provincia de Pamplona, 1549-1650 (Bogotá: Universidad de los Andes, 1969), 7.

${ }^{29}$ Germán Colmenares, La provincia de Tunja en el Nuevo Reino de Granada (Bogotá: Universidad de los Andes, 1970), 72.

${ }^{30}$ Aquí debemos considerar también las obras de Hermes Tovar Pinzón y de Juan y Judith Villamarín.
} 
Pero, ¿cómo logró Colmenares alcanzar sus cifras de población? Su primer paso consistió en determinar el número total de comunidades nativas que fueron registradas durante la visita que, en el siglo XVII, hizo Juan de Valcárcel, para luego establecer una comparación con las cifras obtenidas por Angulo de Castejón, más de siete décadas atrás, en $1562^{31}$. El análisis de Colmenares sobre las dos inspecciones revelaba que había 97 pueblos de indios en la Provincia de Tunja en 1562, dieciocho menos que los 115 registrados por Valcárcel en 1636. Y para los 97 pueblos que pudo identificar, Colmenares calculó, para 1562, una población tributaria de 38.755 , una cifra no muy lejana de la que yo sugiero en este estudio ${ }^{32}$. Como sea, según Colmenares, este total no representa con exactitud la población tributaria de Tunja, ya que, la visita de Angulo de Castejón quedó incompleta, conclusión que creyó haber confirmado por el hecho de que un número muy alto de comunidades nativas que fueron incluidas en la visita de 1636, no se mencionaron en 1562. En efecto, de los 115 pueblos de indios que aparecían en la visita de 1636, un total de 44 nunca fueron mencionados en el reporte de Angulo. Otros cinco pueblos que aparecían en la visita de Luis Enríquez, en 1601, faltaban en los registros de 1562. Esto sorprendió a Colmenares, especialmente a la luz del hecho de que, muchos cacicazgos que existían en 1562, habían desaparecido completamente hacia 1636, debido a la caída demográfica, mientras otros habían sido combinados para crear congregaciones más grandes y pobladas. Si ese era el caso, postulaba Colmenares, debía haber menos pueblos en 1636 que los que había en 1562. ¿Por qué había aumentado el número de pueblos? ¿Qué había pasado con los 49 pueblos aparecidos en inspecciones posteriores? ${ }^{33}$ ¿Por qué fueron ignoradas estas poblaciones en 1562 ?

Colmenares concluye que la ausencia de tantos pueblos en el reporte final de Angulo de Castejón no es necesariamente la negación de su existencia, sino más bien, el resultado de una inspección incompleta de la provincia. Esta es una deducción lógica, especialmente cuando se considera la geografía de la región y la forma como las primeras visitas a la Provincia de Tunja fueron conducidas. Se afirmaba que los obstáculos encarados por los primeros visitadores durante el siglo XVI eran tan grandes, que un reporte minucioso de toda la audiencia de la Nueva Granada habría tomado años en completarse ${ }^{34}$. En la descripción de Tunja de 1610 se sugería que, debido a los patrones dispersos de asentamiento en las comunidades muisca, un

\footnotetext{
${ }^{31}$ Desafortunadamente, los cálculos de Colmenares no eran suficientemente claros. Por ejemplo, él concluye que en 1562, había un total de 97 pueblos en la Provincia de Tunja; sin embargo, en el apéndice, provee cálculos de población para 105 pueblos. También afirma que había 115 pueblos en 1636, pero cita apenas 112 en el apéndice. Para el propósito de este estudio y para evitar confusiones, se citarán únicamente los datos que Colmenares incluyó en su estudio, sin asumir los que no están.

${ }^{32}$ Una de las razones de la diferencia marginal entre las cifras de Colmenares y las mías es que los números que yo cito provienen del AGI en Sevilla, mientras que los de Colmenares fueron recolectados en el Archivo General de la Nación (AGN) en Bogotá. Parece como si las cifras poblacionales enviadas a España luego de la visita fueran redondeadas usualmente a un número menor que el archivado en la Nueva Granada.

${ }^{33}$ Debe notarse que Colmenares encontró un total de 49 pueblos que no aparecían en la visita de 1562, pero que fueron registrados en inspecciones posteriores. Sin embargo, cuando reconstruyó la población tributaria potencial de estos pueblos, inexplicablemente, incluyó apenas 48. Ver: Colmenares, La Provincia, 64.

${ }^{34}$ Ruíz Rivera, Encomienda y mita, 17.
} 
conteo exacto de la población tomaría al menos tres o cuatro años ${ }^{35}$. Incluso entonces, el aislamiento de algunos pueblos nativos de los asentamientos españoles, combinado con la escarpada grandeza de un territorio desconocido y un terreno desafiante, implicaba que algunas comunidades lograran escapar a la inspección personal. Sin embargo, Colmenares afirma que, a pesar de su ausencia de las listas originales de población, recogidas durante la visita de Angulo, era posible asignar, con una exactitud razonable, cifras tributarias para cada pueblo.

Tratando de establecer la población tributaria de los 48 pueblos "perdidos" en 1562, Colmenares intentó reconstruir la población potencial de cada comunidad $^{36}$. Basó estas reconstrucciones en la información recogida en 1635-36 por Juan de Valcárcel, y en las cifras tributarias disponibles de 1562. Aquí, la aproximación más simple pudo consistir en determinar un porcentaje de despoblación regional; en otras palabras, Colmenares pudo haber comparado la población tributaria de los pueblos que aparecían en ambas visitas, para luego calcular un porcentaje de despoblación para toda la provincia. Este es un método muy popular que ha sido adoptado por algunos historiadores demográficos, como Juan Friede. Usando la información tributaria de los pueblos que fueron incluidos en ambas visitas, Colmenares pudo haber calculado un porcentaje de despoblación para toda la provincia, que podría aplicar luego a los pueblos que no aparecían en los registros de 1562. Colmenares adoptó de hecho esta metodología, ampliamente aceptada, para calcular la población nativa de Tunja en el siglo $\mathrm{XVI}^{37}$. Sin embargo, en lugar de sugerir una caída poblacional uniforme para toda la provincia, su aproximación fue un paso más allá. Colmenares fue sensible a las variaciones regionales de pérdida de población y por lo tanto, en un intento de alcanzar lo que consideraba una representación más exacta de la caída demográfica en la provincia, decidió dividir las comunidades nativas en corregimientos.

Una de las mayores contribuciones del estudio de Colmenares sobre cambio poblacional, y una de las diferencias más significativas entre su trabajo y otros estudios de población de la Provincia de Tunja, consiste en que Colmenares reconoció que había importantes variaciones regionales en el índice de caída demográfica dentro de la provincia misma. Por lo tanto, intentó analizar el cambio poblacional a un nivel más local, agrupando pueblos nativos en unidades más pequeñas, es decir, en uno de los ocho corregimientos separados que se habían establecido hacia comienzos del siglo XVII ${ }^{38}$. Aunque encontró que hubo una dramática caída demográfica en la población general de la provincia, su aproximación reveló también variaciones regionales significativas en el nivel de despoblación (ver la Tabla 1 para cifras de población específica).

\footnotetext{
35 "Descripción de la ciudad de Tunja, sacadas de las informaciones hechas por la justicia de aquella ciudad en 30 de mayo de 1610 años", trascrito por Juan Torres de Mendoza, en Colección de documentos inéditos relativos al descubrimiento, conquista y organización de las antiguas posesiones españolas de América y Oceanía, (Madrid: Imprenta de Frías y Compañía, 1868), 9:430.

${ }^{36}$ Ver pie de página 32.

${ }^{37}$ Para una explicación más detallada de las ventajas y defectos del método de porcentaje de despoblación, ver: Noble David Cook, Demographic Collapse: Indian Peru, 1520-1620 (Cambridge: Cambridge University Press, 1981), 4144.

${ }^{38}$ Colmenares, La provincia de Tunja, 99-100. Los ocho corregimientos eran Tenza, Duitama, Sogamoso, Gámeza, Turmequé, Chivatá, Paipa y Sáchica.
} 
Por ejemplo, Colmenares descubrió que la población indígena del corregimiento de Tenza experimentó el más alto índice de pérdida poblacional entre los años 1562 y 1636. La población de Tenza cayó en un asombroso 93\%. Por otro lado, la caída demográfica en comunidades del corregimiento de Sáchica fue mucho menos severa, alcanzando el $65 \%$ en el mismo periodo. Los seis corregimientos restantes sufrieron pérdidas de población mayores que las de Sáchica: la población de Chivatá cayó en $66 \%$, Paipa en $74 \%$, Turmequé en $80 \%$, Gámeza en $83 \%$, y Duitama y Sogamoso en $86 \%{ }^{39}$.

Tabla 1: Descenso en la población tributaria por corregimiento, 1562-1636

\begin{tabular}{|l|r|r|}
\hline TENZA & $\mathbf{1 5 6 2}$ & \multicolumn{1}{|c|}{$\mathbf{6 3 6}$} \\
\hline & 100 & 58 \\
\hline Buisa & & \\
\hline Ciénaga & 800 & 86 \\
\hline Tenza & 450 & 26 \\
\hline Sunaba & 350 & 17 \\
\hline Chiramita & 500 & 34 \\
\hline Ramiriquí & 624 & 58 \\
\hline Gacha ${ }^{40}$ & 200 & 21 \\
\hline Sutamanga \\
\hline \multicolumn{2}{|c|}{ Caída total: 93\% } \\
\hline Ausentes en 1562 & $\mathbf{1 6 3 6}$ \\
\hline Guateque & 38 \\
\hline Ubrita & & 7 \\
\hline Guaneca & 3 \\
\hline Furaquirá & 104 \\
\hline
\end{tabular}

\footnotetext{
${ }^{39}$ Ibídem.

${ }^{40}$ Colmenares no ofrece cifras tributarias de Cuitivá en 1636. Evidencias de archivo indican que había 83 tributarios en Cuitivá cuando Valcárcel realizó su visita. Colmenares no pudo encontrar datos de población para Gacha, Sutamanga y Furaquirá, todos en el corregimiento de Tenza. Los 58 tributarios de Gacha en 1636 incluían tributarios de Furaquirá, y los 21 tributarios de Sutamanga incluían indios de Baganique. Los 104 tributarios reportados para Furaquirá provenían de dos encomiendas distintas: 46 venían de la de Pedro Arias Maldonado, y los 58 restantes, de la de Juan de Osa, que también incluía indios de Gacha.
} 


\begin{tabular}{|l|r|r|}
\hline TURMEQUÉ & $\mathbf{1 5 6 2}$ & $\mathbf{1 6 3 6}$ \\
\hline & & \\
\hline Turmequé & 1.500 & 357 \\
\hline Boyacá & 650 & 128 \\
\hline Icabuco & 2080 & 283 \\
\hline Sora & 450 & 91 \\
\hline \multicolumn{2}{|c|}{ Caída total: 80\% } \\
\hline Ausentes en 1562 & $\mathbf{1 6 3 6}$ \\
\hline Soconsaque & & 6 \\
\hline Tibaná & & 106 \\
\hline Cupasayna (Cupazaine) & & 8 \\
\hline
\end{tabular}

\begin{tabular}{|l|r|r|}
\hline SOGAMOSO & $\mathbf{1 5 6 2}$ & $\mathbf{1 6 3 6}$ \\
\hline & & \\
\hline Monquirá & 629 & 129 \\
\hline Tota & 884 & 71 \\
\hline Iza & 125 & 83 \\
\hline Cuitiva & 206 & $\mathbf{8 3}$ \\
\hline Chameza & \multicolumn{1}{|c|}{591} & 49 \\
\hline \multicolumn{2}{|c|}{ Caída total: 86\% } \\
\hline Ausentes en 1562: & & $\mathbf{1 6 3 6}$ \\
\hline Bombaza & & 82 \\
\hline Guáquira & & 44 \\
\hline Toquecha & & 62 \\
\hline Toquilla & & 9 \\
\hline Firavitoba & & 148 \\
\hline Monguí & & 97 \\
\hline Tutasa & & 24 \\
\hline Tibasosa & & 100 \\
\hline Nobsa & 56 \\
\hline
\end{tabular}

\begin{tabular}{|l|r|r|}
\hline GÁMEZA & $\mathbf{1 5 6 2}$ & $\mathbf{1 6 3 8}$ \\
\hline & & \\
\hline Topaga & 697 & 137 \\
\hline Gámeza $^{41}$ & 550 & 61 \\
\hline
\end{tabular}

\footnotetext{
${ }^{41}$ Aquí, Colmenares da una población tributaria, para 1562, de 1.086. No es claro de dónde obtiene esta cifra, ya que hay evidencia de archivo que muestra claramente que la población tributaria de Gámeza era, hacia la fecha, significativamente menor, alcanzando apenas 550 habitantes. El cálculo de la caída poblacional del $83 \%$ en Gámeza, entre 1562 y 1636, está basado en cifras erróneas, ya que Colmenares parte de 1.086 tributarios y no de 550, como se encuentra registrado.
} 


\begin{tabular}{|l|r|r|}
\hline GÁMEZA & \multicolumn{1}{|c|}{1562} & \multicolumn{1}{|c|}{} \\
\hline & & \\
\hline Busbanzá & 269 & 79 \\
\hline Socotá & 450 & 46 \\
\hline Comeza & 208 & 113 \\
\hline Socha & 728 & 109 \\
\hline Mengua & 291 & 95 \\
\hline \multicolumn{2}{|c|}{ Caída total: 83\% } \\
\hline Ausentes en 1562: & $\mathbf{1 6 3 6}$ \\
\hline Chusbita & & \multicolumn{1}{|c|}{56} \\
\hline
\end{tabular}

\begin{tabular}{|l|r|r|}
\hline PAIPA & $\mathbf{1 5 6 2}$ & $\mathbf{1 6 3 6}$ \\
\hline & & \\
\hline Oicatá & 480 & 138 \\
\hline Tuta & 420 & 159 \\
\hline Paipa & 728 & 159 \\
\hline Sotaquirá & 742 & 135 \\
\hline \multicolumn{2}{|c|}{ Caída total: $\mathbf{7 4 \%}$} \\
\hline Ausentes en 1562: & $\mathbf{1 6 3 6}$ \\
\hline Cómbita & & 66 \\
\hline
\end{tabular}

\begin{tabular}{|l|r|r|}
\hline CHIVATÁ & $\mathbf{1 5 6 2}$ & $\mathbf{1 6 3 6}$ \\
\hline & 520 & 141 \\
\hline Chivatá & 200 & 77 \\
\hline Soracá & 50 & 28 \\
\hline Chaine & 170 & 5 \\
\hline Viracusa & 120 & 86 \\
\hline Siachoque & 20 & 27 \\
\hline Siachaca & 219 & 67 \\
\hline Tocavita Caída total: 66\% & 100 & 44 \\
\hline Turga & & $\mathbf{1 6 3 6}$ \\
\hline \multicolumn{2}{|c|}{} & 26 \\
\hline Ausentes en 1562: & 12 \\
\hline Icaza & 60 \\
\hline Amaca & & 13 \\
\hline Sitaquecipa & 68 \\
\hline Bagaxique & 54 \\
\hline Cormechoque
\end{tabular}




\begin{tabular}{|l|r|r|}
\hline SÁCHICA & $\mathbf{1 5 6 2}$ & $\mathbf{1 6 3 6}$ \\
\hline & & \\
\hline Samacá & 80 & 43 \\
\hline Sáchica & 570 & 142 \\
\hline Chivatá & 520 & 141 \\
\hline Sasa & 300 & 99 \\
\hline Foaca & 80 & 36 \\
\hline Sora & 450 & 91 \\
\hline Tinjacá & 450 & 278 \\
\hline Chiquiza & 60 & 65 \\
\hline Iguaque & 300 & 91 \\
\hline \multicolumn{2}{|c|}{ Caída total: $\mathbf{6 5 \%}$} & $\mathbf{1 6 3 6}$ \\
\hline Ausentes en 1562: & \multicolumn{1}{|c|}{} & 118 \\
\hline Motavita & \multicolumn{2}{|c|}{55} \\
\hline Chiquinquirá & & 49 \\
\hline Ráquira & 99 \\
\hline Tijo & & 8 \\
\hline Tibaquirá
\end{tabular}

Fuente: Colmenares, La Provincia, 99-100.

La indagación de Colmenares le hizo concluir que si lograba determinar la ubicación exacta de cada uno de los pueblos que faltaban en el censo de Angulo, podría establecer una población tributaria verosímil para el total de la provincia. Desafortunadamente, de los cuarenta y ocho pueblos que intentó reconstruir, Colmenares apenas pudo ubicar treinta y uno de ellos en los ocho corregimientos. Nueve estaban situados en el corregimiento de Sogamoso, seis en Chivatá, cinco en Sáchica y cuatro en Tenza. Tres de los pueblos perdidos estaban en Turmequé, dos en Duitama, y uno en los corregimientos de Paipa y Gámeza (ver Tabla 2, más adelante). Usando los porcentajes de despoblación que ya había determinado para los ocho corregimientos, junto con la lista tributaria de 1636 recogida por Valcárcel, Colmenares calculó que hacia la fecha de la inspección de Angulo, los treinta y un pueblos podían mantener una población de 9.955 indios tributarios ${ }^{42}$. Evidentemente, esa cifra no incluía la población tributaria de los diecisiete pueblos que Colmenares no pudo ubicar.

Para estos diecisiete pueblos, Colmenares determinó arbitrariamente una caída poblacional del $80 \%$, lo que se traducía en 4.755 indios tributarios adicionales en 1562. Al final, la población tributaria de los cuarenta y ocho pueblos sumaba 14.710, cifra que Colmenares añadió a su cuenta original de 38.755 , lo que resultaba en una población tributaria de 53.465 indios hacia

\footnotetext{
${ }^{42}$ Colmenares, La provincia de Tunja, 64.
} 
$1562 .{ }^{43} \mathrm{Su}$ coeficiente de 3,2 habitantes por indio tributario, resultaba en una población total de 171.028 indios en la Provincia de Tunja.

Aunque se puede argumentar que el total encontrado por Colmenares para 1562 es algo arbitrario, su aproximación metodológica a la reconstrucción de la población indígena de Tunja en el siglo XVI no está basada sólo en una imaginación creativa. La metodología desarrollada por Colmenares no es más que una ligera variación de un modelo teórico conocido como "método de porcentaje de despoblación", tal vez la técnica más sencilla y directa para calcular la población indígena de la preconquista y la temprana colonia, y uno de los métodos más aceptados por los demógrafos de otras regiones de América Latina ${ }^{44}$.

Sencillamente, el método consiste en tomar cifras conocidas de la población de un periodo para luego construir un porcentaje de despoblación basado en cifras posteriores de la misma área. Usando un censo "completo" (aquí Colmenares se remite a las cifras reunidas por Valcárcel), los porcentajes de despoblación fueron aplicados a la región en 1562, en un intento de alcanzar una cifra para el total de la población tributaria ${ }^{45}$. Por supuesto, este procedimiento no deja de tener debilidades.

Una de las mayores dificultades en la investigación de Colmenares, y un problema común enfrentado por muchos académicos que han adoptado este método, es el número inadecuado de muestras con las que elaboran sus conclusiones. Por ejemplo, para los corregimientos de Sogamoso, Turmequé y Paipa, Colmenares calcula un porcentaje de despoblación basado en las cifras tributarias de apenas cuatro pueblos. Para Tenza incluyó cinco pueblos. Sólo el corregimiento de Duitama, con once muestras, y el de Sáchica, con nueve, contienen una razonable, aunque no concluyente, cantidad de muestras para establecer porcentajes de despoblación confiables. Aún si Colmenares hubiera incluido más ejemplos, se debe recordar que los porcentajes de despoblación estaban basados en la cantidad de indios tributarios en 1636 frente a los que había en 1562, una aceptación peligrosa si se reconoce que la proporción de indios tributarios por cada comunidad, en 1636, parece haber caído significativamente desde el momento en que Angulo de Castejón efectuó su visita ${ }^{46}$. Se debe recordar siempre, que las listas tributarias recogidas por Castejón, Valcárcel y los demás visitadores coloniales incluían pagos

\footnotetext{
${ }^{43}$ Ibídem.

${ }^{44}$ Ver: Cook, Demographic Collapse, 41. Sobre Méjico encontramos los trabajos pioneros de Sherburne Cook y Woodrow Borah, The Indian Population of Central Mexico, 1531-1610 (Berkeley: University of California Press, Ibero-Americana, 1960), 44; también: The Aboriginal Population of Mexico on the Eve of the Spanish Conquest (Berkeley: University of California Press, Ibero-Americana, 1963), 45, y por último The Population of the Mixtec Alta, 1520-1960 (Berkeley: University of California Press, 1968). En Perú, este método ha sido adoptado por distintos investigadores, como: John Rowe, "Inca Culture at the Time of the Spanish Conquest", en Handbook of South American Indians, ed. Julian H. Steward (Washington: Bureau of American Ethnology Bulletins, 1946-1959), 2:183-330. Henry Dobyns, "Estimating Aboriginal American Population: An Appraisal of Techniques with a New Hemispheric estimate", Current Anthropology 7 (1966), 395-449. C.T. Smith, "Depopulation of the Central Andes in the $16^{\text {th }}$ Century", Current Anthropology 11 (1970), 453-464 y Nathan Wachtel, Vision of the Vanquished: The Spanish Conquest of Peru Through Indian Eyes (Hassocks, Sussex: Harvester Press, 1977).

${ }^{45}$ Cook. Demogrphic Collapse, 41.

${ }^{46}$ Ver: Colmenares, Historia económica, 112.
} 
de tributo individual; el creciente grupo de indios reservados (que tal vez alcanzaba el $20 \%$ de la población total en 1636) no aparecía en ellas. Y se debe reconocer que el porcentaje de indios reservados en cada pueblo parece haber sido mucho más alto en 1636 que en 1562, 1571 y aún 1600; por lo tanto, no se pueden comparar simplemente las poblaciones tributarias de diferentes visitas y concluir que la población total cayó en un porcentaje igual al de la tributaria.

Además, lo que empieza a surgir de los limitados registros arqueológicos también nos obliga a reconsiderar la aproximación metodológica de Colmenares, ya que éste asumió que, por haber Valcárcel registrado 115 pueblos de indios en 1636, debía haber por lo menos una cantidad igual en 1562; una afirmación no necesariamente sustentada por datos arqueológicos. Por ejemplo, Carl Langebaek sugiere que había menos asentamientos, aunque más densamente poblados, en el periodo colonial temprano, a pesar de los esfuerzos españoles por congregar los asentamientos indígenas en pueblos más grandes ${ }^{47}$. Langebaek basa sus conclusiones en la evidencia recogida durante su detallada exploración arqueológica por los valles de Fúquene y Susa, a partir de la que afirma que los colonos españoles usurparon progresivamente las tierras más fértiles en la Cordillera Oriental, con lo que los habitantes indígenas del valle se vieron forzados a abandonar sus pueblos más grandes para retornar a los asentamientos dispersos que habían ocupado por cortos periodos, tiempo antes de la conquista ${ }^{48}$. Sin embargo, es difícil aplicar los hallazgos de Langebaek en los valles de Susa y Fúquene al total de la Cordillera Oriental; más estudios regionales como este son necesarios antes de que podamos determinar si sus hallazgos reflejan una tendencia general.

Otra deficiencia en el estudio de Colmenares radica en que su propio análisis de la evidencia demográfica de 1562 fue incompleto; la evidencia que recogió de la inspección de Angulo no representa el total de las cifras tributarias incluidas en dicha visita. Por lo tanto, tal como habíamos visto en los cálculos de Juan Friede para el mismo año, el resultado final fue que los habitantes de muchos cacicazgos muisca fueron contados dos veces. Por ejemplo, de los cuarenta y ocho pueblos "perdidos" que Colmenares señala como faltantes en el censo de Angulo de Castejón, un examen riguroso de los registros tributarios de la visita revela que Angulo sí incluyó cifras poblacionales de, por lo menos, veinte de ellos ${ }^{49}$. Desafortunadamente, de estos veinte pueblos, Angulo provee cifras tributarias precisas de apenas cinco de ellos: Bombaza, en el corregimiento de Sogamoso, Chusbitá, en el corregimiento de Gámeza, Amaca, en el corregimiento de Chivatá, y Ráquira y Tibaquirá, en el corregimiento de Sáchica (ver Tabla 2). Las cifras tributarias específicas de las otras quince encomiendas son poco claras porque los totales de estas fueron anotados junto a las listas tributarias de, al menos, una comunidad distinta, llegando, en algunos casos, a agruparse con tres o cuatro. Consideremos el ejemplo de Cheva, una de las encomiendas de Francisco Salguero. La población tributaria

\footnotetext{
${ }^{47}$ Ver: Carl Henrik Langebaek, From Hunters and Gatherers to Muiscas, Campesinos and Hacendados in the Eastern Highlands of Colombia. An Archaeological Survey in the Valles de Fúquene and Susa (Pittsburg: Universidad de Pittsburg, 1993, disertación doctoral no publicada).

${ }^{48}$ Langebaek, From Hunters, 226.

${ }^{49}$ Los once pueblos que aparecen en el registro de 1636, pero no en los de la visita de 1562, son: Guateque, Furaquirá, Guacha, Toquecha, Toquilla, Monguí, Nobsa, Soconsaque, Icaga, Sitaquecipa y Guatecha.
} 
reportada llegaba a cuatrocientos en 1562, pero esa cifra incluía los indios tributarios de otras encomiendas de Salguero: Ura, Gámeza y Mochasaque. Angulo no provee información desglosada sobre cada encomienda. Ocavita, una encomienda de Juan de Villanueva, por ejemplo, tenía en 1562, una población tributaria de setecientos. Sin embargo, ésta incluía también tributarios de Tupachoque, otra encomienda de Villanueva. Por consiguiente, no hay forma de afirmar con exactitud cuántos indios eran de Ocavita y cuántos de Tupachoque. La población tributaria de Tibasosa también es confusa, ya que entre los quinientos tributarios citados por Angulo había también indios de Chámeza. Y Tibaná, una encomienda de Gonzalo Suárez Rendón, en la que se reportaban 1.800 indios tributarios, incluía en sus listas habitantes de las encomiendas de Icabuco y Guaneca, otras posesiones de Suárez Rendón.

La lista completa de Colmenares, con los treinta y un pueblos "perdidos" y las cifras poblacionales de las veinte encomiendas que fueron encontradas en la visita de Angulo, aparecen en la Tabla 2. Pero, ya que los registros de visita contienen información precisa sobre apenas cinco de las veinte encomiendas, es virtualmente imposible sostener o desafiar los porcentajes de despoblación planteados por Colmenares para los ocho corregimientos de Tunja. Y aún si incluyéramos las cinco encomiendas de las que tenemos información tributaria exacta, los índices de caída demográfica sugeridos por Colmenares cambiarían muy poco. El promedio de descenso poblacional en Sogamoso, entre 1562 y 1636, caería en apenas un cuatro por ciento, de $86 \%$ a un todavía sorprendente $82 \%$. El porcentaje de despoblación de Gámeza cambiaría ligeramente, de $83 \%$ a $81 \%$, y para los otros seis corregimientos los cambios son casi imperceptibles.

Tabla 2: Reporte de los treinta y un pueblos "perdidos" citados por Colmenares

\begin{tabular}{|l|l|l|l|}
\hline Pueblo & Corregimiento & Población tributaria en 1562 & Caída en 1636 \\
\hline & & & \\
\hline Guateque & Tenza & No figura & \\
\hline Ubeita & Tenza & 800 (Incl. Garagoa y Qutequeneme) & \\
\hline Guaneca & Tenza & 1800 (Incl. Icabuco y Tibaná) & \\
\hline Furaquirá & Tenza & No Figura & \\
\hline Ocavita & Duitama & 700 (Incl. Tupachoque) & \\
\hline Guacha & Duitama & No Figura & \\
\hline Bombaza & Sogamoso & 380 & $79 \%$ \\
\hline Guáquira & Sogamoso & 800 (Incl. Tota) & \\
\hline Toquecha & Sogamoso & No Figura & \\
\hline Toquilla & Sogamoso & No Figura & \\
\hline Firavitoba & Sogamoso & 400 (Incl. Cormechoque) & \\
\hline Monguí & Sogamoso & No Figura & \\
\hline Tutasá & Sogamoso & 180 (Incl. Pargua y Chicuasa) & \\
\hline Tibasosa & Sogamoso & 500 (Incl. Chámeza) & $72 \%$ \\
\hline Nobsa & Sogamoso & No Figura & \\
\hline Chusbitá & Gámeza & 200 & \\
\hline & & & \\
\hline
\end{tabular}




\begin{tabular}{|l|l|l|l|}
\hline Pueblo & Corregimiento & Población tributaria en 1562 & Caída en 1636 \\
\hline Soconsaque & & & \\
\hline Tibaná & Turmequé & No Figura & \\
\hline Cupasayna & Turmequé & 1800 (Incl. Icabuco y Guaneca) & \\
\hline Icaga & Turmequé & 200 (Incl. Motavita) & \\
\hline Amaca & Chivatá & No Figura & \\
\hline Sitaquecipa & Chivatá & 40 & $70 \%$ \\
\hline Bagaxique & Chivatá & No Figura & \\
\hline Cormechoque & Chivatá & 60 (Incl. Tontavita) & \\
\hline Guatecha & Chivatá & 400 (Incl. Firavitobá) & \\
\hline Cómbita & Chivatá & No Figura & \\
\hline Motavita & Paipa & 280 (Incl. Suta) & \\
\hline Chiquinquirá & Sáchica & 200 (Incl. Cupasayna) & \\
\hline Ráquira & Sáchica & 300 (Incl. Suta) & $73 \%$ \\
\hline Tijo & Sáchica & 180 & $84 \%$ \\
\hline Tibaquirá & Sáchica & 150 (Incl. Teusa) & \\
\hline
\end{tabular}

Fuentes: Colmenares, La Provincia de Tunja, 99-100; Ana María Falchetti, Arqueología de Sutamarchán, Boyacá (Bogotá: Biblioteca Banco Popular, 1975), 61; AGI, Justicia, 649.

Críticas similares a las cifras propuestas por Colmenares para 1562 pueden ser establecidas contra las que alcanzó para otros periodos de los siglos XVI y XVII; en particular, se debe cuestionar la confiabilidad de sus primeras cifras poblacionales para el siglo XVI. El total establecido por Colmenares, de 61.500 indios tributarios en 1551, se basó en apenas una cifra, considerada como primera referencia de la población nativa de Tunja. La cifra viene del cuarto libro de la Recopilación historial, la crónica del siglo XVI escrita por Pedro de Aguado. En ésta, Aguado reporta que en 1551, año en que Juan Ruiz de Orejuela condujo la primera inspección general de la Provincia de Tunja, había un total de 41.000 indios casados en la provincia, cifra que no incluía a los viejos, los solteros, ni los menores de quince años ${ }^{50}$. El cronista afirmaba haber consultado los registros de la visita de Orejuela. Desafortunadamente, el lenguaje de Aguado es bastante ambiguo, por lo que no queda totalmente claro si estos 41.000 indios casados incluían a hombres solteros en edad de tributar ${ }^{51}$. Colmenares argumentaba que

\footnotetext{
${ }^{50}$ Pedro Aguado, Recopilación historial (Bogotá: Biblioteca de la Presidencia de Colombia, 1956), 1:409. Es aceptado generalmente que Aguado se estaba refiriendo a los números citados en la inspección de Tunja que llevó a cabo Juan Ruiz de Orejuela. Aunque los registros originales de la visita de Orejuela nunca fueron encontrados, se cree que Aguado pudo consultarlos para la escritura de algunas partes de su crónica. De acuerdo con Aguado, la orden de Orejuela fue la de inspeccionar cada pueblo en la Provincia de Tunja y, con la ayuda de un traductor, registrar el testimonio de cada cacique y capitán en la provincia, para así, determinar el número de hombres casados en cada comunidad. Estas cifras no incluían a los viejos ni a los solteros menores de quince años. Ibídem, 404.

${ }^{51}$ La reconstrucción que Colmenares hace de las cifras de Orejuela está basada en su interpretación de una referencia que aparece en las crónicas de Aguado. En dos ocasiones distintas, el cronista hace referencia a las cifras poblacionales recogidas por Orejuela, pero advierte a sus lectores que éstas (41.000 hombres), no incluyen a los viejos, los hombres jóvenes ni los menores de quince años. Así, nos quedamos con la impresión de que Aguado se
} 
no. Por consiguiente, modificó la cifra de Aguado (Orejuela) añadiendo los adultos solteros al total. Para conseguir esta cifra, Colmenares vuelve a los registros del censo realizado veinte años después del de Orejuela, durante la visita de López de Cepeda, en 1571-1572. Colmenares examinó estos registros, bastante más detallados que los de Orejuela, para determinar el estatus marital de la población masculina en cada cacicazgo, encontrando que el número de hombres solteros en edad tributaria oscilaba entre el $22 \%$ y el $83 \%$ en cada pueblo. Aunque reconoció el amplio margen de error, Colmenares escogió arbitrariamente una tasa del 50\% para representar el total de solteros tributarios por pueblo. Según Colmenares, esto significaba que las cifras de población tributaria recogidas por Orejuela eran demasiado conservadoras y debían ser aumentadas en 20.500 indios, pasando de 41.000 a $61.500^{52}$.

Desafortunadamente, las cifras de Colmenares para 1551 están, con seguridad, abiertas a la crítica, especialmente cuando se considera que el cálculo del tributo en la Tunja colonial temprana nunca estuvo claramente estructurado. Cuando los inspectores reales llegaban a calcular la población tributaria de un pueblo (o encomienda), no hacían distinciones entre individuos casados y solteros. Además, ¿qué significaba exactamente "casado" para los muisca en 1551? Muy simple, las listas tributarias debieron incluir a todos los hombres que parecieran suficientemente jóvenes, o suficientemente viejos, para pagar tributo.

El mismo Colmenares se encontró en un terreno ligeramente más sólido cuando inició el cálculo de poblaciones posteriores; pero aún entonces descubría que la escasez de evidencia documental hacía necesaria la reconstrucción de grandes franjas de población indígena en Tunja. Por ejemplo, para el año 1572, Colmenares llega a una población tributaria total de 38.495 con una población global de 123.184, habiendo encontrado evidencia documental de sesenta y nueve pueblos (encomiendas), con una población tributaria ubicada en algún punto entre 22.124 y $22.720^{53}$. Los otros 16.000 tributarios fueron añadidos por la reconstrucción que Colmenares hizo de los pueblos que aparecían en la visita de Valcárcel pero que no fueron registrados en la de López de Cepeda. Según Colmenares, los sesenta y nueve pueblos sobre los que descubrió evidencia documental, representaban apenas la mitad de los asentamientos muisca en 1572; por consiguiente, adoptó el mismo método usado en el cálculo de la población de 1562, para reconstruir el tamaño de las poblaciones que López de Cepeda había omitido registrar.

La misma metodología fue usada para determinar los tamaños de población en 1595 y 1602 , aunque con menos soporte documental. Sin duda, la información de archivo de la visita de Egas de Guzmán, en 1595-1596, es escasa, por la sencilla razón de que la visita jamás fue completada. Por lo tanto, no es sorpresivo que Colmenares encontrara información tributaria de

refiere a tres categorías diferentes de personas. En todo caso, los términos que usa Aguado son bastante ambiguos: "...sin los viejos, mozos y muchachos de quince años para abajo". Colmenares interpreta que 'mozos' y 'muchachos' son dos categorías distintas y separadas, representando 'mozos' a todos los hombres solteros en edad tributaria. De cualquier modo, puede argumentarse también que el cronista (y Orejuela para el mismo efecto) nunca hizo tal distinción, representando ‘mozos' y ‘muchachos' una sola categoría de hombres por debajo de los quince años.

${ }^{52}$ Colmenares, La provincia de Tunja, 65-66.

${ }^{53}$ Colmenares, La provincia de Tunja, 93-98. 
apenas dieciséis encomiendas. Su total de 16.680 indios tributarios en 1596 estuvo así basado en la reconstrucción de noventa y nueve pueblos. Por otro lado, la larga visita de Enríquez fue mucho más minuciosa que la iniciada cinco años atrás, y Colmenares encontró cifras poblacionales de casi la mitad de los pueblos que aparecieron más tarde en el reporte de Valcárcel. Los sesenta pueblos sobre los que Colmenares descubre evidencia a partir de la visita de Enríquez tenían una población tributaria combinada de 10.294, que luego de completar sus reconstrucciones, Colmenares corrigió a $16.348^{54}$. Un conteo completo de las cifras poblacionales de Colmenares para la Tunja colonial se incluye en la Tabla 3.

Tabla 3: Cifras poblacionales de Colmenares para la Provincia de Tunja

\begin{tabular}{|c|c|c|}
\hline Año & Indios tributarios & Población total \\
\hline 1551 & 61.500 & 196.800 \\
1562 & 53.465 & 171.028 \\
1572 & 38.495 & 123.184 \\
1596 & 16.680 & 53.376 \\
1602 & 16.348 & 52.313 \\
$1635-36$ & 8.610 & 41.328 \\
1755 & & 24.892 \\
\hline
\end{tabular}

Fuente: Colmenares, La Provincia de Tunja, 72.

Es importante reconocer que Colmenares admitió que sus cálculos para los siglos XVI y XVII eran apenas aproximaciones generales, basadas en fuentes escasas y algunas veces cuestionables. Él consideraba que las cifras de la visita de Valcárcel, en 1636, eran las únicas representaciones exactas de la población colonial de Tunja. La desafortunada escasez de evidencia confiable, tanto documental como arqueológica, lo disuadió de intentar establecer el tamaño de la población de la preconquista en la provincia. Dadas las obvias reservas de Colmenares sobre la confiabilidad de sus propias cifras, es bastante sorprendente que, desde 1970, año en que fue publicado su estudio sobre la Provincia de Tunja, ningún intento serio de desafiar sus resultados se haya hecho para mejorar nuestro conocimiento de la demografía histórica de Tunja ${ }^{55}$. Por más de tres décadas, las conclusiones de Colmenares (y de Juan Friede, para el caso de la población de contacto en Tunja) han permanecido intactas. Tal vez se ha asumido que Colmenares agotó todas las fuentes de archivo disponibles, y que sin trabajo arqueológico no podía haber nuevas contribuciones al tópico. Afortunadamente, ese no es el

\footnotetext{
${ }^{54}$ Ibídem.

${ }^{55}$ Podemos decir que la publicación, en 1988, de No hay caciques ni señores, de Hermes Tovar Pinzón, fue una contribución valiosa a nuestro conocimiento de la población de Tunja en la temprana colonia (al fin y al cabo, incluía cifras no publicadas de una visita anónima hecha en 1560); pero Tovar simplemente presentaba las cifras, sin ubicarse en el amplio contexto del cambio poblacional, la enfermedad, ó en los términos de las conclusiones de Colmenares.
} 
caso. La investigación de archivos ha abierto registros completos de censo para 1560 y 1562, al igual que una gran cantidad de evidencia de la visita de López de Cepeda que Colmenares no había descubierto. También disponemos de algunas cifras de 1595 y el Archivo General de Indias, en Sevilla, alberga el reporte completo de la inspección de Luis Enríquez a comienzos del siglo XVII.

Como ya he mencionado en la introducción, los ricos registros de censo en la zona durante el periodo colonial temprano, que se cuentan entre los más detallados para cualquier región del Nuevo Mundo, sirven como un barómetro del cambio poblacional en la provincia. No obstante, los números solos no ofrecen una explicación del desastre demográfico que siguió a la llegada de los europeos a la Cordillera Oriental colombiana. Por ejemplo, ¿cómo debemos explicar la dramática diferencia entre el número de indios tributarios registrados en 1560 y el mucho menor consignado en 1562 ? Y ¿por qué no se recuperó la población nativa durante las primeras décadas del siglo XVII, como sí ocurrió en otras zonas del Nuevo Mundo? Aparecerá sin sorpresa para cualquier persona familiarizada con la conquista española y el periodo colonial temprano, que la introducción de las enfermedades del Viejo Mundo jugó un papel significativo en la catastrófica pérdida de población sufrida por los pueblos nativos a lo largo de las Américas. Aún nos hace falta una investigación de largo término sobre la enfermedad y sus efectos sobre la población nativa colombiana. La siguiente sección bosqueja la secuencia epidémica en la Provincia de Tunja, y demuestra que los brotes de enfermedades del Viejo Mundo jugaron un papel central en la precipitada caída poblacional.

\section{La llegada de los "asesinos invisibles" a la Cordillera Oriental}

Se acepta generalmente que el porcentaje más alto de mortalidad entre los pueblos nativos de las Américas ocurrió durante los primeros cien años de contacto ${ }^{56}$. El patrón de despoblación en Tunja parece apoyar esa teoría. Como se verá más adelante, entre los años 1537 y 1636, la población india de la región cayó en casi un $80 \%$, de casi 230.000 en vísperas de la conquista a un exiguo 47.554, cuando Juan de Valcárcel condujo su visita en el siglo XVII (ver Tabla 5). Y aunque las cifras posteriores siguieron su caída hasta registrar menos de 25.000 en la década de 1750, el porcentaje de caída desde mediados del siglo XVII hasta mediados del siglo XVIII fue mucho menor. Por supuesto, muchas de las bajas iniciales se dieron durante las guerras de conquista y por la crueldad de los primeros conquistadores. Un número aun más grande pereció durante las costosas expediciones que en los 1540 buscaron El Dorado ${ }^{57}$. En todo caso, a pesar de la alta pérdida de población durante los años iniciales de la conquista, la mayor parte de la caída al final del primer siglo de gobierno español no debe ser atribuida a la crueldad de los hombres blancos recién llegados, ni de sus sirvientes negros; los visitantes más letales de las Américas fueron los "asesinos invisibles" que tanto europeos como africanos llevaban en su sangre y en su aliento ${ }^{58}$.

\footnotetext{
${ }^{56}$ Alfred W. Crosby, The Columbian Exchange: Biological and Cultural Consequences of 1492 (Westport: Greenwood Press, 1972), 37.

${ }^{57}$ Villamarín, Encomenderos and Indians, 29.

${ }^{58}$ Crosby, The Columbian Exchange, 31.
} 
Mucho se ha escrito sobre el desastre epidemiológico que siguió a la conquista. Por lo tanto, no es necesario que revisemos vasto cuerpo de literatura dedicado a él. La mayoría de investigadores aceptan hoy que el intercambio biológico fue considerablemente más mortífero para los amerindios que para quienes llegaron del Viejo Mundo ${ }^{59}$. En su estudio pionero sobre las consecuencias biológicas del "descubrimiento" de Colón, Alfred Crosby concluía que hasta las enfermedades benignas europeas se convertían en asesinas eficaces en el Nuevo Mundo, y los males que eran fatales en el Viejo Mundo probaron ser aún más mortíferos en América ${ }^{60}$. Viruela, sarampión, influenza, peste bubónica, fiebre amarilla, cólera, y posiblemente tifo, estaban entre los males previamente desconocidos por los habitantes de las Américas, y por lo tanto, eran enfermedades para las que los nativos no habían adquirido inmunidad ${ }^{61}$. Y aunque hay todavía alguna controversia sobre la presencia de enfermedades como malaria, tuberculosis, y sífilis en la América precolombina, hasta la fecha no hay evidencia concluyente que sugiera que los nativos americanos sufrieran de alguna de las enfermedades "masivas" (crowd-type) que afectaron a la población del Viejo Mundo ${ }^{62}$.

La enfermedad no fue solamente una causa mayor de mortalidad entre los indios, también fue responsable del creciente número de abortos e infertilidad. Por ejemplo, una mujer embarazada que contraía sarampión estaba en alto riesgo de dar a luz hijos deformes o muertos ${ }^{63}$. También es probable que enfermedades como la viruela y las paperas causaran infertilidad entre la población masculina ${ }^{64}$. $\mathrm{Y}$ aunque son virtualmente imposibles de cuantificar, las tasas decrecientes de fertilidad nos pueden ayudar a explicar por qué la población nativa de Tunja jamás se recuperó de la acometida inicial de las enfermedades del Viejo Mundo.

El propósito de esta sección es dar una cronología general de las enfermedades epidémicas en la Provincia de Tunja, un tópico que ha recibido muy poca atención académica en la literatura histórica colombiana. Lo que esta cronología quiere ayudar a mostrar es que el "bombardeo de micro-organismos", que produjo en promedio una gran epidemia por década, constituye la principal explicación de la continua caída demográfica en la población nativa.

En su reciente estudio del cambio demográfico en el Ecuador de la temprana colonia, Linda Newson sugiere que, tanto los muisca como los nahua del centro de Méjico, experimentaron una

\footnotetext{
${ }^{59}$ Algunos de los estudios más útiles al respecto son: Crosby, The Columbian Exchange; Suzanne Austin Alchon, Native Society and Disease in Colonial Ecuador; Don Brothwell, "On Biological Exchanges between the Two Worlds", en The Meeting of Two Worlds, ed. Warwick Bray (Oxford: Oxford University Press, 1993); Noble David Cook y W. George Lovell (eds.), Secret Judgments of God: Old World Disease in Colonial Spanish America (Norman: University of Oklahoma Press, 1992); y Linda A. Newson, Life and Death in Early Colonial Ecuador (Norman: University of Oklahoma Press, 1995).

${ }^{60}$ Crosby, The Columbian Exchange, 37.

${ }^{61}$ Hay algunas sugerencias en el reciente estudio de Suzanne Austin Alchon, Native Society and Disease in Colonial Ecuador, 22, de que el tifo pudo haber existido en América antes de la llegada de los europeos.

${ }^{62}$ Ibídem, 19.

${ }^{63}$ Cook, Demographic Decline, 65.

${ }^{64}$ Newson, Life and Death, 7.
} 
caída poblacional más drástica que la de los habitantes de Perú o Ecuador. Newson desarrolló dos posibles explicaciones para estas elevadas tasas de mortalidad. Una teoría es que las enfermedades europeas fueron introducidas con mayor frecuencia en Méjico y Colombia a través de los importantes puertos de Veracruz y Cartagena ${ }^{65}$. Sin embargo, es más significativo, según Newson, que la mayor concentración de asentamientos españoles tuviera lugar en el centro de Méjico y en la Cordillera Oriental de la Nueva Granada, precisamente las regiones con mayor número de habitantes nativos ${ }^{66}$. La evidencia documental indica que entre $1537 \mathrm{y}$ 1636, estallaron no menos de siete grandes epidemias en la Provincia de Tunja. En esos cien años la viruela golpeó tres veces, la primera en 1558, seguida por dos pequeñas explosiones en 1607 y 1621. La influenza brotó dos veces, en 1568-1569 y luego en 1587-1590. En 1617-1618 hubo un brote de sarampión, y en 1633 los nativos de Tunja fueron devastados por un tifo epidémico letal.

Curiosamente, no tenemos registro alguno de epidemias ampliamente expandidas en Tunja en los años precedentes a las plagas mortales de 1558-1560. Sin embargo, no tenemos certeza de que la epidemia de 1558 fuera la primera del siglo XVI. Se ha demostrado que en otras regiones de América los asentamientos españoles permanentes no eran un prerrequisito necesario para la transmisión de enfermedades de origen europeo. Por ejemplo, la primera epidemia de viruela que golpeó al Perú se remonta hasta 1524, ocho años antes de la llegada de Francisco Pizarro y sus hombres a Cajamarca ${ }^{67}$. Es posible que algunos virus provenientes del Viejo Mundo llegaran a territorio muisca mucho antes de que se hubiera establecido contacto directo con los europeos. El contacto con tribus indígenas costeras se dio en Colombia desde fechas tan tempranas como 1500. Asentamientos españoles permanentes fueron establecidos a lo largo de la costa entre 1520 y comienzos de la siguiente década ${ }^{68}$. Además, otras expediciones españolas se habían ya adentrado profundamente en territorio colombiano, años antes de que Jiménez de Quezada y sus hombres tuvieran su primer contacto con los muisca. Francisco Pizarro, Pascual de Andagoya y Diego Almagro fueron algunos de los que ya en la década de los veinte habían logrado cruzar por el Daríen hasta el Chocó colombiano ${ }^{69}$. Por lo tanto, dadas las redes de comercio que los muisca habían establecido antes de la conquista con los pueblos habitantes de las costas colombianas, es posible que la llegada de enfermedades epidémicas resultara en un descenso demográfico significativo en el territorio muisca en los años que precedieron a la llegada de la expedición de Gonzalo Jiménez de Quesada en $1537^{70}$. Y parece aun más probable

\footnotetext{
${ }^{65}$ Ibídem, 11. Hacia la década de 1560, España había regularizado una fuerza naval en las Américas con la flota que navegaba entre España y Veracruz, y los galeones que desembarcaban en Nombre de Dios (Panamá), pero reposaban en el puerto de Cartagena durante el invierno. Ver J.H. Elliot, Spain and its World 1500-1700: Selected Essays (New Haven: Yale University Press, 1989), 19-20.

${ }^{66}$ Newson, Life and Death, 11.

${ }^{67}$ Cook, Demographic Collapse, 60.

${ }^{68}$ La ciudad costera de Santa Marta fue fundada por Rodrigo Bastidas en 1526. Pedro de Heredia fundó siete años después la ciudad portuaria de Cartagena, en 1533.

69 Para descripciones detallas de estas tempranas expediciones véase: Caroline Anne Hansen, Conquest and Colonization in the Colombian Chocó, 1510-1740, (Warwick: University of Warwick, 1991, tesis doctoral), 13-31.

${ }^{70}$ En una reciente discusión llevada a cabo en el AHA en Nueva York, Noble Cook sugirió la posibilidad de que los muisca experimentaran por lo menos dos grandes epidemias antes de la llegada de los españoles.
} 
que algunos de los habitantes indígenas de Tunja fuesen expuestos a virus provenientes del Viejo Mundo en algún momento durante las dos primeras décadas del régimen colonial. En Perú, por ejemplo, Noble David Cook pudo documentar veintitrés epidemias en el periodo comprendido entre 1524 y 1635 . Por lo menos seis de ellas ocurrieron en los quince años que siguieron a la llegada de Pizarro a Cajamarca ${ }^{71}$. Y en las montañas de Guatemala, una región con un número mucho menor de colonos europeos que el que habitaba la Cordillera Oriental colombiana, George Lovell encontró que los indígenas de las montañas de Cuchumatán experimentaron, por lo menos, tres grandes epidemias en los veinte años siguientes a la conquista $^{72}$. En Colombia misma, Juan Friede descubrió que ya en el temprano año de 1546 los indios Quimbaya del Valle del Cauca sufrieron de una grave epidemia. No es claro, sin embargo, si ésta misma alcanzó a propagarse hasta alcanzar a los habitantes de las Cordillera Oriental colombiana ${ }^{73}$.

Con todo, a pesar de la temprana aparición de enfermedades provenientes del Viejo Mundo en otras regiones de América, hasta la fecha no se ha presentado evidencia concluyente que sugiera que los habitantes de la Provincia de Tunja experimentaron algún tipo de epidemia de gran escala antes de finales de la década de 1550 . Si este hubiera sido el caso, se esperaría que hubiera evidencia documental, bien sea en los registros de las primeras visitas, en reportes o cartas enviadas a España, o en los trabajos de los cronistas de los siglos XVI y XVII. La expansión de enfermedades epidémicas es un tema común en los registros escritos del periodo colonial temprano y es muy improbable que se diera una epidemia de gran escala sin que de ella se hiciera registro alguno. Los testimonios de los nativos constantemente hacían referencia a la aparición de extrañas dolencias aun después de años e incluso décadas de la llegada de las mismas. Las enfermedades se constituyeron en un punto de referencia constante a partir del cual, los nativos enmarcaban sus testimonios y hasta su concepto del tiempo. Los eventos solían describirse como ocurridos antes o después de la aparición de alguna gran plaga. Sin embargo, no hay registro escrito alguno que mencione pestes anteriores a 1558. No hay ninguna referencia en la visita anónima de 1560 ni en ninguna de las otras visitas importantes del siglo XVI. Tampoco los cronistas de la colonia hacen referencia a epidemias anteriores a la de 1558.

Como hemos visto, la primera epidemia documentada que azotó a los habitantes de Tunja apareció casi veinte años después de la llegada de los españoles a la Cordillera Oriental. Se ha sugerido que la epidemia de 1558-1560 se trató realmente de dos epidemias, viruela y sarampión, que atacaron simultáneamente y que fueron introducidas desde la costa caribe colombiana. También se ha sugerido que desde ahí, ambos virus viajaron hacia el sur, dejando un camino de muerte a lo largo de la Audiencia de la Nueva Granada hasta el Virreinato del Perú $^{74}$. Según el autor anónimo de la visita a Tunja de 1560, en 1559 hubo un brote de viruela y

\footnotetext{
${ }^{71}$ Véase Cook, Demographic Collapse, 60-61.

${ }^{72}$ W. George Lovell, Conquest and Survival in Colonial Guatemala: A Historical Geography of the Cuchumatán Highlands, 1500-1821, edición revisada (Montreal y Kingston: McGill-Queen’s University Press, 1992), 149.

${ }^{73}$ Cook and Borah, Essays in, 421.

${ }^{74}$ Newson. Life and Death, 148.
} 
de sarampión, que dejó como resultado un gran número de indígenas muertos ${ }^{75}$. Más tarde escribiría el cronista español Pedro Aguado que esta epidemia apareció en Tunja por primera vez a finales de 1558 y que 15.000 personas, la mayor parte de ellas indígenas, murieron a causa de ella ${ }^{76}$. No es de sorprender que dicha epidemia no fuera olvidada rápidamente. Algunos de los habitantes nativos de la provincia hacían referencia a ella aún en 1595, año en que Egas de Guzmán llevó a cabo su inspección general de Tunja. Un nativo del pueblo de Boyacá, al ser interrogado por un visitador acerca de si conocía a una cierta testigo, declaró conocerla desde la aparición del primer brote epidémico de viruela, "hace unos treinta y seis años" epidemia siguiera siendo un punto de referencia después de tantos años constituye un testimonio sorprendente acerca del impacto devastador que tuvo.

De hecho, los registros de censo provenientes de la visita anónima y de la inspección de Angulo sugieren que, entre 1560 y 1562 , la población tributaria de Tunja decreció en una cifra aproximada de 16.000. De 52.525 pasó a 36.425 , una disminución del treinta y uno por ciento en sólo un par de años ${ }^{78}$. Un colapso demográfico tan dramático en un periodo de tiempo tan corto parece imposible. Sin embargo, no sólo se asemeja asombrosamente este declive de población al citado por Aguado, sino que también se adecua a descubrimientos recientes acerca de lo que ocurre cuando el sarampión y la viruela son introducidos en poblaciones aisladas que no han tenido contacto previo con dichas enfermedades. Se ha documentado en casos similares que las cifras de mortalidad alcanzan niveles entre el 30 y el 60 por ciento de la población expuesta ${ }^{79}$. Haciendo uso del modelo de mortalidad por enfermedad de Noble David Cook y de las cifras demográficas posteriores a la epidemia, provenientes de la visita de Angulo en 1562, podríamos concluir que la población tributaria de Tunja debía oscilar, antes de la epidemia, entre los 47.350 y los 58.280. Así, la cifra de 52.525 tributarios mencionada en la visita anónima de 1560, no resulta imposible, ni siquiera descabellada. Hasta podríamos llegar a considerarla más bien como una cifra conservadora.

La epidemia de 1558 fue la más grave del siglo XVI. Sin embargo, otras plagas devastadoras le siguieron. De hecho sólo pasaron ocho años antes de que otra peste arremetiera contra la provincia. Esta vez se trataba de un brote de influenza. Desafortunadamente existe mucha menos evidencia documental de la epidemia de 1568-69. Perece ser que las tasas de mortalidad fueron mucho menores que aquellas que siguieron a la peste de 1558. La descripción de Tunja hecha por Juan López de Velasco en 1574 hace referencia a un solo brote epidémico en el cual "muchos murieron" de un testimonio declarado siete años después por Guaritagua, un capitán del pueblo de Susa.

\footnotetext{
${ }^{75}$ Tovar, No hay caciques ni señores, 85-86.

${ }^{76}$ Véase: Aguado, Recopilación historial, 1:424. Según los habitantes nativos del Chicamocha, la epidemia de 1558 dejó su pueblo paralizado. Véase: AGN, Bogotá, Visitas de Boyacá, 13, fols. 306 y 315.

${ }^{77}$ AGN, Bogotá, Caciques e Indios, 22, fol. 883r.

${ }^{78} \mathrm{Se}$ debe ser cuidadoso en el uso de las cifras de 1560 puesto que es probable que los registros censales citados en la visita de 1560 hubiesen sido reunidos desde 1551 .

${ }^{79}$ Cook, Demographic Collapse, 71.

${ }^{80}$ Juan López de Velasco, "Geografía y descripción universal de las Indias", en Biblioteca de Autores Españoles, ed. Don Marcos Jiménez de la Espada, N.248 (Madrid: Ediciones Atlas, 1971), 185.
} 
Según actas de 1575, Guaritagua sostenía que los indígenas habitantes de Susa y sus alrededores habían sido azotados por una peste mortal, debido a la cual, muchos, incluso su hermano, habían perdido sus vidas ${ }^{81}$. Pero, a juzgar por los registros tributarios de las visitas de Angulo de Castejón y Juan López de Cepeda, y por la escasez de referencia documental acerca de los efectos de la enfermedad, es quizá prematuro asumir que la epidemia de influenza afectó a los habitantes de toda la provincia. No obstante, las cifras tributarias sugieren que la población de Tunja continuó disminuyendo en una tasa alarmante. Si adoptáramos el método de porcentaje de despoblación y consideráramos la proporción del descenso demográfico entre 1562 y 1572 , podríamos ver que la población tributante de Tunja se redujo en aproximadamente un $11 \%$, de 31.330 a 27.759.

La tercera y última epidemia del siglo XVI tuvo lugar en 1587, y duró casi tres años. Existen aún debates en torno a la identificación de la enfermedad. Se ha sugerido que se trataba, o bien de un nuevo brote de influenza, o probablemente de tifo. El tipo de evidencia documental que ha sobrevivido, hace que sea virtualmente imposible la identificación del virus. Por lo general no se hacían distinciones entre los distintos tipos de enfermedades. Los testimonios indígenas suelen referirse indiscriminadamente a todas las epidemias como viruelas o sarampión. Desafortunadamente las referencias documentales de la epidemia de 1587-90 son limitadas. En ellas no se encuentran descripciones detalladas de los síntomas.

Sin embargo, varios nativos, testigos en posteriores inspecciones, hicieron referencia a éste periodo de viruela ${ }^{82}$. Funcionarios españoles escribieron también informes alarmantes acerca de los efectos que estas epidemias tenían sobre la población nativa. Por ejemplo, Juan Sanz de Hurtado, procurador general para las ciudades de la Nueva Granada, escribió en 1603 un reporte en el cual culpaba al contagio de enfermedades del acelerado descenso de la población indígena. En su reporte escribió que "es también cierto que ha habido dos epidemias de viruela y sarampión, y que estas[enfermedades], sin ningún miramiento, han reducido su población" ${ }^{\prime 83}$. En abril de 1602, después de su prolongada inspección de la Provincia de Tunja, el visitador Luis Enríquez concluyó que "[las epidemias] de viruela y los servicios personales [forzados] han consumido miles [de vidas], y cada día [la población nativa] se hace más pequeña" ${ }^{, 84}$.

El siglo XVII no constituyó una tregua ante la devastación causada por enfermedades. En las tres décadas que siguieron a la inspección de la provincia llevada a cabo por Luis Enríquez, la población tributaria disminuyó casi en un cincuenta por ciento. Entre 1607 y 1621, hubo otros

\footnotetext{
${ }^{81}$ AGN, Bogotá, Caciques e Indios, 20, fol. 975v.

${ }^{82}$ Varios testimonios del pueblo indígena de Chiramita incluían referencias a la epidemia de viruela de 1587-90. Al ser preguntado por su edad, Diego confesó no saberla, pero aseguró que él era ya adulto cuando azotó la última epidemia. Él parecía tener unos 25 años, siendo demasiado joven como para haber estado vivo durante la epidemia de 1558-60. Por lo tanto, debía estar refiriéndose a la epidemia de 1587-90. De forma similar, Luis Neamia sostenía haberse mudado a Chiramita antes del brote general de viruela. Y aunque no se proporcione ninguna fecha específica, se decía que Luis aparentaba tener treinta años, y así no estaba vivo siquiera cuando la primera epidemia brotó. Véase: AGN, Bogotá, Caciques e Indios, fol. 758r.

${ }^{83}$ AGI, Sevilla, Santafé 60, N.44, 3v.

${ }^{84}$ AGI, Sevilla, Santafé 18, N.11, Ramo 3, B1.2, 2v.
} 
dos grandes brotes de viruela y uno de sarampión. Después de la epidemia de 1607, el cabildo de Tunja envió una solicitud a la Audiencia para que se suspendiera, tanto la construcción de iglesias que involucrara mano de obra nativa, como el alquiler general ${ }^{85}$.

De la epidemia de 1617, identificada como sarampión, se decía que tuvo lugar después de un periodo de hambruna generalizada en la provincia ${ }^{86}$, provocada por una plaga de langostas que arrasó con los cultivos de maíz. Según el presidente de la Audiencia, Juan de Borja, dicha epidemia se extendió bastante, afectando no sólo a los habitantes de tierra caliente, sino también a los de tierra fría ${ }^{87}$.

La epidemia más devastadora del siglo XVII se presentó en territorio muisca a principios de 1633. La enfermedad fue identificada como tifo exantemático y, según un informe del cabildo de Santafé, fue responsable de la muerte de aproximadamente un tercio de la población indígena de Santafé y Tunja ${ }^{88}$. En una carta con fecha del 23 de agosto de 1633, el arzobispo de Santafé declaraba:

Todo este reino ha sido azotado por una terrible plaga que comenzó hace seis meses en la ciudad de Santafé [...] y que se está extendiendo a lo largo de esta tierra, trayendo gran ruina a españoles y nativos, cuyos pueblos están, en su gran mayoría, desiertos, habiendo muerto casi 5000 personas tan sólo en la ciudad de Santafé $[\ldots]^{89}$.

Ese mismo año, Don Pedro Piraquibsa, cacique de Sotaquirá, presentó una queja a la Audiencia, en la cual impugnaba al encomendero Juan de Vargas Hermoso por continuar forzando a indígenas saludables a trabajar sus tierras. Según Don Pedro, a causa de esto no quedaba nadie en Sotaquirá para atender al gran número de enfermos ${ }^{90}$. Ya al final del año, los funcionarios españoles se encontraban tan alarmados por la alta tasa de mortalidad entre los nativos, que ordenaron a los corregidores en la jurisdicción de Tunja que elaboraran listas detalladas de todos los indígenas tributarios sobrevivientes ${ }^{91}$. Se ha sugerido que la enfermedad persistió por más de dos años y que los niveles de mortalidad alcanzaron un tope del $80 \%$ en la Sabana de Bogotá $^{92}$.

\footnotetext{
${ }^{85}$ Colmenares, Historia económica, 84.

${ }^{86}$ Ruíz Rivera, Encomienda y rnita, 103-104.

${ }^{87}$ Ibídem, 104.

${ }^{88}$ Juan A. Villamarín, Encomenderos and Indians in the formation of Colonial Society in the Sabana de Bogotá, Colombia -1537 to 1740- (Brandeis: Brandeis University, 1972, tesis doctoral), 1:252. Según Villamarín, el término español tabardillo, que solía aplicarse a la enfermedad, cubre tan amplia variedad de síntomas que podría pensarse que realmente se trataba de varias enfermedades. No obstante, Villamarín concluye que la epidemia de 1633 fue de tifo exantemático. AGI, Sevilla, Santafé 61, citado en Villamarín y Villamarín, "Epidemic Disease”, 114.

${ }^{89}$ AGI, Sevilla, Santafé, 227, N.14, Ir.

${ }^{90}$ AGN, Bogotá, Caciques e Indios, 50, fol. 736r.

${ }^{91}$ AGN, Bogotá, Miscelanea, 3, fol. 1034r. Carta de Don Sancho Girón, Marqués de Sófraga a los corregidores de Tunja.

92 Jaramillo Uribe, Ensayos sobre, 130. Jaramillo citaba a José Manuel Groot, Historia eclesiástica y civil del Nuevo Reino de Granada (Bogotá, 1953), 2:658.
} 
Tabla 4: Principales epidemias en la Provincia de Tunja, 1537-1636

\begin{tabular}{|c|c|c|}
\hline Fechas & Epidemias & Fuentes \\
\hline $\begin{array}{l}\text { Antes de } \\
1558\end{array}$ & $? ?$ & $\begin{array}{l}\text { No hay evidencia de archivo acerca de epidemias } \\
\text { anteriores a } 1558\end{array}$ \\
\hline $1558-1560$ & Viruela y Sarampión & $\begin{array}{l}\text { AGI, Sevilla, Audiencia de Santafé, 188, fols. 226r-226v. } \\
\text { Aguado, Recopilación historial, 1:424. } \\
\text { Tovar, No hay caciques ni señores, } 85-86 . \\
\text { Newson, Life and Death } 148 .\end{array}$ \\
\hline $1568-1569$ & Influenza & $\begin{array}{l}\text { Villamarin y Villamarin, "Epidemic Disease", } 114 . \\
\text { AGN, Bogotá, Caciques e Indios, 3, fol. 225v. }\end{array}$ \\
\hline $1587-1590$ & Influenza (¿o tifo? $)^{93}$ & $\begin{array}{l}\text { AGN, Bogotá, Caciques e Indios, 3, fol. 780r. } \\
\text { Jaramillo Uribe. "Ensayos sobre..., pág. } 129 \\
\text { Newson. Life and Death ..., pág. } 149\end{array}$ \\
\hline 1607 & Viruela & Colmenares, Historia econónomica, 84. \\
\hline $1617-1618$ & $\begin{array}{l}\text { Sarampión } \\
\text { (precedido por } \\
\text { hambruna) }\end{array}$ & $\begin{array}{l}\text { Ruíz Rivera, Encomienda y mita, 103-104. } \\
\text { Juan Villamaría, Encomenderos and Indians, } 252 .\end{array}$ \\
\hline 1621 & Viruela & Villamarín y Villamarín. "Epidemic Disease", 114. \\
\hline 1633 & Tifo (tabardillo) & $\begin{array}{l}\text { AGI, Sevilla, Audiencia de Santafé 227, N. 14, fol. 1r. } \\
\text { AGI, Sevilla, Audiencia de Santafé } 61 . \\
\text { AGN, Bogotá, Caciques e Indios, 50, fol. } 736 \text { r. } \\
\text { AGN, Bogotá, Miscelanea, 3, fol. 1034r. }\end{array}$ \\
\hline
\end{tabular}

Además de las siete grandes epidemias de las cuales tenemos evidencia documental, es probable que otros brotes menores se dieran localmente a lo largo de la colonia temprana. El estudio del cambio poblacional en las montañas de Cuchumatán en Guatemala, realizado por W. George Lovell, reveló que hubo no menos de nueve brotes locales entre 1550 y $1639^{94}$.

Las fuentes parecen indicar que un proceso similar tuvo lugar en Tunja. La mayor parte de las visitas coloniales tempranas a la provincia hacen referencia a la aparición de brotes locales. En 1571, por ejemplo, durante la inspección realizada por Cepeda al pueblo de La Sal, se aseveró

\footnotetext{
${ }^{93}$ Según Newson, es probable que esta epidemia hubiese sido introducida a través de Cartagena por la flota de Sir Francis Drake alrededor de 1585, luego de su toma de la ciudad. Descripciones de la enfermedad la llevaron a concluir que se trató de una epidemia de tifo y no de influenza, como sostuvo Jaime Jaramillo Uribe. Véase Newson, Life and Death, 149-150.

${ }^{94}$ Lovell, Conquest and Survival, 150-151.
} 
que algunos indígenas estaban sufriendo de "bubas" proviene de la encomienda de Isabel de Zambrano de Citaquezipa, donde la repentina disminución de población entre 1602 y 1604, llevó a los indígenas a solicitar a la Audiencia la reducción de su tributo. Un informe de la Audiencia ordenó que, a partir de 1604, el tributo de Citaquezipa fuera recaudado de 87 tributarios, debido a que la población de "indios tributarios que van (¿quedan?) han bajado a razón de diez por ciento..." ${ }^{\text {. }}$.

El hecho de que se les haya disminuido el gravamen a los indígenas de Citaquezipa no constituye de por sí una prueba de que una enfermedad haya azotado a la comunidad. Sin embargo, la reacción de la Audiencia en Santafé frente a la petición demuestra que los funcionarios españoles consideraban habitual un descenso poblacional del 10 por ciento en tan sólo un par de años. En el caso de Citaquezipa resulta difícil determinar si la caída poblacional fue resultado de una enfermedad, de migraciones o de una astuta artimaña urdida por los gobernantes de Citaquezipa para lograr que su tributo fuera reducido ${ }^{97}$. Para alcanzar una mejor comprensión de las variaciones regionales del cambio demográfico en Tunja se requeriría de un análisis mucho más cuidadoso de fuentes documentales hasta ahora desatendidas, tales como aquellas que descansan en parroquias locales y en archivos municipales. Investigaciones arqueológicas con éste propósito, deberían resultar provechosas también en tanto esfuerzos tendientes a determinar la capacidad de carga tributaria de diferentes regiones de la provincia. En otras palabras, hay aún muchas oportunidades para ampliar nuestra comprensión del cambio poblacional en la Nueva Granada de la colonia temprana, a pesar del número de estudios de población que actualmente existen. Es importante tener en cuenta que la mayor parte del material demográfico recogido para este estudio fue tomado de las visitas generales de los siglos XVI y XVII.

\section{¿Constituyen las visitas coloniales datos demográficos confiables?}

Las fuentes más valiosas con las que contamos actualmente para establecer las cifras de población nativa previa a la conquista y de la colonia temprana son los registros de censos reunidos por funcionarios españoles. Desafortunadamente estos registros no se recolectaban con gran frecuencia. Lapsos de décadas solían separar una inspección general de otra y, en muchas partes de la América española, comunidades nativas enteras lograban escapar al ojo inquisidor del visitador colonial. Sin embargo, para el periodo entre 1560 y 1636, un total de cinco visitas generales, y por lo menos dos inspecciones parciales, fueron llevadas a cabo en la Provincia de Tunja, haciendo de ella no sólo la región más documentada de la Nueva Granada, sino también la que tiene los registros más detallados de toda la Latinoamérica colonial ${ }^{98}$. Por supuesto

\footnotetext{
${ }^{95}$ AGN, Bogotá, Visitas de Boyacá, 29, fols. 57r-60r. Sobre alrededor de media docena de personas, todos hombres, se decía que tenían "bubas".

${ }^{96}$ AGN, Bogotá, Caciques e Indios, 50, fols. 168r-169r

${ }^{97}$ Ésta última opción parece ser la menos probable, ya que dicha reducción no contó con ninguna objeción por parte de la encomendera Isabel de Zambrano.

${ }^{98}$ Woodrow Borah, "The Historical Demography of Aboriginal and Colonial America: An Attempt at Perspective", en Denevan, ed., The Native Population, 33.
} 
existen dificultades inherentes a los informes de censos coloniales tempranos, y el uso de estos registros en la reconstrucción de la población nativa de Tunja ha sido controvertido. Por ejemplo, pocos de los censos coloniales para Tunja fueron lo suficientemente detallados como para proveernos con perfiles precisos de las comunidades nativas basados en nombre, edad o género. Por el contrario, la mayoría de las inspecciones contenían solamente listas de hombres adultos. Esto, por supuesto, no es del todo sorprendente si se tiene en cuenta que los censos eran usados por funcionarios reales con el fin de asignar los montos del tributo a recaudar para cada pueblo. Pero como veremos, a pesar de sus evidentes defectos, los registros de censos que existen de Tunja proporcionan al menos un reflejo exacto del tamaño de la población indígena, y suelen ser apoyados por una amplia gama de documentación colonial.

Para el siglo XVI hay varias referencias generales al tamaño de la población indígena de Tunja. Esta clase de material quizá pueda ser incluido en la categoría a la que Sherburne Cook y Woodrow Borah, historiadores demográficos, se refirieron como "cuentas de contenido demográfico indirecto" $" 99$. Las descripciones españolas tempranas de la región, por ejemplo, indicaban constantemente que la Provincia de Tunja estaba densamente poblada. Según Pedro Simón, cronista del siglo XVII, la primera expedición española que llegó a la Nueva Granada quedó impresionada por el tamaño y densidad de población indígena de Tunja. Simón describió la región como altamente poblada; tanto que según él, Quesada y sus hombres comparaban la imagen de los indios en el campo con la de un enjambre de abejas en la miel ${ }^{100}$. Del valle de Guachetá, por ejemplo, un estrecho valle de apenas una legua de longitud y de dos o tres tiros de mosquete de ancho, se dijo que contenía más de mil bohíos, todos habitados ${ }^{101}$.

Desafortunadamente, aparte del Epitome de la conquista del Nuevo Reino de Granada, atribuido a Jiménez de Quesada, ninguno de los participantes en la conquista de dicha región dejaron registros escritos de la expedición, ni de sus primeras impresiones del territorio muisca. Esta escasez de informes de primera mano se extiende hacia atrás, hasta la llegada del primer grupo de conquistadores. De hecho, no tenemos registros escritos de ninguno de los participantes de las primeras seis expediciones que se hicieron al interior de la Cordillera Oriental ${ }^{102}$. Una de las descripciones más tempranas de primera mano hecha de la Provincia de Tunja fue escrita casi diez años después de que Quesada y sus hombres pisaran territorio muisca. El 13 de febrero de 1547, poco después de su llegada a la Nueva Granada, el licenciado Miguel Díez de Armendáriz envió una carta al rey de España en la cual bosquejaba sus impresiones iniciales de la Cordillera Oriental colombiana. Aunque el contenido de la carta carecía de detalles significativos, la descripción hecha por Armendáriz de la provincia retrataba un territorio que había sido densamente poblado antes de la llegada de los españoles. Él contaba que entre los dos asentamientos españoles de Vélez y de Santafé recientemente fundados,

\footnotetext{
${ }^{99}$ Cook y Borah, Essays in Population History (Berkeley: University of California Press, 1971), 1:8.

${ }^{100}$ Pedro Simón, Noticias historiales de las conquistas de tierra firme en las Indias Occidentales (Bogotá: Banco Popular, 1981), 3:159.

${ }^{101}$ Ibídem, 166.

${ }^{102}$ La expedición de Gonzalo Jiménez de Quesada fue seguida poco tiempo después por las de Nicolás de Federmán, Sebastián de Belalcázar, Jerónimo Lebrón, Lope Montalvo de Lugo y Alonso Luis de Lugo.
} 
separados por una distancia de treinta y dos leguas, no había más de dos leguas que no evidenciaran signos de cultivos de maíz, papa, frijoles, algodón o coca ${ }^{103}$.

El cronista Pedro Aguado, que llegó por primera vez a la Nueva Granada en 1562, relató sus impresiones iniciales de los atestados mercados en el territorio muisca. Hablaba del "infinito" número de indios que se reunían en el mercado de Tunja cada cuatro días ${ }^{104}$. Y aunque ningunas de estas observaciones tempranas proporcionen cifras exactas de población, dan la impresión de que no se está hablando de una región escasamente poblada y de que la posibilidad de que hubiera una densa población es verdadera. Aquí, los expedientes de censos de inspecciones a mediados del siglo XVI y comienzos del XVII pueden ser usados para apoyar esta conclusión.

La primera visita general a la Provincia de Tunja fue realizada en 1551 por Juan Ruíz de Orejuela. Del informe final de Orejuela se dice que constó de 228 folios. Las cifras de población incluidas en él fueron utilizadas después, en 1555, por la Audiencia de la Nueva Granada para establecer la primera tasación general de los tributos de los indios. Desafortunadamente, los estudiosos modernos no han podido localizar el informe original y, aparte de un par de referencias ambiguas, las cifras exactas de población recopiladas durante la inspección son desconocidas ${ }^{105}$. Sin embargo, como suele ser el caso con la mayoría de los datos de censos del período colonial temprano, hay indicaciones de que las cifras presentadas por Orejuela eran en gran parte inexactas.

En una carta de 1556 a la Corona, el factor real, Bartolomé González de la Peña, se quejaba de que la visita de Orejuela era incompleta y de que las cifras que contenía no eran dignas de confianza:

[...] cuando vine a esta tierra a entender en el oficio de factor que vuestra majestad me hizo merced, hallé visitados los indios que tienen los vecinos desta ciudad de Santafé, Tunja y Vélez y esta visita fue muy mal hecha $[\ldots]^{106}$

Según González, el principal problema con esta primera visita fue que Orejuela no inspeccionó personalmente las distintas comunidades. En lugar de esto, la recolección de los datos de población fue confiada a varios vecinos españoles, todos los cuales poseían indios. González contó que los encomenderos con una gran cantidad de indios tributarios daban testimonios falsos porque temían que les quitaran algunos de sus indios ${ }^{107}$. Y los encomenderos con pocos indios mentían también: atestiguaron tener menos indios, esperando que su aparente desgracia

\footnotetext{
${ }^{103}$ Colmenares, La provincia de Tunja, 59.

${ }^{104}$ Aguado, Recopilación historial, 1:341.

${ }^{105}$ Colmenares, La provincia de Tunja, 53.

${ }_{107}^{106}$ AGI, Sevilla, Santafé 188, fol. 89v.

107 Existían ciertos fundamentos para este temor. En 1547, cuatro años antes de que Orejuela comenzara su inspección, Carlos $\mathrm{V}$ ordenó que todas las encomiendas con un número excesivo de indígenas fueran reducidas. Véase Juan Friede, Documentos inéditos para la historia de Colombia (Bogotá: Academia Colombiana de Historia, 1955), 8:246.
} 
influenciaría a funcionarios reales para concederles encomiendas más grandes ${ }^{108}$. Germán Colmenares expresó dudas considerables sobre la validez de los datos demográficos recopilados por Juan Ruíz de Orejuela; él sugirió que la información daba cuenta probablemente de menos de un tercio de la población indígena total de las provincias ${ }^{109}$. Por supuesto, la dificultad más obvia en cualquier análisis crítico comprensivo de las cifras de Orejuela es que no sabemos exactamente cuáles eran los números. Debemos, en cambio, confiar en las cifras encontradas en recuentos más tardíos.

El censo más temprano que ha sobrevivido de la población indígena de Tunja proviene de un informe anónimo relativamente oscuro, fechado en $1560^{107}$. Esta relación, transcrita recientemente en un trabajo de Hermes Tovar Pinzón, contiene descripciones detalladas, incluyendo poblaciones tributarias, de los distritos de Popayán, Cartagena, Santa Marta, y de todo el Nuevo Reino de Granada (que incluía las provincias de Santafé y de Tunja). Según esta relación, en 1560 había 114 encomiendas en la Provincia de Tunja, con una población tributaria total de 52.525 (véase el Anexo 1). Desafortunadamente, la relación no revela quién recolectó los datos demográficos, ni cómo fueron obtenidos. Hay, sin embargo, evidencia de que las cifras tributarias citadas en ella estaban basadas en alguna fuente anterior. Aunque el informe anónimo tiene fecha del mismo año en el que Tomás López llevó a cabo su visita general de Tunja, parece muy improbable que los registros de población que en él aparecen fueran recopilados durante su inspección, en 1560. El propósito de su visita nunca fue proporcionar un censo de la población nativa. Sus principales responsabilidades eran más bien las de asegurarse de que cada comunidad fuera beneficiada con un cierto grado de supervisión espiritual, de que se estuvieran construyendo iglesias, de que los encomenderos no abusaran de los nativos y las demandas tributarias no fueran excesivas ${ }^{110}$.

Pero incluso si el informe anónimo había sido escrito por López, es claro que las cifras de población incluidas en él no fueron recogidas el mismo año que tuvo lugar la inspección:

Los naturales desta ciudad paresce que van en aumento que aunqueste año de cinquenta y nueve ovo una pestilencia de viruelas y saranpión de que murieron generalmente en esta ciudad y en las demas deste distrito mucha cantidad de yndios, no se podrá saber es quantos, sin tornar a hazer la descrición aunque a la de los yndios dizen aver sido mucha la cantidad de los muertos $[\ldots]^{111}$

Existe la posibilidad de que los números mencionados en la relación anónima de 1560 estuvieran basados en los que se recolectaron durante la inspección de Juan de Orejuela. No hay

\footnotetext{
108 Juan Friede, Fuentes documentales para la historia del Nuevo Reino de Granada (Bogotá: Banco Popular, 1960), $3: 48$.

${ }^{109}$ Colmenares, La provincia de Tunja, 54

${ }^{107}$ Una trascripción completa de esta relación, así como de las cifras de población que incluía, puede encontrarse en: Tovar, No hay caciques ni señores, 21-120.

${ }^{110}$ Colmenares, La provincia de Tunja, 55.

111 Tovar, No hay caciques ni señores, 86.
} 
referencia directa a Orejuela. Sin embargo, el informe afirma claramente: "halláronse antes de la pestilencia la cantidad que parescera en esta suman [... $]^{\prime 112}$. Quizás el autor del informe había tenido acceso a las listas de tributarios de la visita de 1551.

Como mencionamos anteriormente, las cifras citadas en el informe indicaban que antes de la epidemia de viruela de 1558-60, la población tributaria de Tunja era de 52.525. Si multiplicamos eso por el coeficiente de Colmenares de 3,2 habitantes por tributario, alcanzamos una población indígena total, previa a la epidemia, de 168.080. Aun cuando esta cifra deba ser tomada con cierta precaución, constituye una imagen plausible de la población indígena de Tunja antes de la epidemia. Podemos decir esto con una cierta confianza puesto que tenemos registros de censos para el período inmediatamente anterior al brote y un poco después ${ }^{113}$.

Apenas dos años después de haberse escrito el informe anónimo, la Audiencia de la Nueva Granada ordenó una nueva inspección a los indios de Tunja, y que sus pagos de tributo fueran reajustados teniendo en cuenta la caída poblacional. En octubre de 1561, el oidor Angulo de Castejón fue designado para realizar la visita. Como respuesta al dramático descenso de población que siguió a la epidemia de 1558-60, a Angulo le fue ordenado implementar medidas para asegurar que la población indígena se recuperara del desastre o, por lo menos, para garantizar que sus números no cayeran en tasas tan alarmantes. Según el fiscal García de Valverde, "las tasas de mortalidad han sido tan altas que algunas provincias y regiones de este distrito han quedado completamente desiertas" $" 114$.

Angulo de Castejón fue igualmente criticado por no inspeccionar las comunidades nativas en persona. Él se fiaba de los testimonios de seis de los principales vecinos de Tunja, todos los cuales poseían encomiendas. A Diego Montañez, Diego Rincón, Domingo de Aguirre, Juan López, Cristóbal de Roa y Pedro Rodríguez de Carrión fue confiado el suministro de los cálculos poblacionales para cada una de las 143 encomiendas de la provincia. Angulo recogió también testimonios de miembros la elite indígena. Los indios de Chipa, Pisba, Guáquira, Soatá y Onzaga testimoniaron que, en vez de visitar personalmente sus comunidades, Angulo de Castejón convocó a caciques distantes a Tunja y ordenó a cada uno contar granos de maíz para representar el número de indios tributarios de sus pueblos ${ }^{115}$. Es poco probable que los caciques entregaran datos demográficos precisos a sabiendas de que las cifras poblacionales recolectadas por Angulo en últimas determinarían la cuantía del tributo que cada comunidad llegaría a pagar. Un año después de que Angulo de Castejón terminara su visita, el fiscal de la Nueva Granada, García de Valverde escribió:

\footnotetext{
${ }^{112}$ Ibídem.

${ }^{113}$ En la sección anterior argumentamos que el porcentaje de descenso poblacional entre los dos censos (31 por ciento), es consistente con las tasas de mortalidad documentadas para otras regiones afectadas por desastres epidémicos similares.

${ }^{114}$ Colmenares, Historia económica., 78.

115 Tovar, Documentos sobre tributación, 43, 52, 56-59.
} 
[...] para llevar a cabo una visita [adecuada], el visitador debe mirar a los nativos con sus propios ojos, tal como el término visitador claramente lo implica; [el tiene que] verificar en persona el número de indios [presentes] en cada pueblo, contando casas y residentes [...] cosa que no hizo [Angulo] ${ }^{116}$.

En cambio, se quejaba Valverde, los caciques le mintieron al visitador y ofrecieron un cuadro tributario que sus encomenderos les dijeron que dieran ${ }^{117}$. Él agregaba:

[...] habiendo después pasado por los tales pueblos tantas muertes, tantas persecuciones, tantas guerras, tantas pestilencias y enfermedades que pueblo que tenia en otro tiempo mil vecinos, como es notorio y por tal lo alego, no tiene agora cincuenta o cien vecinos, $y$ esto es muy general en toda la tierra $[\ldots]^{118}$

Valverde no fue el único en levantar una queja contra el visitador. Don Diego de Torres, cacique mestizo de Turmequé, dijo acerca de la inspección de Angulo de Castejón:

[...] en la visita que hizo el Licenciado Angulo, como no parecieron los indios personalmente, sino por los números que los encomenderos les hicieron dar a cada cacique, no dándoles a entender con que fin se hacia la dicha visita, dieron número de dos tercios mas de indios de los que realmente tenían, con el cual engaño fueron muy cargados en los tributos $[\ldots]^{119}$

Los testimonios de Torres y Valverde plantean serias preguntas en cuanto a la exactitud de estos recuentos de población. Para 1564, la cantidad de quejas levantadas contra Angulo había conducido a la suspensión de la retasa de 1562. La Audiencia decidió que otra inspección general era necesaria. Hasta entonces, los indios debían seguir pagando el tributo asignado bajo la primera tasa general de 1555. Sin embargo, menos de cuatro meses después de haber sido suspendida, la Audiencia se retractó de su decisión y ordenó que la tasa de Angulo fuera adoptada nuevamente ${ }^{120}$.

La inspección de 1571 llevada a cabo por Juan López de Cepeda también generó protestas similares, tanto de españoles como de indios. Los testimonios de Juan Huyamque, un capitán de Chiribí, y de don Gonzalo, cacique de Icabuco, señalaban que hubo intentos de por lo menos un encomendero, por exagerar el número de indios tributarios ${ }^{121}$. Según ambos testigos, el encomendero de Icabuco, Gonzalo Suárez Rendón, les dijo que incluyeran en las listas de tributo a aquellos indios nacidos en Icabuco que, desde su infancia, habían vivido en otras

\footnotetext{
${ }^{116}$ AGI, Sevilla, Justicia 649, fol. 31v.

${ }_{117}^{11}$ AGI, Sevilla, Justicia 649, fols. 31r-34v.

${ }_{118}^{118}$ Colmenares, La provincia de Tunja, 57.

${ }^{119}$ Ibídem, 57.

${ }^{120}$ AGI, Sevilla, Justicia 641, bl.1,fols. 71v-72r.

${ }^{121}$ Chiribí formaba parte de Icabuco, un pueblo más grande
} 
partes del reino. Algunos de estos indios se habían asentado años antes en Tunja, mientras que otros hacía mucho residían en sitios tan lejanos como Pamplona, Mariquita y "otras partes remotas" ${ }^{\prime 22}$. A cambio de sus falsos testimonios, Suárez garantizó que designaría a varios guardias, cuya labor consistiría en localizar a los indios y traerlos de regreso a Icabuco. En 1583, más de una década después de la visita de Cepeda, don Juan y don Gonzalo se quejaron de que ninguno de los indios había sido traído de vuelta y de que, como resultado de este fraude, "cada indio [de Icabuco] viene a pagar la mitad más de demora de lo que están tasados"123.

Una situación similar fue reportada años más tarde por un indio de Chiramita. Sostenía que el cacique de Tenza lo había engañado y que a causa de dicho engaño fue forzado a pagar tributo tanto en Tenza como en Chiramita ${ }^{124}$. Sin embargo, los indios fueron también condenados por dar cifras de población inexactas. Por ejemplo, en agosto de 1571, los capitanes de Onzaga, una de las encomiendas de Miguel Sánchez, fueron acusados de ocultar al visitador una gran cantidad de indios ${ }^{125}$. Al insistir los capitanes en que habían provisto a Cepeda de una lista completa de los tributarios de Onzaga, el juez a cargo de la investigación, Juan Suárez, ordenó detener a cada uno de los capitanes hasta que acordaran revelar el número verdadero de indios bajo sus jurisdicciones. Después de una o dos horas en custodia (y quizás algún grado de coerción física), los capitanes admitieron su error y presentaron a Suárez más nombres ${ }^{126}$.

Con tantos defectos patentes, ¿cómo podemos aceptar cualquiera de las cifras tributarias del siglo XVI como representaciones precisas de la población indígena de Tunja? No sólo eran altamente sospechosos los métodos para obtener datos de población, sino que la naturaleza misma del sistema de encomienda en la Tunja del siglo XVI sugiere que no hubiera sido difícil para los encomenderos exagerar el número de los indios tributarios bajo su control, ni para los caciques muisca encubrir un gran número de ellos para bajar el gravamen anual del tributo. Debe reconocerse que no fueron introducidos corregidores a lo largo de la región hasta 1593, y, por lo tanto, para la mayor parte del siglo XVI, la recolección del tributo quedó bajo la jurisdicción del encomendero. Seguramente se debieron cometer abusos.

Con todo, a pesar de la tentación de aceptar la sugerencia de que los encomenderos de Tunja exageraban las cifras de población para procurarse tributos más altos, hay pocos indicios de un fraude sistemático generalizado, bien sea por parte de la corona, de las docenas de encomenderos españoles, o de sus indios. Como hemos visto, el trato cruel que recibían los indígenas, incluyendo la imposición de exigencias tributarias injustas, alentaba a los nativos a huir de sus comunidades para buscar condiciones de vida más ventajosas, bien fuera en ciudades españolas, como súbditos de un nuevo cacique o encomendero, o como criados personales. Algunos indios, por su parte, prefirieron huir a regiones más remotas donde pudieran evitar todo contacto con europeos.

\footnotetext{
${ }^{122}$ AGI, Sevilla, Santafé 56A, N.17, bl.3, fols. 3v-4r.

${ }^{123}$ Ibídem.

${ }^{124}$ Testimonio de Neamucheguya, AGN, Bogotá, Caciques e Indios, 3, fol. 765r (1598).

${ }^{125}$ Sánchez fue también el encomendero de Soatá.

${ }^{126}$ AGN, Bogotá, Visitas de Boyacá, 30, fol. 924r.
} 
Consideremos las experiencias de Juan de Zarate Chacón, uno de los residentes más prominentes de Tunja en la colonia temprana. A finales de 1570, Zarate trabajó como corregidor y justicia mayor de Tunja. También poseía cinco encomiendas en la provincia, con una población tributaria combinada que superaba los seiscientos indios ${ }^{127}$. Sin embargo, en 1596 Zarate comenzó a quejarse ante el tribunal superior de Santafé por la gran cantidad de indios "suyos" que habían huido y que se ocultaban en otros pueblos alrededor de la provincia. La respuesta de la Audiencia consistió en publicar un decreto real, ordenando a todos los indios de las encomiendas de Zarate, que permanecieran en sus pueblos nativos, y que

[...] ningún encomendero, cacique, capitán, o persona aceptara o encubriera a ninguno de los indios de Zarate, bien se tratara de los ladinos o chontales ${ }^{128}$.

Sin embargo, el decreto parece haber surtido poco efecto y, menos de dos años más tarde, Zarate decidido tomar el asunto en sus propias manos. El encomendero comisionó al juez Jusepe de Valtierra para encontrar a los indios "perdidos" y traerlos de vuelta. El 16 de diciembre de 1598, Valtierra convocó a los dos caciques de Tenza, don Carlos y don Diego, y les solicitó que bosquejaran un memorial con los nombres de todos los súbditos suyos que ya no residían en Tenza. Según el informe, por lo menos 356 indios habían huido de los repartimientos de Zarate ${ }^{129}$. Valtierra pasó cuarenta días intentando recuperar indios de Zarate, pero solamente logró encontrar un puñado de ellos. Zarate solicitó una extensión de la comisión de Valtierra por sesenta días para permitir que el juez terminara su tarea. Otros treinta días le fueron concedidos, pero nuevamente, para consternación de Zarate, la gran mayoría de sus tributarios jamás fueron encontrados.

Por supuesto, el caso de Zarate debe ser visto con cierta cautela. No hay sugerencia alguna en los expedientes de que los indios hubieran huido de Tenza a causa de una injusta carga tributaria. Los expedientes coloniales ofrecen una retahíla de explicaciones para la migración, sólo una de las cuales era la excesiva demanda tributaria. Uno puede también encontrar numerosas referencias a caciques y capitanes abusivos, a la imposición de trabajos forzados, tales como la mita o el alquiler general, a daños de cultivos causados por ganado errante, y a la violencia doméstica. Todas éstas eran justificaciones para huir una región a otra. Y esto no era algo particular de la Tunja colonial. La migración indígena fue una característica compartida por todo el mundo colonial a lo largo de América Latina ${ }^{130}$. Eso es lo que nos revelan las experiencias de Zarate.

Zarate no estaba solo. Las autoridades reales intervinieron. En 1577, la corona expidió un decreto que exigía que todos los indios volvieran a sus pueblos nativos y que "reconocieran" a

\footnotetext{
${ }^{127}$ Las encomiendas de Zarate eran las de Chaine, Tenza, Sutatenza, Teguas, y Ubeita.

${ }^{128}$ AGN, Bogotá, Caciques e Indios, 3, fol. 734r.

${ }^{129}$ AGN, Bogotá, Caciques e Indios, 3, fols. 737v-744v.

${ }^{130}$ David Robinson, ed., Migration in Colonial Spanish America (Cambridge: Cambridge University Press, 1990$), 1$.
} 
sus antiguos caciques y capitanes ${ }^{131}$. Cualquier indio que huyera de su pueblo nativo debía ser azotado y su pelo rapado; y cualquier cacique que fuera encontrado culpable de albergar indios que hubieran huido, sería multado con cuatro mantas del algodón por cada indio protegido. Finalmente, en 1589, la corona patrocinó la primera de dos campañas (la otra en 1598) para recuperar sus indios. Designaron a Diego de Rivera para localizar a todos los indígenas que habían huido de encomiendas de la corona y para traerlos de vuelta a sus pueblos. Interrogó individualmente a caciques y capitanes, solicitando a cada uno que dijera los nombres de los indios ausentes, y su paradero en caso de ser conocido (la Tabla 5 contiene la lista de lugares a donde los indios habían huido). Desafortunadamente, no conocemos el número exacto de indios que habían dejado las encomiendas de la corona. Todo lo que sabemos es que Rivera logró localizar y traer de vuelta a 131. Si la campaña de Rivera resultó exitosa, lo fue solamente a corto plazo. Diez años más tarde la corona designó a otro juez, Jusepe de Valtierra, la repetición de la tarea. Su campaña fue también fallida; después de sesenta días, había encontrado menos del diez por ciento de la gente que había huido (a 113 de 1.219 individuos, 695 de los cuales eran tributarios) ${ }^{132}$.

\footnotetext{
${ }^{131}$ Archivo Regional de Boyacá (en adelante citado como ARB), Tunja, Archivo Histórico, Legajo 11, fol. 39r. ${ }^{132}$ AGN, Bogotá, Caciques e Indios, 32, fol. 1025.
} 
Tabla 5: Destinos de los indios que huyeron de las encomiendas de la corona, basada en el Reporte final de indios ausentes de las encomiendas de la corona en la Provincia de Tunja, elaborado por Diego Rivera en 1589.

\begin{tabular}{|c|c|c|c|}
\hline A & $\bar{F}$ & $\mathrm{O}$ & S (Cont.) \\
\hline \multirow[t]{2}{*}{ Alonso de Roa } & Fuisa (sic) & {$[\mathrm{H}]$ Onda } & Sáchica \\
\hline & Foacá & Ontibón & Susa \\
\hline B & Foraquirá & Oicatá & Santafé \\
\hline Baganique & Firavitobá & Onzaga & Sunuba \\
\hline Boyacá & Fúquen[e] & Ocavita & Sasa \\
\hline Bonza & & & Samaca \\
\hline Busbanza & G & $\mathrm{P}$ & Sotaquirá \\
\hline Boavita & Guaneca & Pamplona & Socotá \\
\hline Bombaza & Gachancipá & Palma & Sogotá \\
\hline Beteitivá & Guavita & Pacho & Sitacipa \\
\hline \multirow{2}{*}{ Boza } & Gameza & Paipa & \\
\hline & Garagoa & Pesca & $\mathrm{T}$ \\
\hline $\mathrm{C}$ & Gota & & Tibaná \\
\hline Cuqueitagacha & Guachetá & Q & Tibasosa \\
\hline Cormechoque & & Quito & Tobasía \\
\hline Cucaita & I & & Temeza \\
\hline Cuitivá & Iguaque & $\mathrm{R}$ & Turca \\
\hline Comeza & Icabuco & Remedios & Tunja \\
\hline Coga & Ibagué & Rasgón & Tinjacá \\
\hline Chiquisa & Iza & Ramiriquí & Toca \\
\hline \multirow[t]{2}{*}{ Combitasuta } & & Ratuaquirá & Tutasa \\
\hline & $\mathrm{L}$ & & Tequía \\
\hline $\mathrm{CH}$ & Lenguasaque & S & Tequía \\
\hline Chocontá & & Santagueda & Tenza \\
\hline Chiribí & M & Sopo & Tinjacá \\
\hline Chicamocha & Mariquita & Siénaga (sic) & Tupachoque \\
\hline Chiquinquirá & Muzo & Subaytuna & Totaguaquirá \\
\hline Chipasa & Mérida & Susacón & Topía \\
\hline Chameza & Monquirá & Socha & Tocaima \\
\hline Chiquisa & Machetá & Sipaquirá(sic) & Tibayta \\
\hline Chiramita & Motavita & Soatá & Turmequé \\
\hline Chitagoto & Mesua & Sogamoso & Tobsa \\
\hline Chavia & Mucha & Siatame & Tausa \\
\hline Chía & & Sisquile & \\
\hline \multirow{2}{*}{ Chipaquirá } & $\mathrm{N}$ & Suba & $\mathrm{U}$ \\
\hline & Nemocón & Seniza (sic) & Usaquén \\
\hline $\mathrm{D}$ & Niza & Suesca & Ubate \\
\hline \multirow[t]{2}{*}{ Duitama } & Nemsa & Soacá & Ubeita \\
\hline & Nobsa & Sutaytausa & Ubaque \\
\hline E & Neacacha & Sutamanga & \\
\hline \multirow[t]{4}{*}{ Enzerma (sic) } & Nemicha & Suta & V \\
\hline & & Somondoco & Villa de Leiva \\
\hline & & Soraca & Vélez \\
\hline & & Satiba & \\
\hline
\end{tabular}

Fuente: AGN, Bogotá, Caciques e Indios, 74, fol. 15r-15v (1589). 
Se puede decir que no resultaba del todo beneficioso para los encomenderos de Tunja exagerar demasiado el número de indígenas tributarios que poseían. Tales declaraciones eran rápida y constantemente cuestionadas, o bien por el visitador, o por el fiscal, o el protector de indígenas, $\mathrm{u}$ otros encomenderos, o por los caciques y los capitanes nativos ${ }^{133}$. Más aun, si las exigencias tributarias llegaban a ser excesivas, los encomenderos codiciosos corrían el riesgo de que los indígenas de su encomienda recurrieran a su arma más eficaz de resistencia: sus pies. Los españoles tenían poco control sobre el movimiento de la población indígena de Tunja y, una vez que un indio hubiera huido, era virtualmente imposible para el encomendero localizarlo(a) nuevamente. Lo que entonces surgió, podría ser visto como un verdadero sistema de contrapesos; un sistema bajo el cual las aseveraciones falsas se veían enfrentadas a respuestas de muy diversos niveles. Esta visión contrasta con las afirmaciones que aparecen en mucha de la historiografia de la Nueva Granada colonial. Se ha sugerido que los encomenderos en Tunja forzaban a sus súbditos a pagar tributos excesivos mediante la invención de la cifra de tributarios bajo su jurisdicción, y que ni los funcionarios coloniales ni los mismos indígenas se enteraron de este engaño ${ }^{134}$. La cantidad de documentación de la época colonial temprana, las peticiones, las multas, las súplicas y las reinspecciones, parecen contradecir esta conclusión. La idea de que la población indígena de Tunja era víctima de una conspiración consciente y uniforme por parte de sus encomenderos no es convincente; y que ni los indígenas (ni los funcionarios españoles encargados de protegerlos) estaban enterados de esta situación parece aún más inverosímil. De hecho, puede sostenerse que si de hecho se dio un fraude generalizado, no fue el encomendero el responsable, sino que más bien lo fueron los caciques y capitanes indígenas, quienes lograron encubrir a una gran cantidad de indios tributarios de la inspección oficial.

Esta interpretación, por lo menos en el caso de Tunja, es también insatisfactoria. Evidentemente, algunos caciques procuraron, y lograron, ocultar indígenas de sus encomenderos y del visitador. Sin embargo, el mismo sistema de contrapesos se aplicaba a ellos. Por lo tanto, aun si un cacique o un capitán lograra encubrir a algunos indígenas de la inspección, es improbable que su número fuera muy grande. En algunos casos, es sorprendente la semejanza que hay entre los cálculos de población dados por los líderes nativos y las cifras recogidas durante las inspecciones. Un ejemplo de esto puede encontrarse en un pleito de 1586, en el cual el cacique de Toca intentó evitar la usurpación de tierras de la comunidad. Durante el curso de los procedimientos, el cacique atestiguo:

\footnotetext{
${ }^{133}$ Por ejemplo, los indígenas de Duitama eran rápidos para responder a la caída en el número de los tributarios de su pueblo. En 1609, Juan Ibáñez, actuando a nombre del cacique de Duitama, don Álvaro, envío una petición a la Audiencia en Santafé, en la cual demandaba que la población tributaria de Duitama había disminuido en veintiocho indígenas desde que Luis Enríquez condujo su visita, y por lo tanto era necesario reajustar el tributo de Duitama. Ver AGN, Bogotá, Caciques e Indios, 1, fol. 553r. No está enteramente claro si las muertes fueron o no causadas por enfermedad. Es posible que parte de la población haya sucumbido a la epidemia de viruela de 1607; pero el documento también indica que dieciséis indígenas ya habían muerto antes de 1605, dos años antes de que la epidemia entrara. Ver: Ibídem, fols. 554r y 555r.

${ }^{134}$ Esperanza Gálvez Piñal, La Visita de Monzón y Prieto de Orellana a Nuevo Reino de Granada (Sevilla: Escuela de Estudios Hispano-Americanos, 1974), 18.
} 
[...] se ha acrecentado mucho la población [de Toca] y ha ido en mucho aumento el dicho pueblo de Toca porque hay de presente en él más de dos mil indios e indias y muchachos que viven políticamente y como cristianos los mas dellos, y por ser personas miserables y sin defensa se temen que las justicias y cabildos y governadores del dicho Reino les quitarán de las dichas tierras para señalar en ellas estancias a sus criados $[\ldots]^{135}$

En este caso, uno puede estar tentado a sugerir que el cacique había exagerado el número de habitantes de Toca para disputar su caso con mayor eficacia. No obstante, si se tiene en cuenta que había 475 tributarios en Toca en 1571, y que no se han documentado epidemias importantes para el período entre 1571 y 1586 , dar una población total de 2.000 para este último año difícilmente parece una afirmación exagerada ${ }^{136}$. Por el contrario, era probablemente un cálculo bastante exacto de la población total del pueblo.

Otra manera de interpretar los registros tributarios de la colonia temprana es asumiendo que el sistema de contrapesos conllevaba que, ni los indígenas ni sus encomenderos podrían falsificar de manera exagerada el número total de tributarios. Por supuesto, esto no implica que no haya habido ningún fraude. Las listas tributarias de la provincia, por lo tanto, se deben seguir viendo con cierta precaución; pero se puede afirmar que proporcionan un reflejó más o menos exacto del número de tributarios presentes.

Por esa razón, los 52.525 y los 36.375-36.475 tributarios para los años 1560 y 1562 respectivamente, pueden ser vistos como representativos de la población tributaria de Tunja ${ }^{137}$. De cualquier forma, ambas cifras deben ser vistas como totales conservadores para la provincia en su conjunto. Para 1636, los europeos habían alcanzado una familiaridad mucho mayor con la región y, en la medida en que sus exploraciones y asentamientos se expandieron hacia el norte y hacia el este al interior de los Llanos, varias comunidades remotas fueron incorporadas al sistema de encomienda.

Mientras que las listas tributarias de la relación anónima de 1560, y de la inspección de 1562 de Angulo son posiblemente completas, para los años de 1571 y 1595 ha sido necesario presumir los tamaños potenciales de la población basándose en la limitada evidencia documental disponible. Sin embargo, es preferible no asumir el método de Colmenares de reconstruir poblaciones "imaginarias" basándose en el número de pueblos encontrados durante la inspección de Valcárcel, en 1636. En lugar de esto, es recomendable comparar solamente cifras

\footnotetext{
${ }^{135}$ AGI, Sevilla, Santafé 88, R.3, N.30, fol. 1r.

${ }^{136}$ Las cifras recogidas por Egas de Guzmán en 1595 indican que la población tributaria de Toca había caído a 299. Sin embargo, es importante reconocer que esta declinación, en una gran escala, habría sido un resultado del brote de influenza de 1587-90 (o posiblemente de tifus). Ver las cifras de Egas de Guzmán en el Anexo.

${ }^{137}$ Con el fin de determinar un total de población para los dos años, simplemente multiplicamos las cifras tributarias por 3.2 (Ver Tabla 6).
} 
poblacionales conocidas, de los pueblos que aparecen en ambas visitas, y a partir de allí calcular una tasa general de despoblación para la provincia entera ${ }^{138}$.

Éste es también un enfoque metodológico algo arbitrario y problemático, puesto que no refleja exactamente la verdadera naturaleza del cambio demográfico. Los expedientes de censos anuales, de haber sido recogidos para Tunja, habrían mostrado indudablemente periodos de disminución aguda seguidos por años de rápida recuperación, y posteriormente, más descenso. Desafortunadamente, la evidencia documental no provee semejantes detalles. Sin embargo, un examen cuidadoso de las cifras tributarias revela que, por lo menos en el corto plazo, la población de algunos pueblos aumentó en pequeños porcentajes, mientras que la de otros disminuyó drásticamente. La explicación para estas variaciones no esta del todo clara, y hasta que tengamos mayor conocimiento sobre la localización exacta de cada pueblo muisca, junto con las variaciones regionales en el clima, altitud, formas de producción, densidad demográfica y patrones de migración colonial, cualquier intento por explicar las diferencias en las tendencias poblacionales será puramente especulativo ${ }^{139}$. Actualmente, estamos obligados a restringir nuestro análisis del cambio demográfico a los expedientes de censos coloniales.

Como mencionamos anteriormente, ni Juan López de Cepeda ni Egas de Guzmán proporcionaron listas completas de la población tributaria de Tunja. Cepeda, sin embargo, se aproximó de manera asombrosa, algo que contradice la mayoría de nuestras presunciones acerca de su visita. Se ha sostenido que las cifras de Cepeda daban cuenta de aproximadamente la mitad de la población tributaria de Tunja. Germán Colmenares, por ejemplo, encontró evidencia documental para solamente alrededor de 22.000 indios tributarios. Su subsecuente reconstrucción de pueblos "perdidos" lo llevó a un total de un poco menos de 40.000. Esta cifra es apenas mayor que mi propio cálculo proporcionado en esta sección. Sin embargo, el descubrimiento de evidencia adicional de primera mano de la misma visita me ha permitido obtener un total más exacto.

Una de las dificultades para cualquier análisis detallado de las cifras de Cepeda es que el material de la visita se encuentra disperso. La sección de Visitas del AGN en Bogotá no es el único lugar en el cual los segmentos de la inspección de Cepeda están guardados. Por el contrario, porciones de la visita, incluidos los cálculos de población, se pueden encontrar sin catalogar en diversos fondos. El AGI en Sevilla ofrece poca ayuda sobre esta materia, puesto que, al parecer, Cepeda nunca envió una copia de su informe final al consejo de Indias en España $^{140}$.

\footnotetext{
${ }^{138}$ Mi decisión de usar las cifras de Valcárcel para establecer una relación de despoblación, se debe a que estas son generalmente aceptadas como las más precisas.

${ }^{139}$ Newson, Life and Death, 153.

${ }^{140}$ En su detallado estudio del tributo y del trabajo indígena en la Nueva Granada, el cual se basó, en su mayoría, en evidencia recolectada en el AGI en Sevilla, María Ángeles Eugenio Martínez no encontró ninguna evidencia del informe final de López de Cepeda. No está claro ni siquiera si fue o no enviado a España.
} 
Sin embargo, hay cifras de población de 105 encomiendas provenientes de la visita de Cepeda, con una población tributaria combinada de 27.759 (véase el Anexo). Si consideramos la tasa de despoblación entre 1571 y 1636 para las 105 encomiendas, y luego aplicamos dicha tasa a la provincia en su totalidad, llegaríamos a un total levemente más alto de 32.418 tributarios, y a una población total de 103.738 (véase Tabla 6).

La breve inspección de Guzmán a la provincia, en 1595, facilitó solamente una pequeña muestra del material demográfico. El visitador recogió registros tributarios de apenas diecinueve encomiendas. El método de porcentaje de despoblación (nuevamente basado en la tasa promedio de descenso entre 1595 y 1636 , para las diecinueve encomiendas, y su posterior aplicación a la provincia entera), fue utilizado para calcular una población tributaria de 20.472 en 1595 , y una población total de 65.510. Por supuesto, con apenas diecinueve muestras para este año, los totales resultan bastante sospechosos.

De cualquier forma, tal cálculo llega a ser mucho más convincente si se compara con los datos recopilados durante ese mismo año en la provincia sureña de Santafé (efectivamente, la otra mitad del territorio muisca). La inspección realizada por Juan de Ibarra en 1595, de la provincia de Santafé, incluyó una descripción de todas las encomiendas de la región. El informe de Ibarra, que se puede encontrar en el AGI en Sevilla, contiene detallados conteos de toda la población indígena adulta masculina y femenina, de sus niños, así como una lista de los nativos que habían huido de sus encomiendas y de los que habían sido enviados fuera de la provincia para trabajar en las minas de plata ${ }^{141}$. Ibarra encontró un total de 19.161 indígenas varones en la provincia de Santafé. Esta cifra incluía a todos los caciques, capitanes, indios tributarios y ancianos. Otra lista, que sumó 42.224 indígenas, daba cuenta de todas las mujeres, niños, y familias. Unos 1.300 nativos más fueron catalogados como ausentes y había 106 indios que habían sido enviados por sus encomenderos a trabajar en las minas en La Plata. Si sumáramos todas las diferentes categorías, llegaríamos a una población total de 20.564 para la provincia, una cifra apenas un poco más alta que la de mi propia "reconstrucción" de la más densamente poblada Provincia de Tunja ${ }^{142}$.

Mientras que las cifras de población de las visitas del siglo XVI han dado lugar a muchos debates, existe una controversia mucho menor sobre la exactitud de los datos poblacionales recopilados durante las dos extensas inspecciones de Luis Enríquez y Juan de Valcárcel en el siglo XVII. Por lo tanto, la variación entre mis cálculos para 1602 y 1636 , y aquellas presentadas por Colmenares, son el resultado del descubrimiento de más evidencia documental, especialmente en el caso de la inspección de Enríquez. Debe reconocerse que, semejante a lo que sucede con el informe de Cepeda, el material de la visita de Enríquez, entre 1600 y1602, está disperso en diferentes archivos en Colombia y España; y por lo tanto, existe la duda de si todas las encomiendas dentro de la jurisdicción de Tunja están representadas allí. De cualquier forma, los 19.616 indios tributarios mencionados en el Anexo y en la Tabla 6 se acercan a las

\footnotetext{
${ }^{141}$ AGI, Sevilla, Santafé 164, N.8, Imágenes 1-14.

${ }^{142}$ Ibídem, Imagen 2.
} 
cifras dadas por el visitador mismo en los informes enviados a España. En uno de sus informes al Consejo de Indias, Enríquez escribió:

[...] parece que hay 19.000 tributarios varones [indios], exceptuando caciques, capitanes, reservados, mujeres y niños $[\ldots]^{143}$.

En otro informe del mismo año, Enríquez sugirió que la población total de la provincia era de 80.000 , cerca de cuatro veces el tamaño de la población tributaria ${ }^{144}$. Y aunque este total sugiere que el tamaño de las familias estaba en aumento a comienzos del siglo XVII (como consecuencia de las epidemias mortales entre 1587-90), hemos mantenido nuestro coeficiente en 3,2:1, con el resultado de que la población total para 1602 es de 62.771, un total levemente más conservador.

Si hay algún censo del período colonial del cual la mayoría de los estudiosos aceptan la exactitud de sus cifras de población, es el censo realizado en 1636 por Juan de Valcárcel. Quizás la explicación más simple para esta unidad de opinión es que todas las cifras tributarias de la inspección de Valcárcel están organizadas cuidadosamente en un solo legajo en el Archivo General de la Nación de Colombia ${ }^{145}$. Desafortunadamente, el informe de Valcárcel nunca fue lo suficientemente detallado como para permitirnos construir pirámides de edad o proporcionar una clasificación detallada de género en la provincia. De cualquier forma, el informe proporciona una representación exacta del número de tributarios en Tunja, así como su población total. Por esta razón, hay poca diferencia entre mis propias estimaciones y aquellas dadas anteriormente por Juan Friede y Germán Colmenares. Como lo demuestra la Tabla 6, Valcárcel encontró un total de 10.144 tributarios y una población combinada para la provincia de 48.691 (ver las cifras en el Anexo).

Finalmente, seguimos enfrentados a la frustrante tarea de intentar establecer el tamaño de la población al momento de la conquista española. Uno de los muchos problemas a los que nos vemos enfrentados cuando intentamos determinar una población de contacto para Tunja, (pero no el menor, aunque nos encontremos ante el obvio dilema de que nuestro censo más temprano sólo fue realizado hasta pasadas dos décadas desde la llegada del primer grupo de conquistadores), es la cuestión de cómo determinar lo que debe entenderse por población de "contacto". ¿Nos referimos acaso al número de habitantes en el momento exacto en que Jiménez de Quesada y sus hombres llegaron por primera vez a territorio muisca? ¿O debemos devolvernos hasta 1500, o incluso hasta antes, cuando los europeos tuvieron el primer contacto con los habitantes de las costas colombianas? Como mencionamos antes, existe la posibilidad de que los habitantes nativos de Tunja hayan sufrido de alguna epidemia importante mucho antes de 1537. Pero dado que no existe evidencia alguna de esto, se ha asumido que las primeras

\footnotetext{
${ }^{143}$ AGI, Sevilla, Santafé 18, N.29, Ramo 4, fol. 20v. Otro conteo, esta vez de la Descripción de la Provincia de Tunja, de 1610, reportaba que había alrededor de 20.000 indios de demora (o indígenas que pagan tributo) en Tunja. Ver Descripción de la ciudad, 417.

${ }^{144}$ AGI, Sevilla, Santafé 18, N.11, Ramo 3, B1.2, fol. 2v.

${ }^{145}$ En este punto hago referencia al siguiente legajo: AGN, Bogotá, Visitas de Boyacá, 11.
} 
epidemias que llegaron a la Cordillera Oriental colombiana fueron las de viruela y sarampión en 1558-60. Por lo tanto, se ha elegido el año 1537 como "punto de contacto".

Para lograr esto, fue necesario calcular el cambio anual fraccionario, necesario para dar cuenta del índice de despoblación en el período de cinco años que separa las inspecciones de Egas de Guzmán y de Luis Enríquez; un período para el cual no existe evidencia alguna de enfermedad epidémica. Entonces aplicamos esta variación anual a cada uno de los veintitrés años entre 1537 y 1560 . El resultado es una población tributaria de contacto de 71.697, la cual, si aceptamos el coeficiente de 3,2 habitantes por tributario, daría como resultado un total de población prehispánica de 229.431 para la Provincia de Tunja. Curiosamente, la única referencia registrada en el siglo XVI que da un estimado para la población indígena de Tunja en la víspera de la conquista, proporciona un total asombrosamente similar. La referencia aparece en un conocido mapa de la provincia, dibujado en los primeros años de la década de 1580 por el cacique mestizo de Turmequé, Diego de Torres. En el centro del mapa, Torres escribió que a la hora de la conquista había un total de 66.000 indios [tributarios] en la provincia. Las cifras de Torres siguen siendo unas de las únicas referencias conocidas de la población indígena de Tunja al momento de la conquista.

Tabla 6: Población Nativa en la Provincia de Tunja, 1537-1636

\begin{tabular}{|c|c|c|}
\hline Año & Indios tributarios & Población Total \\
\hline 1537 & 71.695 & 229.431 \\
c. 1558 & $52.525^{\circ}$ & 168.080 \\
1562 & $36.375-36.475$ & $116.400-116.720$ \\
$1571-1572$ & 32.418 & 103.738 \\
$1595-1596$ & 20.472 & 65.510 \\
$1600-1602$ & 19.616 & 62.771 \\
$1635-1636$ & 10.144 & 48.691 \\
\hline
\end{tabular}

\footnotetext{
- En su estudio No hay caciques ni señores, Hermes Tovar Pinzón dio una cifra de 52.647 para el mismo año. Sin embargo, parece haber un leve error, o bien en los números que citó, o en sus cálculos, puesto que las cifras que proporcionó en el texto, daban un total de 52.525.
} 
Gráfico 1: Población nativa de Tunja, 1537-1650

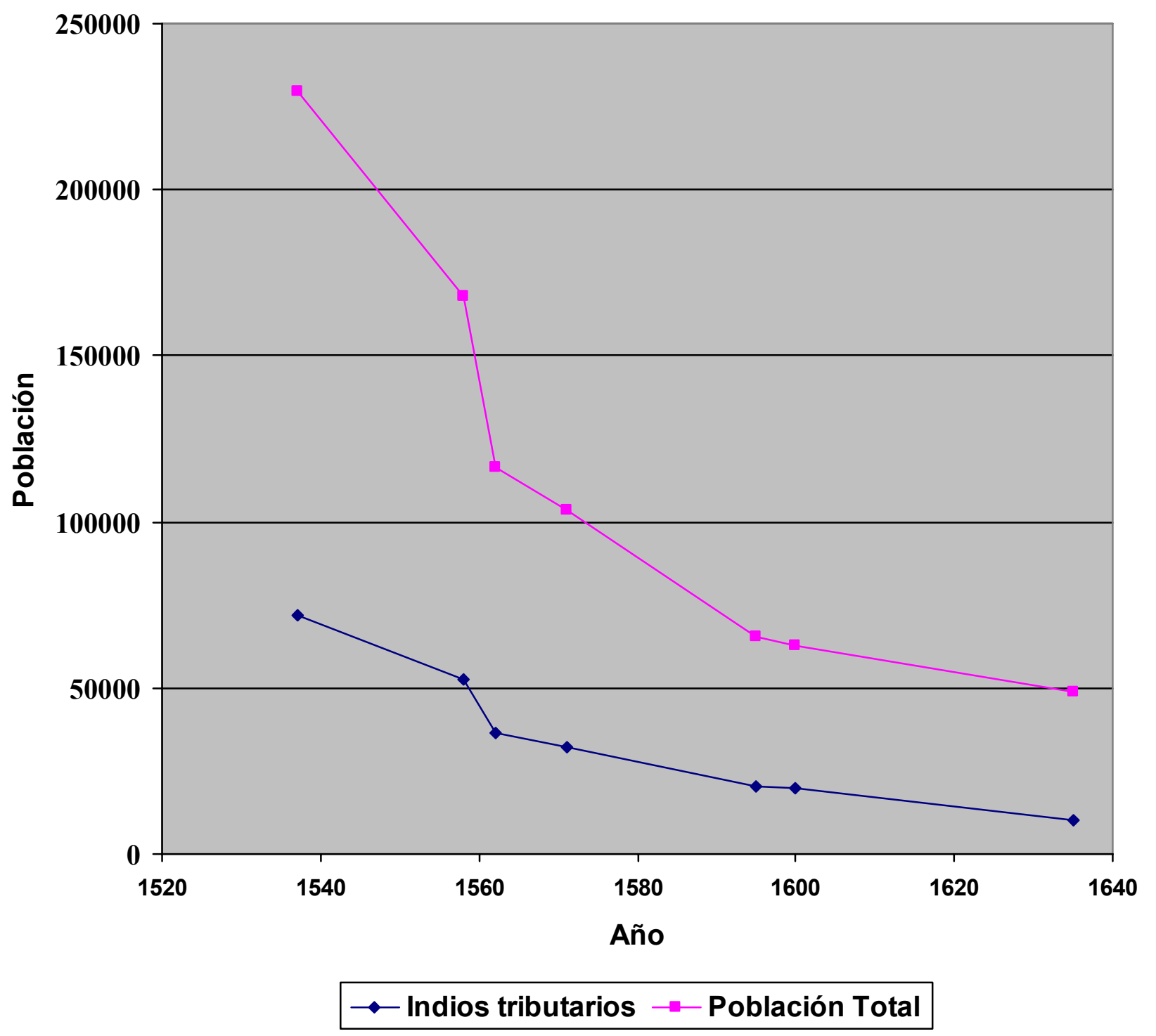




\section{Conclusiones}

Estamos hasta ahora comenzando a ensamblar la historia del cambio poblacional en Colombia. En este sentido, hay un par de asuntos importantes que requieren de mayor investigación. Primero que todo, siempre hubo la posibilidad de que los habitantes nativos de Tunja hubieran experimentado efectivamente pérdidas severas de población debido a enfermedades epidémicas mucho antes del brote general de 1558, especialmente si se tiene en cuenta la naturaleza de los intercambios precolombinos entre los muisca y otros grupos étnicos más distantes ${ }^{146}$. El análisis detallado de expedientes de los años 1530 y 1540, de la Audiencia de Santo Domingo, apoya esta teoría, o en su defecto, se puede decir que la evidencia de archivo no proporciona ninguna pista sobre una epidemia generalizada en la Cordillera Oriental de Colombia antes del brote de 1558. Sin embargo, hasta que no aparezca una evidencia más concluyente, ya sea a través de investigación arqueológica o documental, sería inadecuado y hasta irresponsable, asumir que en los años anteriores a 1558-60, años para los cuales se tiene información bien documentada sobre epidemias, una o más plagas afligieron a la población indígena de Tunja.

Otro problema característico de prácticamente cada estudio demográfico de Tunja, incluyendo a este mismo, ha sido el enfoque metodológico relativamente estrecho que han adoptado los especialistas. Por alguna razón, no hemos sido aún influenciados (o por lo menos este interés no se refleja en la historiografía) por la gran cantidad de métodos ingeniosos usados por los demógrafos de otras regiones de América Latina. Por ejemplo, en su innovador estudio del cambio demográfico en Perú, Noble David Cook demostró que existe una amplia variedad de métodos que uno podría adoptar para llegar a cálculos razonablemente exactos de la población nativa precolombina y de la época colonial temprana en las Américas. Los porcentajes de despoblación, las proyecciones de censos, la evidencia arqueológica, los modelos de mortalidad por enfermedad, el establecimiento de un máximo potencial ecológico para una región, así como los cálculos basados en la organización social indígena, son todas, maneras legítimas mediante las cuales los especialistas pueden abordar el problema de la reconstrucción de poblaciones indígenas ${ }^{147}$. Por lo general, solamente uno de estos métodos, específicamente, el método de porcentaje de despoblación, se ha adoptado para establecer el tamaño de la población indígena de la Provincia de Tunja en las etapas de precontacto y en la colonia temprana.

Una notable excepción a este enfoque la hace el geógrafo Roberto Eidt, quien, en 1959, procuró determinar la población prehispánica de la Cordillera Oriental colombiana (Santafé y Tunja) basándose en la información sobre los rendimientos de las cosechas y en la observación de fotografías aéreas. Eidt concluyó que las cuencas fértiles que caracterizaron a las provincias de Bogotá y de Tunja, fácilmente habrían podido sostener una población de más de 600.000

\footnotetext{
${ }^{146}$ Noble David Cook sugirió que cualquier intento por establecer una población de contacto para Tunja debe considerar el impacto de las epidemias de la última etapa del siglo XV y principios del XVI que afectaron zonas del Caribe. Él sugirió que una posible población de "contacto" para la Cordillera Oriental colombiana debe remontarse hasta 1493.

${ }^{147}$ Para información más detallada sobre estas aproximaciones ver: Cook, Demographic Collapse, 14-114.
} 
habitantes ${ }^{148}$. Por lo tanto, mis propios estimativos se ajustan a lo que Eidt consideraba ser la capacidad de sostenimiento de la región. Y aunque la provincia sostenía una gran cantidad de habitantes, no hay evidencia que permita sugerir que los muisca hubieran alcanzado un nivel de densidad demográfica tal, que excediera la capacidad de sostenimiento de la tierra ${ }^{149}$. Carl Langebaek hizo alusión a los altos niveles de densidad demográfica durante el último período muisca (1200-1600), y presumió que la presión de la población pudo haber provocado una cierta competencia sobre la tierra, especialmente en la Provincia de Tunja ${ }^{150}$. De cualquier forma, el estudio de Langebaek es demasiado estrecho para hacer generalizaciones; en otras palabras, es quizás prematuro aplicar sus conclusiones a la totalidad de la provincia.

Si bien el enfoque de Germán Colmenares, en donde se analiza el cambio poblacional separando las comunidades nativas en sus respectivos corregimientos, es útil, requiere un entendimiento mucho más sutil de los cacicazgos muisca, y desafortunadamente, la evidencia documental deja muchos interrogantes sin responder. El descubrimiento del censo de 1634 a los indios tributarios del corregimiento de Tenza es gratificante en la medida en que sugiere que existe la posibilidad de que tales expedientes existan para otros corregimientos de Tunja. Sin embargo, a pesar de su riqueza, la evidencia documental no es en sí misma muy adecuada. Por lo tanto, ésta es una zona en la que es fundamental realizar estudios arqueológicos adicionales.

Otra importante limitación inherente a todas las inspecciones coloniales es que los expedientes de los censos incluyeron solamente a los indios tributarios. Los indígenas que se ofrecían como criados personales a españoles, de manera individual, o que huyeron en conjunto de la provincia, no siempre fueron considerados en el censo colonial. Lo mismo se puede decir de los nativos que decidían abandonar sus hogares y trasladarse a ciudades españolas tales como Tunja, Vélez y Santafé, en donde eran empleados como artesanos. Para 1610, por ejemplo, había por lo menos ocho talleres textiles, u obrajes, en la ciudad de Tunja y todos estos habrían empleado a trabajadores indígenas ${ }^{151}$. Igualmente, estos indígenas que se trasladaron a las ciudades españolas, fueron, en la mayoría de los casos, omitidos en las listas oficiales de tributo $^{152}$. La Descripción de Tunja también demostró que una gran cantidad de indígenas trabajaron en esa ciudad como sastres, fabricantes de sombreros, carpinteros, zapateros, albañiles, y en otros trabajos manuales ${ }^{153}$. Desafortunadamente, en la actualidad no sabemos casi nada sobre estos movimientos. Por ejemplo, sería útil saber cuál fue el porcentaje de la población indígena que vivió en ciudades españolas, o el número de los que trabajaban como

\footnotetext{
148 Robert C. Eidt, "Aboriginal Chibcha Settlement in Colombia”, Annals of the American Association of Geographers 49 (diciembre, 1959), 380-381.

${ }^{149}$ Esta conclusión se corresponde con los resultados arqueológicos recientes de Carl Langebaek, quien encontró que, a pesar de la evidencia de una población densa, las poblaciones prehispánicas de los Valles de Fúquene y Susa nunca excedieron la capacidad de sostenimiento de la región.

${ }^{150}$ Langebaek, From Hunters and Gatherers, 181.

${ }^{151}$ Ver: McFarlane, Colombia Before Independence, 20-21.

${ }^{152}$ Algunos de los indígenas que huyeron a otras partes del reino o aún a lugares más distantes, eran a menudo incluidos en las listas de censo (especialmente en la inspección de Juan de Valcárcel) como indios huidos, y por lo tanto, fueron contados en el censo de población de 1636.

153 "Descripción de la ciudad de Tunja", 431-432.
} 
criados personales antes de 1571. Igualmente, saber si este porcentaje había aumentado para el momento en que Enríquez o Valcárcel condujeron sus inspecciones. Es decir, ¿estaba el porcentaje de adultos tributarios declinando en relación con el total de población masculina adulta? Si es así, quizás las cifras poblacionales de la visita de Valcárcel, en 1636, no son el mejor índice para establecer porcentajes de despoblación. Este es precisamente el tipo de consideraciones que cualquier investigación adicional debe considerar, en lugar de continuar haciendo hincapié en la cifras de la visita. Un largo debate sobre los defectos inherentes a la "lista de tributo" se asemeja a la polémica de la Leyenda Negra. De cualquier forma, discutir sobre los méritos y los defectos de tales fuentes nunca nos llevará a entender la verdadera naturaleza del cambio en la población. Los especialistas deben ahora alejar su enfoque de las listas oficiales de tributo, de las visitas coloniales, y en lugar de ello, llevar su atención hacia fuentes alternativas de información, especialmente hacia la evidencia arqueológica.

Una última advertencia: como en todo estudio sobre cambio demográfico, al final, lo que realmente queda es un conjunto de números. Por lo tanto, los estudios poblacionales siempre corren el riesgo de no decirnos nada diferente sobre la sociedad indígena, a que los indígenas murieron, y en cantidades alarmantes ${ }^{154}$. Es difícil refutar la observación realizada por Noble David Cook y W. George Lovell, de que el derrumbamiento demográfico de las poblaciones indígenas del Nuevo Mundo fue la característica más trágica de la experiencia colonial. De cualquier forma, es también importante recordar que los números en sí mismos no nos dicen mucho sobre la naturaleza de la sociedad muisca bajo el régimen colonial, ni del proceso de transición de cacicazgos independientes a sujetos coloniales. Las cifras de población en sí mismas no explican cómo los muisca reaccionaron, respondieron, se adaptaron y resistieron, a los varios desafíos del régimen colonial. $\mathrm{Y}$, mientras la población muisca continuó su precipitado descenso a través de los siglos XVI y XVII, las voces lejanas de quienes sobrevivieron al constante impacto de enfermedades mortales siguen, casi imperceptibles, esperando ser oídas.

\footnotetext{
${ }^{154}$ Karen Powers, Andean Journeys: Migration, Ethnogenesis, and the State in Colonial Quito (Albuquerque: University of New Mexico Press, 1995), 43.
} 


\section{Anexos}

Anexo 1: Cifras de población 1560

\begin{tabular}{|c|c|c|}
\hline Encomiendas & $\begin{array}{c}\text { Indios } \\
\text { Tributarios } \\
\end{array}$ & Encomenderos \\
\hline$?$ & 160 & Diego de Paredes \\
\hline$?$ & 150 & Francisco Chinchilla \\
\hline Almazaque & 134 & Diego Rincón \\
\hline Amaca & 60 & Antón Rodríguez Casalla \\
\hline Bagaxique & 114 & Diego de Paredes Alarcón \\
\hline Baganique & 640 & Pedro de Orozco \\
\hline Boavita & 260 & Pedro Niño \\
\hline Bombaza & 1000 & Pedro de Madrid \\
\hline Bonza & 242 & Isabel Maldonado \\
\hline Boyacá & 506 & Diego de Partearroyo \\
\hline Busbanza & 396 & Gonzalo Macías \\
\hline Casaguey & 400 & Pedro Niño \\
\hline Ceitiba & 540 & Juan de Salamanca \\
\hline Ceniza & 1080 & Antonio de Castro \\
\hline Chaine & 100 & Diego García Pacheco \\
\hline Chámeza & 700 & Miguel Holguín \\
\hline Cheva & 319 & Francisco Salguero \\
\hline Chibatá & 540 & Pedro Bravo de Rivera \\
\hline Chicamocha & 940 & Juan Rodríguez de León \\
\hline Chiramita & 400 & Juan de Chinchilla \\
\hline Chiscas & 165 & Francisco de Monsalve \\
\hline Chiscas & 153 & Pedro Rodríguez Salamanca \\
\hline Chita & 1077 & Pedro Rodríguez Salamanca \\
\hline Chitagoto & 866 & Francisco de Velandia \\
\hline Chusbitá & 179 & Pedro Rodríguez de León \\
\hline Coasa & 640 & Alonso de Aguilar \\
\hline Cochavita & 90 & Andrés López de Galarza \\
\hline Cocuy & 1387 & Andrés López de Galarza \\
\hline Cómbita & 300 & Pedro Sánchez de Velasco \\
\hline Comeza & 245 & Ortuño Ortíz \\
\hline Cormechoque & 421 & Luis de Sanabria \\
\hline Coromoro & 100 & Antón de Esquivel \\
\hline Cucaita & 460 & Gregorio Suárez de Deza \\
\hline Cuitivá & 436 & Pedro López Monteagudo \\
\hline Cuqueitagacha & 150 & Antón de Córdoba \\
\hline Duitama & 1300 & Alonso Maldonado \\
\hline En Los Llanos & 500 & Pedro Ruíz Herrezuelo \\
\hline En Los Llanos & 300 & Pedro de Zamora \\
\hline Furabita & 260 & Juan Quincoces de Llana \\
\hline Foacá & 94 & Gonzalo García \\
\hline Gameza & 770 & Juan de Avendaño \\
\hline Garagoa & 710 & Diego García Pacheco \\
\hline Guacamayas & 87 & Francisco de Monsalve \\
\hline Guachetá & 385 & Francisco Melgarejo \\
\hline Guaquirá & 440 & Diego de Montañez \\
\hline Icabuco & 1724 & Gonzalo Suárez Rendón \\
\hline Icabuco & 580 & Gonzalo García \\
\hline Iguaque & 329 & Pedro Rodríguez Carrión \\
\hline Iza & 173 & Juan de Torres \\
\hline La Miel & 70 & Francisco de Sierra \\
\hline Lenguazaque & 400 & Manuel Méndez \\
\hline Lenguna & 260 & Diego Rincón \\
\hline Los Llanos & 600 & Pedro Rodríguez de Salamanca \\
\hline Monga & 460 & Francisco de Monsalve \\
\hline Moniquirá & 183 & Martín Sánchez Ropero \\
\hline Moniquirá & 580 & Juan de Barrera \\
\hline Morcote & 260 & Pedro Niño \\
\hline Neacacha & 80 & Pedro Ruíz Herrezuelo \\
\hline Ocavita & 980 & Mateo Sánchez Cogolludo \\
\hline
\end{tabular}

\begin{tabular}{|c|c|c|}
\hline Encomiendas & $\begin{array}{c}\text { Indios } \\
\text { Tributarios } \\
\end{array}$ & Encomenderos \\
\hline Ochita & 260 & Antón Rodríguez Casalla \\
\hline Oicatá & 420 & Pedro Ruíz Corredor \\
\hline Onzaga & 1590 & Miguel Sánchez \\
\hline Paipa & 1064 & Gómez de Cifuentes \\
\hline Panqueba & 236 & Pedro Ruíz Herrezuelo \\
\hline Pinjacá & 400 & Andrés de Ayala \\
\hline Pisba & 970 & Diego Rincón \\
\hline Pueblo de La Sal & 244 & Pedro Rodríguez de Salamanca \\
\hline Quecanieba & 72 & Pedro Ruíz Herrezuelo \\
\hline Ramiriquí & 1100 & Capitán Patiño \\
\hline Sáchica & 1000 & Juan López \\
\hline Samaca & 100 & Antón de Esquivel \\
\hline Saquencipá & 100 & Antón de Santana \\
\hline Sasa & 330 & Hernando de Rojas \\
\hline Sátiva & 420 & Bartolomé Camacho \\
\hline Sátiva & 310 & Bernardo de Santiesteban \\
\hline Sativaquirá & 66 & Antón de Córdoba \\
\hline Sichacá & 50 & Luis de Sanabria \\
\hline Soacá & 117 & Juan Rodríguez Gil \\
\hline Soacá & 110 & Pedro Rodríguez de Salamanca \\
\hline Soata & 920 & Pedro Vásquez \\
\hline Socha & 507 & Jerónimo de Cárvajal \\
\hline Socotá & 724 & Martín Sánchez Ropero \\
\hline Sogamoso & 1000 & Encomiendas de la Corona \\
\hline Sora & 564 & (García?) Arias Maldonado \\
\hline Soraca & 210 & Francisco Rodríguez \\
\hline Sotaquirá & 890 & Pedro Yañez \\
\hline Sunuba & 756 & Diego de Paredes Calderón \\
\hline Susa & 336 & Isabel Maldonado \\
\hline Suta & 368 & Antón de Santana \\
\hline Sutamanga & 360 & Hernando de Rojas \\
\hline Tenza & 1338 & Cristóbal de Roa \\
\hline Tibasosa & 396 & Miguel Holguín \\
\hline Tinjacá & 680 & (García?) Arias Maldonado \\
\hline Tinjacá & 260 & Diego Alonso \\
\hline Tinxaque & 91 & Francisco de Monsalve \\
\hline Tipa & 386 & Alonso Martín Cobo \\
\hline Tobasía & 242 & Juan Quincoces de Llana \\
\hline Toca & 850 & Pedro García Ruíz \\
\hline Tocavita & 193 & Andrés de Ayala \\
\hline Topaga & 950 & Domingo de Aguirre \\
\hline Toscotobazía & 360 & Pedro Hernández de Reina \\
\hline Tota & 600 & Diego de Montañez \\
\hline Tupachoque & 280 & Mateo Sánchez Cogolludo \\
\hline Turga & 100 & Isabel Maldonado \\
\hline Turmequé & 1457 & Juan de Torres \\
\hline Tuta & 300 & Juan de Avendaño \\
\hline Tuta & 212 & Antonio de Castro \\
\hline Ubeita & 353 & Diego García Pacheco \\
\hline Ura & 294 & Francisco Salguero \\
\hline Viracacha & 118 & Juan de Chinchilla \\
\hline Viracacha & 75 & Francisco Martín \\
\hline Viracusa & 132 & Mateo Sánchez Cogolludo \\
\hline \multicolumn{3}{|l|}{ Totales } \\
\hline Encomiendas & 114 & \\
\hline Indios encomendados & 52525 & \\
\hline Encomenderos & 70 & \\
\hline $\begin{array}{c}\text { Encomiendas de la } \\
\text { Corona }\end{array}$ & 1 & \\
\hline
\end{tabular}

Fuente: Tovar, No hay caciques ni señores, 86-90. 


\section{Anexo 2: Cifras de población 1562}

\begin{tabular}{|c|c|c|}
\hline Encomiendas & Indios Tributarios & Encomenderos \\
\hline Amaca & 40 & Antón Rodríguez Casalla \\
\hline Baganique & 450 & Juan de Orozco \\
\hline Bagaxique & 60 (incl.Tontavita) & Diego de Paredes \\
\hline Banasuga & $\begin{array}{l}200 \text { (incl. Boavita \& } \\
\text { Cusaguey) }\end{array}$ & Pedro Niño \\
\hline Beteitiba & 200 (Incl. Ceitiba) & Juan de Salamanca \\
\hline Boavita & $\begin{array}{c}200 \text { (Incl.Casaguey \& } \\
\text { Banasuga) }\end{array}$ & Pedro Niño \\
\hline Bombaza & 380 & Pedro de Madrid \\
\hline Bonza & 200 & Isabel Maldonado \\
\hline Boyacá & 650 & Diego de Partearroyo \\
\hline Busbanza & 250 & Diego Rincón \\
\hline Ceitiba & 200 (Incl. Beteitiba) & Juan de Salamanca \\
\hline Ceniza & 700 & Antonio de Castro \\
\hline Chaine & 50 & Diego García Pacheco \\
\hline Chameza & 500 (Incl. Tibasosa) & Miguel Holguín \\
\hline Cheva & $\begin{array}{c}400 \text { (Incl. Ura, Gameza } \\
\text { \& Mochasaque) }\end{array}$ & Francisco Salguero \\
\hline Chibatá & $400-500$ & Pedro Bravo de Rivera \\
\hline Chicamocha & 600 (Incl. Tequia) & Juan Rodríguez Parra \\
\hline Chicamocha & 50 (Incl. Rasgón) & María Aguilar de Sotelo \\
\hline Chicuasa & $\begin{array}{l}180 \text { (Incl. Tutasa \& } \\
\text { Pargua) }\end{array}$ & Gonzalo Macías \\
\hline Chiquinquirá & 300 (Incl. Suta) & Antón de Santana \\
\hline Chiquisa & 60 (Incl. Tinsa) & Pedro Rodríguez de León \\
\hline Chiramita & 350 & Juan de Chinchilla \\
\hline Chiscas & 150 (Incl. Guacamayas) & Catalina de Pineda \\
\hline Chiscas & 70 & $\begin{array}{c}\text { Gonzalo Jiménez de } \\
\text { Quesada }\end{array}$ \\
\hline Chita & 350 & $\begin{array}{c}\text { Gonzalo Jiménez de } \\
\text { Quesada }\end{array}$ \\
\hline Chitagoto & 350 & Francisco de Velandia \\
\hline Chusbitá & 200 & Pedro Rodríguez de León \\
\hline Ciénaga & 120 & $\begin{array}{l}\text { Diego de Paredes } \\
\text { Calderón }\end{array}$ \\
\hline Coasa & 450 (Incl. Siama) & Catalina de Robles \\
\hline Cochavita & 65 & Andrés López de Galarza \\
\hline Cocuy & 500 & Andrés López de Galarza \\
\hline Combita & 280 (Incl. Suta) & Pedro Sánchez de Velasco \\
\hline Comeza & 200 & Juan Ortíz \\
\hline Cormechoque & 400 (Incl. Firavitoba) & Luis de Sanabria \\
\hline Coromoro & 80 & Antón de Esquivel \\
\hline Cucaita & 350 & Gregorio Suárez de Deza \\
\hline Cuitivá & 450 (Incl. Topia) & $\begin{array}{l}\text { Pedro López de } \\
\text { Monteagudo }\end{array}$ \\
\hline Cupasayna & 200 (Incl. Motavita) & Lázaro López de Sálazar \\
\hline Cuqueitagacha & 100 & Antón de Córdoba \\
\hline Cusaguey & $\begin{array}{c}200 \text { (Incl. Boavita \& } \\
\text { Banasuga) }\end{array}$ & Pedro Niño \\
\hline Duitama & 700 & Alonso Maldonado \\
\hline Faracuca & 230 & Juan Quincoces de Llana \\
\hline Firavitoba & 400 (Incl. Cormechoque) & Luis de Sanabria \\
\hline Foacá & 80 & Juan García \\
\hline Gacha & 600 (Incl. Icabuco) & Gonzalo García \\
\hline Gameza & 650 (Incl. Sotaquirá) & Pedro Yañez \\
\hline Gameza & 550 & Juan de Avendaño \\
\hline Gameza & $\begin{array}{l}400 \text { (Incl. Ura, Cheva \& } \\
\text { Mochasaque) }\end{array}$ & Francisco Salguero \\
\hline Garagoa & $\begin{array}{l}800 \text { (Incl. Ubeita \& } \\
\text { Qutequeneme) }\end{array}$ & Diego García Pacheco \\
\hline Guacamayas & 150 (Incl. Chiscas) & Catalina de Pineda \\
\hline Guachetá & 250 & Isabel de Leguisamo \\
\hline Guaneca & $\begin{array}{c}1800 \text { (Incl. Icabuco \& } \\
\text { Tibana) }\end{array}$ & Gonzalo Suárez Rendón \\
\hline Guaquirá & 800 (Incl. Tota) & Diego de Montañez \\
\hline Icabuco & $\begin{array}{c}1800 \text { (Incl. Timana \& } \\
\text { Guaneca) }\end{array}$ & Gonzalo Suárez Rendón \\
\hline Icabuco & 600 (Incl. Gacha) & Gonzalo García \\
\hline
\end{tabular}

\begin{tabular}{|c|c|c|}
\hline Encomiendas & Indios Tributarios & Encomenderos \\
\hline Iguaque & 300 & Pedro Rodríguez Carrión \\
\hline Iza & 120 & Juan de Torres \\
\hline Lenguasaque & 250 & Lázaro López de Sálazar \\
\hline Lengupa & 150 & Francisco Calderón de la Barca \\
\hline Miaca & 60 & Catalina de Pineda \\
\hline Mochasaque & $\begin{array}{c}400 \text { (Incl. Ura, Cheva \& } \\
\text { Gameza) }\end{array}$ & Francisco Salguero \\
\hline Monga & 300 & Francisco de Monsalve \\
\hline Monquirá & 160 & Martín Sánchez Ropero \\
\hline Monquirá & 300 (Incl. Saquencipá) & Juan de Barrera \\
\hline Monquirá & 130 & (Juan de) Chinchilla \\
\hline Morcote & 300 & Pedro Niño \\
\hline Motavita & 200 (Incl. Cupasayna) & Lázaro López de Sálazar \\
\hline Motavita & 60 & Gonzalo Jiménez de Quesada \\
\hline Muecha & 60 & Francisco Calderón de la Barca \\
\hline Neacacha & 40 & Pedro Ruíz Herrezuela \\
\hline Ocavita & 700 (Incl. Tupachoque) & Juan de Villanueva \\
\hline Ochica & 300 & Antón Rodríguez Casalla \\
\hline Oicata & 500 & Pedro Ruíz Corredor \\
\hline Onzaga & 700 & Miguel Sánchez \\
\hline Paipa & 700 & Gómez de Cifuentes \\
\hline Panqueba & 200 (Incl. Quecanieba) & Pedro Ruíz Herrezuelo \\
\hline Pargua & $\begin{array}{c}180 \text { (Incl. Tutasa \& } \\
\text { Chicuasa) }\end{array}$ & Gonzalo Macías \\
\hline Pesca & 400 & Pedro de Madrid \\
\hline Pisba & 700 & Diego Rincón \\
\hline Pueblo de La Sal & 50 & Gonzalo Jiménez de Quesada \\
\hline Quecanieba & 200 (Incl. Panqueba) & Pedro Ruíz Herrezuelo \\
\hline Ramiriquí & 500 & Pedro López Patiño de Haro \\
\hline Ráquira & 180 & Diego Alonso \\
\hline Rasgón & 50 (Incl. Chicamocha) & María Aguilar de Sotelo \\
\hline Sáchica & 600 & Juan López \\
\hline Samaca & 100 & Antón de Esquivel \\
\hline Saquencipá & 300 (ncl. Moniquirá) & Juan de Barrera \\
\hline Sasa & 300 & Hernando de Rojas \\
\hline Sátiva & 340 & Bartolomé Camacho \\
\hline Sátiva & 160 & Bernardo de Santiesteban \\
\hline Sativaquirá & 50 & Antón de Córdoba \\
\hline Siachoque & 130 & Juan de Chinchilla \\
\hline Siama & 450 (Incl. Coasa) & Catalina de Robles \\
\hline Sichaca & 30 & Luis de Sanabria \\
\hline Soacá & 200 & Juan Rodríguez Gil \\
\hline Soatá & 130 & Miguel Sánchez \\
\hline Soatá & 500 & Pedro Vásquez \\
\hline Socha & 350 & Jerónimo de Carvajal \\
\hline Socotá & 450 & Martín Sánchez Ropero \\
\hline Sogamoso & 800 & Encomienda de la Corona \\
\hline Somondoco & 450 & Diego de Paredes Calderón \\
\hline Sora & 450 & García Arias Maldonado \\
\hline Soraca & 200 & Francisco Rodríguez \\
\hline Sotaquirá & 650 (Incl. Gameza) & Pedro Yañez \\
\hline Sunuba & 500 & Diego de Paredes Calderón \\
\hline Susa & 250 & Isabel Maldonado \\
\hline Susacón & 80 (Incl. Tocavita) & Juan Quincoces de Llana \\
\hline Suta & 300 & Antón de Santana \\
\hline Suta & 280 (Incl. Combita) & Pedro Sánchez de Velasco \\
\hline Sutamanga & 200 & Hernando de Rojas \\
\hline
\end{tabular}




\section{Anexo 2: Cifras de población 1562, continuación}

\begin{tabular}{|c|c|c|}
\hline & & \\
\hline Encomiendas & Indios Tributarios & Encomenderos \\
\hline Táquira & 200 & Diego Alonso \\
\hline Tasco & 180 (Incl. Tuta \& Tobasia) & $\begin{array}{c}\text { Pedro Hernández de } \\
\text { Reina }\end{array}$ \\
\hline Tenza & 900 & Cristóbal de Roa \\
\hline Tequia & 600 (Incl. Chicamocha) & Juan Rodríguez Parra \\
\hline Teusa & 150 (Incl. Tijo) & Andrés de Ayala \\
\hline Tibaná & $\begin{array}{c}1800 \text { (Incl. Icabuco \& } \\
\text { Guaneca) }\end{array}$ & $\begin{array}{l}\text { Gonzalo Suárez } \\
\text { Rendón }\end{array}$ \\
\hline Tibasosa & 500 (Incl. Chameza) & Miguel Holguín \\
\hline Tijo & 150 (Incl.Teusa) & Andrés de Ayala \\
\hline Tinjacá & 450 & $\begin{array}{l}\text { García Arias } \\
\text { Maldonado }\end{array}$ \\
\hline Tinjacá & 160 (Incl. Tuta) & Antonio de Castro \\
\hline Tinsa & 60 (Incl. Chiquisa) & $\begin{array}{l}\text { Pedro Rodríguez de } \\
\text { León }\end{array}$ \\
\hline Tipa & 500 & (Alonso) Martín (Cobo) \\
\hline Tobasía & 50 & $\begin{array}{c}\text { Juan Quincoces de } \\
\text { Llana }\end{array}$ \\
\hline Tobasía & 180 (Incl. Tuta \& Tasco) & $\begin{array}{c}\text { Pedro Hernández de } \\
\text { Reina }\end{array}$ \\
\hline Toca & 500 & Pedro García Ruíz \\
\hline Toca & 140 & Andrés de Ayala \\
\hline Tocavita & 80 (Incl. Susacón) & $\begin{array}{l}\text { Juan Quincoces de } \\
\text { Llana }\end{array}$ \\
\hline Tontavita & 60 (Incl. Bagaxique) & Deigo de Paredes \\
\hline Tópága & 650 & Domingo de Aguirre \\
\hline Topía & 450 (Incl. Cuitivá) & $\begin{array}{l}\text { Pedro López } \\
\text { Monteagudo }\end{array}$ \\
\hline Tota & 800 (Incl. Guáquira) & Diego de Montañez \\
\hline Tupachoque & 700 (Incl. Ocavita) & Juan de Villanueva \\
\hline Turga & 100 & Pedro Nuñez Cabrera \\
\hline Turmequé & 1500 & Juan de Torres \\
\hline Tuta & 160 (Incl. Tinjacá) & Antonio de Castro \\
\hline Tuta & 200 & Juan de Avendaño \\
\hline Tuta & $\begin{array}{c}180 \text { (Incl. Tobasía \& } \\
\text { Tasco) }\end{array}$ & $\begin{array}{l}\text { Pedro Hernández de } \\
\text { Reina }\end{array}$ \\
\hline Tutasa & $\begin{array}{c}180 \text { (Incl. Pargua \& } \\
\text { Chicuasa) }\end{array}$ & Gonzalo Macías \\
\hline Ubeita & $\begin{array}{c}800 \text { (Incl. Garagoa \& } \\
\text { Qutequeneme) }\end{array}$ & Diego García Pachecho \\
\hline Ura & $\begin{array}{c}400 \text { (Incl. Cheva \& } \\
\text { Mochasaque) }\end{array}$ & Franscisco Salguero \\
\hline Viracacha & 120 & Francisco Martín \\
\hline Viracusa & 40 & Juan Rodríguez Parra \\
\hline Viracusa & 110 & Juan de Villanueva \\
\hline \multicolumn{3}{|l|}{ Totales } \\
\hline Encomiendas & 143 & \\
\hline $\begin{array}{c}\text { Indios } \\
\text { encomendados }\end{array}$ & $36.375-36.475$ & \\
\hline Encomenderos & 72 & \\
\hline $\begin{array}{c}\text { Encomiendas de } \\
\text { la Corona }\end{array}$ & 1 & \\
\hline
\end{tabular}

Fuente: AGI, Sevilla, Justicia 649. 
Anexo 3: Cifras de población 1571-72

\begin{tabular}{|c|c|c|}
\hline Encomiendas & Indios Tributarios & Encomenderos \\
\hline Amaca & 28 & \\
\hline Baganique & 256 & (Diego Rincón?) \\
\hline Beteitiba & 227 (Incl. Ceitiba) & \\
\hline Boavita & 112 (Incl. Cusaguey) & \\
\hline Boaza & 536 (Incl. Pesca) & (Pedro de Madrid?) \\
\hline Bombaza & 278 & \\
\hline Bonza & 112 & \\
\hline Boyacá & 424 & \\
\hline Busbanza & 252 & \\
\hline Ceitiba & 227 (Incl. Beteitiba) & \\
\hline Chameza & 467 (Incl. Tibasosa) & \\
\hline Chibatá & 155 & \\
\hline Chicamocha & 586 (Incl. Tequía) & Juan Rodríguez Parra \\
\hline Chicamocha & 30 (Incl. Rasgón) & (María Aguilar de Sotelo?) \\
\hline Chicuasa & $\begin{array}{c}138 \text { (Incl. Pargua \& } \\
\text { Tutasa) }\end{array}$ & (Gonzalo Macías?) \\
\hline Chipa & $\begin{array}{c}111 \text { (Incl. } \\
\text { Comezaquirá }\end{array}$ & \\
\hline Chiquinquirá & 265 (Incl. Suta) & Santana \\
\hline Chiramita & 203 & (Juan de Chinchilla?) \\
\hline Chita & 407 & \\
\hline Chitagoto & 380 & (Francisco de Velandia?) \\
\hline Chusbitá & 155 & (Pedro Rodríguez de León?) \\
\hline Ciénaga & 100 & \\
\hline Coasa & 278 (Incl. Sieama) & (Catalina de Robles?) \\
\hline Cocuy & 383 & \\
\hline Comezaquirá & 111 (Incl. Chipa) & \\
\hline Cuqueita & 322 & (Alvaro Suárez?) \\
\hline Cusaguey & 112 (Incl. Boavita) & \\
\hline Cuscanieba & 333 (Incl. Panqueba) & \\
\hline Duitama & 613 & (Alonso Maldonado?) \\
\hline Faracuca & 113 & (Juan de Orozco?) \\
\hline Firavitobá & 415 & (Luis de Sanabria?) \\
\hline Foacá & 83 & (Iñigo López de Fonseca?) \\
\hline Gacha & 391 (Incl. Icabuco) & (Sebastián García?) \\
\hline Gameza & 534 & Juan de Avendaño \\
\hline Gameza & 346 (Incl. Sotaquirá) & (Pedro) Yañez \\
\hline Garagoa & 573 (Incl. Ubeita) & (Diego García?) \\
\hline Guachetá & 376 & Bernardino de Mojica Guevara \\
\hline Guáquira & 473 (Incl.Tota) & (Diego de Montañez?) \\
\hline Guatecha & 100 & \\
\hline Icabuco & 1686 (Incl. Tibana) & Gonzalo Suárez Rendón \\
\hline Icabuco & 391 (Incl. Gacha) & (Sebastián García?) \\
\hline Icaga & 73 (Incl. Meaca) & \\
\hline Iguaque & 301 & \\
\hline Lenguasaque & 240 & \\
\hline Lengupa & 120 & \\
\hline Meaca & 73 (Incl. Icaga) & \\
\hline Mochasaque & 371 & (Francisco Salguero?) \\
\hline Monga & 344 & \\
\hline Moniquirá & 288 (Incl. Sauencipá) & Juan Barrera \\
\hline Moniquirá & 333 & Bernardino de Mojica Guevara \\
\hline Morcote & 222 & (Pedro Niño?) \\
\hline Motavita & 60 & \\
\hline Muecha & 56 & (Rincón?) \\
\hline Ocavita & $\begin{array}{c}383 \text { (Incl. } \\
\text { Tupachoque) }\end{array}$ & \\
\hline Ochica & 272 & (Antón Rodríguez Casalla?) \\
\hline Ocusa & 224 & \\
\hline
\end{tabular}

\begin{tabular}{|c|c|c|}
\hline Encomiendas & Indios Tributarios & Encomenderos \\
\hline Oicatá & 383 (Incl. Nemusa) & \\
\hline Onzaga & 364 & Miguel Sánchez \\
\hline Paipa & 542 & \\
\hline Panqueba & 333 (Incl. Cuscanieba) & \\
\hline Pargua & $\begin{array}{l}138 \text { (Incl. Chicuasa \& } \\
\text { Tutasa) }\end{array}$ & (Gonzalo Macías?) \\
\hline Pesca & 536 (Incl. Boaza) & (Pedro de Madrid?) \\
\hline Pisba & 497 & \\
\hline Pueblo de La Sal & 115 & \\
\hline Ramiriquí & 402 & (Cap. Patiño?) \\
\hline Rasgón & 30 (Incl. Chicamocha) & (María Aguilar de Sotelo?) \\
\hline Sáchica & 444 & $\begin{array}{l}\text { Diego García Zarter? o Juan } \\
\text { López }\end{array}$ \\
\hline Samaca & 103 & $\begin{array}{l}\text { (Encomienda de la } \\
\text { Corona?) }\end{array}$ \\
\hline Saquencipá & 288 (Incl. Moniquirá) & Juan de Barrera \\
\hline Sasa & 292 & Hernando Rojas \\
\hline Sativa & 150 & \\
\hline Siama & 278 (Incl. Coasa & (Catalina de Robles?) \\
\hline Soatá & 160 & Miguel Sánchez \\
\hline Soatá & 382 & (Pedro de Vásquez?) \\
\hline Socotá & 333 & $\begin{array}{l}\text { La viudad del Ropero } \\
\text { (Catalina-india) }\end{array}$ \\
\hline Socha & 280 & (Jerónimo de Carvajal?) \\
\hline Somondoco & 500 & \\
\hline Sora & 392 & Juan Prieto Maldonado \\
\hline Soraca & 240 & Juan Rodríguez de Morales \\
\hline Sotaquirá & 346 (Incl. Gameza) & (Pedro) Yañez \\
\hline Sunuba & 417 & \\
\hline Suta & 265 (Incl. Chiquinquirá) & Santana \\
\hline Sutamanga & 81 & (Hernando de Rojas?) \\
\hline Tamara & 522 & \\
\hline Tequía & 586 (Incl. Chicamocha) & Juan Rodríguez Parra \\
\hline Tenza & 456 & (Cristóbal de?) Roa \\
\hline Tibana & 1686 (Incl. Icabuco) & Gonzalo Suárez Rendón \\
\hline Tibasosa & 467 (Incl. Chameza) & \\
\hline Tinjacá & 470 & Juan Prieto Maldonado \\
\hline Tinjacá & 198 & Diego Alonso \\
\hline Tinjacá & 140 & Antonio Castro \\
\hline Tobasía & 165 & \\
\hline Toca & 475 & (Pedro García Ruíz?) \\
\hline Tocavita & 83 & \\
\hline Topaga & 361 & \\
\hline Tota & 473 (Incl. Guáquira) & (Diego de Montañez?) \\
\hline Tupachoque & 697 (Incl. Ocavita?) & (Juan de Villanueva?) \\
\hline Turca & 156 & Gonzalo de Vega \\
\hline Turmequé & 872 & Pedro de Torres \\
\hline Tutasa & $\begin{array}{l}138 \text { (Incl. Pargua \& } \\
\text { Chicuasa) }\end{array}$ & (Gonzalo Macías?) \\
\hline Ubeita & 573 (Incl. Garagoa) & (Diego García?) \\
\hline Viracacha & 112 & \\
\hline Viracusa & 32 & (Juan Rodríguez Parra?) \\
\hline Viracusa & 108 & (Juan de Villanueva?) \\
\hline \multicolumn{3}{|l|}{ Totales } \\
\hline Encomiendas & 143 & \\
\hline $\begin{array}{c}\text { Indios } \\
\text { encomendados }\end{array}$ & $36.375-36.475$ & \\
\hline Encomenderos & 72 & \\
\hline $\begin{array}{c}\text { Encomiendas de la } \\
\text { Corona }\end{array}$ & 1 & \\
\hline
\end{tabular}

Fuentes: AGI, Sevilla, Santafé 56a , N. 17; AGN, Bogotá, Visitas de Boyacá, 30, exp. 11. 
Anexo 4:Cifras de población 1571-72

\begin{tabular}{|c|c|c|}
\hline Encomiendas & $\begin{array}{c}\text { Indios } \\
\text { Tributarios }\end{array}$ & Encomenderos \\
\hline Bombaza & 102 & (Pedro Daza?) \\
\hline Bonza & 81 & (Juan de Sandoval?) \\
\hline Chibatá & 216 & Encomienda de la Corona \\
\hline Cormechoque & 127 & (Martín de Rojas?) \\
\hline Cuitiva & 165 & (Isabel Ruíz de Quesada?) \\
\hline Duitama & 347 & (Encomienda de la \\
\hline Corona?)
\end{tabular}

Fuentes: AGI, Sevilla, Santafé 166: AGN, Bogotá, Caciques e Indios, 70, nos. 11 y 19. 
Anexo 5: Cifras de población 1600-02

\begin{tabular}{|c|c|c|}
\hline Encomiendas & Indios Tributarios & Encomenderos \\
\hline Amaca & 31 & Antón Rodríguez Casalla \\
\hline Baganique & $\begin{array}{l}123 \text { (Incl. Lengupa \& } \\
\text { Sutamanga) }\end{array}$ & Juan de Avalos Martín \\
\hline Bagaxique & 19 & Diego Núñez Estupiñan \\
\hline Beteitiba & 121 & Juan de Avalos Martín \\
\hline Boavita & 66 & Pedro Niño (el mozo) \\
\hline Bombaza & 91 & Pedro Daza \\
\hline Bonza & 76 & Juan de Sandoval \\
\hline Boyacá & 281 & Miguel López de Partearroyo \\
\hline Buisa & 31 & Alvaro Suárez de Daza \\
\hline Busbanza & 269 (Incl. Tobon) & Diego Rincón (el mozo) \\
\hline Caiboca & 77 (Incl. Goboro) & Francisco de Vargas \\
\hline Cavita & 58 (Incl. Cupiagua) & Diego Suárez Rendón \\
\hline Ceniza & 345 & Andrés de Velosa y Castro \\
\hline Chaine & 36 & Juan de Zarate \\
\hline Chameza & 88 & Diego Holguín Maldonado \\
\hline Chameza & 40 & Andrés Patiño \\
\hline Chameza & 44 & Pedro Daza \\
\hline Chausa & 161 (Incl. Sasa) & Hernando de Rojas \\
\hline Cheva & $\begin{array}{c}164 \text { (Incl. Ura \& } \\
\text { Ogamora) }\end{array}$ & Sebastián de Velandia \\
\hline Chibabá & 141 (Incl. Tijo) & Luis Bermúdez \\
\hline Chibata & 244 & Encomienda de la Corona \\
\hline Chicamocha & 45 & Antonio de Enciso \\
\hline Chicuasa & 87 (Incl. Tutasa) & Diego de Vargas \\
\hline Chinata & $\begin{array}{l}152 \text { (Incl. Ocusa, } \\
\text { Sativa \& Tinsa) }\end{array}$ & Francisco Niño Bueno \\
\hline Chipatá & $\begin{array}{l}294 \text { (Incl. Topaga, } \\
\text { Satoba \& Gotamo) }\end{array}$ & Antonio Bravo Maldonado \\
\hline Chiquinquirá & 40 & Francisco de Aguilar Santana \\
\hline Chiquisa & 83 & Catalina de Vargas \\
\hline Chiramita & 137 & Pedro Pacheco \\
\hline Chiribí & $\begin{array}{c}1030 \text { (Incl. Icabuco \& } \\
\text { Tibana) }\end{array}$ & Miguel Suárez \\
\hline Chita & 219 & Fernando de Berrio \\
\hline Chitagoto & 163 & Francisco de Velandia \\
\hline Chusbitá & 85 & Alonso Rivera Santana \\
\hline Ciénaga & 74 & Juan de la Fuente Calderón \\
\hline Citaquezipa & 96 & Isabel Zambrano \\
\hline Coasa & 96 & Antonio de Ezquivel \\
\hline Cocuy & 170 & Pedro Núñez Cabrera \\
\hline Combitá & 122 & Pedro Niño \\
\hline Comeza & 154 (Incl. Cosquetibá) & Juan Ortíz de Godoy \\
\hline Cormechoque & 123 & Martín de Rojas \\
\hline Coromoro & 124 (Incl. Comeza) & Pedro de Valdelomar \\
\hline Cosquetibá & 154 (Incl. Comeza) & Juan Ortíz de Godoy \\
\hline Crabos & 40 & Encomienda de la Corona \\
\hline Cuchavitas & 51 & Pedro Núñez Cabrera \\
\hline Cuitiva & 150 & Isabel Ruíz de Quesada \\
\hline Cupasayna & 144 & Juan Cerón de Sálazar \\
\hline Cupiagua & 58 (Incl. Cavita) & Diego Suárez de Vargas \\
\hline Cuqueita & 183 & Alvaro Suárez de Deza \\
\hline Cuqueitagacha & 54 & Alonso de Carvajal \\
\hline Cusaguey & 85 & Pedro Niño Zambrano \\
\hline
\end{tabular}

\begin{tabular}{|c|c|c|}
\hline Encomiendas & Indios Tributarios & Encomenderos \\
\hline Duitama & 340 & Encomienda de la Corona \\
\hline Firavitobá & 229 & Martín de Rojas \\
\hline Foacá & 64 & Diego Bravo de Guzmán \\
\hline Furaquirá & 91 & Luis Arias Maldonado \\
\hline Gacha & 223 (Incl. Sumita & Sebastián García de la Parra \\
\hline Gameza & 98 & Francisco Yañez Hermoso \\
\hline Pedro Pacheco & 291 & Pedro Pacheco \\
\hline Garagoa & 187 & Juan de la Peña \\
\hline Goboro & 77 (Incl. Caiboca) & Francisco de Vargas \\
\hline Gotamo & $\begin{array}{l}294 \text { (Incl. Topoga, } \\
\text { Chipata \& Satoba) }\end{array}$ & Antonio Bravo Maldonado \\
\hline Guacamayas & 41 & María de Monsalve \\
\hline Guachetá & 242 & Isabel de Leguisamo \\
\hline Guaneca & 53 & Miguel Suárez \\
\hline Guaquirá & 105 & Juan de Torres \\
\hline Guaravitebas & 62 & María de Monsalve \\
\hline Guatatibe & 40 & Alvaro Suárez de Deza \\
\hline Guatecha & 64 & Antonio Bravo Maldonado \\
\hline Guatenzana & 46 & Fernando de Berrio \\
\hline Guateque & 143 & Luis Cabeza de Vaca \\
\hline Icabuco & $\begin{array}{c}1030 \text { (Incl. Tibana \& } \\
\text { Chiribí) }\end{array}$ & Miguel Suárez \\
\hline Icaga & 51 & María de Monsalve \\
\hline Iguaque & 151 & Juan de Olálora \\
\hline Iza & 112 & Sebastián de Velandia \\
\hline Labranza Grande & 77 & Encomienda de la Corona \\
\hline Lenguasaque & 188 & Juan Cerón de Sálazar \\
\hline Lengupa & $\begin{array}{l}123 \text { (Incl. Baganique } \\
\text { \& Sutamanga) }\end{array}$ & Juan Sánchez de la Parra \\
\hline Monga & 220 & Encomienda de la Corona \\
\hline Monguí & 124 & Encomienda de la Corona \\
\hline Moniquirá & 134 & Encomienda de la Corona \\
\hline Moniquirá & 85 & Luis Arias Maldonado \\
\hline Moniquirá & 139 (Incl. Toquecha) & Bartolomé de Alarcón \\
\hline Motavita & 144 & Juan Cerón de Sálazar \\
\hline Motavita & 55 & Juan Sanz Hurtado \\
\hline Muecha & 6 & Bartolomé Calderón \\
\hline Neacacha & 51 & Estéban de Albarrazín \\
\hline Nemusa & 294 (Incl. Oicatá) & Miguel Ruíz Corredor \\
\hline Nobsa & 118 & Diego Holguín Maldonado \\
\hline Ocavita & 135 & Jerónimo de Lisarazo \\
\hline Ochica & 145 & Antonio Rodríguez Casalla \\
\hline Ocusa & $\begin{array}{l}152 \text { (Incl. Sativa \& } \\
\text { Tinsa) }\end{array}$ & Francisco Niño Bueno \\
\hline Ogamora & $\begin{array}{c}164 \text { (Incl. Ura \& } \\
\text { Cheva) }\end{array}$ & Sebastián de Velandia \\
\hline Oicatá & 294 (Incl. Nemusa) & Miguel Ruíz Corredor \\
\hline Onzaga & 145 & Hernando Mateos \\
\hline Pachaquirá & 50 & Hernando de Rojas \\
\hline Paipa & 320 & $\begin{array}{l}\text { Francisco de Cifuentes } \\
\text { Monsalve }\end{array}$ \\
\hline Panqueba & 163 & Juan de la Fuente Calderón \\
\hline Pesca & 108 & Pedro Daza \\
\hline Pueblo de La Sal & 51 & Fernando de Berrio \\
\hline Ramiriquí & 83 & Luis Arias Maldonado \\
\hline
\end{tabular}




\section{Anexo 5: Cifras de población 1600-02 continuación}

\begin{tabular}{|c|c|c|}
\hline Encomiendas & Indios Tributarios & Encomenderos \\
\hline Ráquira & 96 & Diego Alonso \\
\hline Rasgón & 8 & Juan de Sierra San Miguel \\
\hline Sáchica & 263 & María Magdalena de Velasco \\
\hline Samaca & 75 & Encomienda de la Corona \\
\hline Saquencipá & 139 (Incl. Moniquirá) & Isabel de Leguisamo \\
\hline Sasa & 161 (Incl. Chausa) & Hernando de Rojas \\
\hline Sátiva & $\begin{array}{l}152 \text { (Incl. Ocusa \& } \\
\text { Tinsa) }\end{array}$ & Francisco Niño Bueno \\
\hline Sátiva & 72 & Gonzalo de Santiesteban \\
\hline Sativaquirá & 30 & Alonso de Carvajal \\
\hline Satova & $\begin{array}{l}294 \text { (Incl. Topaga, } \\
\text { Chipata \& Gotamo) }\end{array}$ & Antonio Bravo Maldonado \\
\hline Siachoque & 100 & Juan de Otálora \\
\hline Sichacá & 28 & Martín de Rojas \\
\hline Soacá & 129 & $\begin{array}{l}\text { Francisco Rodríguez Gil } \\
\text { Melgarejo }\end{array}$ \\
\hline Soatá & 131 & Hernando Mateos \\
\hline Soatá & 121 & Encomienda de la Corona \\
\hline Socha & 212 (Incl. Tasco) & Alonso de Carvajal \\
\hline Soconsaque & 22 & Luis Arias Maldonado \\
\hline Soconsuco & 66 & Martín González Piedrabuena \\
\hline Socotá & 147 & Juan de Otálora \\
\hline Sogamoso & 318 & Encomienda de la Corona \\
\hline Somondoco & 290 & Rodrigo Maldonado de Mendoza \\
\hline Sora & 226 & Antonio Patiño de Haro \\
\hline Soraca & 168 & Juan Rodríguez de Morales \\
\hline Sotaquirá & 189 & Francisco Yañez Hermoso \\
\hline Sumita & 223 (Incl. Guacha) & Sebastián García de la Parra \\
\hline Sunuba & 130 & Diego Núñez de Estupiñan \\
\hline Susa & 300 & Isabel Ruíz Lanchero \\
\hline Susa & 122 & Juan de Sándoval \\
\hline Susacón & 55 & Antonio Bravo Maldonado \\
\hline Suta & 175 & Alonso Sánchez Merchán \\
\hline Suta & 122 & Pedro Niño \\
\hline Sutamanga & $\begin{array}{c}123 \text { (Incl. Lengupa \& } \\
\text { Baganique) }\end{array}$ & Juan Sánchez de la Parra \\
\hline Sutatenza & $\begin{array}{l}241 \text { (Incl. Tenza, } \\
\text { Teguas, Ubeita \& } \\
\text { Chaine) }\end{array}$ & Juan de Zarate Chacón \\
\hline Tamara & 678 & Fernando de Berrio \\
\hline Tasco & 212 (Incl. Socha) & Alonso de Carvajal \\
\hline Tenza & 365 & Juan de Zarate Chacón \\
\hline Tequía & 90 & Antonio de Enciso \\
\hline Tibana & $\begin{array}{c}1030 \text { (Incl. Icabuco \& } \\
\text { Chiribí) }\end{array}$ & Miguel Suárez \\
\hline Tibasosa & 214 & Diego Holguín Maldonado \\
\hline Tijo & 141 (Incl. Chibaba) & Luis Bermúdez \\
\hline Tinjacá & 301 & Francisco de Avendaño \\
\hline Tinjacá & 67 & Andrés de Velosa y Castro \\
\hline Tinsa & $\begin{array}{l}152 \text { (Incl. Ocusa \& } \\
\text { Sativa) }\end{array}$ & Francisco Niño Bueno \\
\hline Tiren & 46 & Encomienda de la Corona \\
\hline Tobasía & 45 & Antón Rodríguez Casalla \\
\hline Tobon & 269 (Incl. Busbanza) & Diego Rincón \\
\hline
\end{tabular}

\begin{tabular}{|c|c|c|}
\hline Encomiendas & Indios Tributarios & Encomenderos \\
\hline Toca & 286 & Antonio Mancipe \\
\hline Tocavita & 129 & Luis Bermúdez \\
\hline Tópaga & $\begin{array}{c}294 \text { (Incl. Chipata, } \\
\text { Satova \& Gotamo) }\end{array}$ & Antonio Bravo Maldonado \\
\hline Topía & 151 & Isabel Ruíz de Quesada \\
\hline Toquecha & 101 (Incl. Moquecha) & Bartolomé de Alarcón \\
\hline Toquilla & 23 & Andrés Patiño \\
\hline Tota & 115 & Diego Suárez de Vargas \\
\hline Tunebas & 72 (Incl. Chiscas) & Fernando de Berrio \\
\hline Tupachoque & 83 & ??? \\
\hline Turca & 118 & Gonzalo de Vega \\
\hline Turga & 50 & Juan Rodríguez de Vergara \\
\hline Turmequé & 580 & Encomienda de la Corona \\
\hline Tuta & 244 & Francisco de Avendaño \\
\hline Tutasa & 87 (Incl. Chicuasa) & Diego de Vargas \\
\hline Tutasa & 62 & Encomienda de la Corona \\
\hline Ubeita & 44 & Juan de Zarate Chacón \\
\hline Ura & 164 (Incl. Cheva \& & Sebastián de Velandia \\
\hline Oiracacha & 82 & Alvaro Suárez de Deza \\
\hline Viracusa & 21 (Incl. & Antonio de Enciso \\
\hline Viracusa & 6 & Antón Rodríguez Casalla \\
\hline Totales & & \\
\hline Encomiendas & $\mathbf{1 6 8}$ & \\
\hline $\begin{array}{c}\text { Indios } \\
\text { encomendados }\end{array}$ & $\mathbf{1 9 . 6 1 6}$ & \\
\hline Encomenderos & $\mathbf{7 3 - 7 4}$ & \\
\hline Encomiendas de la \\
Corona
\end{tabular}

Fuente. AGI, Sevilla, Santafé 18, R.A, no. 29. 


\section{Anexo 6: Cifras de población 1634}

\begin{tabular}{|c|c|c|}
\hline Encomiendas & Indios Tributarios & Encomenderos \\
\hline Baganique & 18 (2 en Las Lajas) & (Laureano de la Parra?) \\
\hline Buisa & 16 (3 en Las Lajas) & Diego ParedesCalderón \\
\hline Chiramita & 20 (2 en Las Lajas) & (Bartolomé de Velosa y \\
Castro?)
\end{tabular}

Fuentes: AGN, Bogotá, Miscelánea, 3, no. 48, Relación de Juan Gaitán, corregidor de Tenza. 
Anexo 7: Cifras de población 1634

\begin{tabular}{|c|c|c|}
\hline Encomiendas & Indios Tributarios & Encomenderos \\
\hline Amaca & 12 & Juan de Borja \\
\hline Baganique & 21 (Incl. Sutamanga) & $\begin{array}{c}\text { Laureano de la } \\
\text { Parra }\end{array}$ \\
\hline Bagaxique & 13 & $\begin{array}{l}\text { Diego Núñez de } \\
\text { Estupiñan }\end{array}$ \\
\hline Beteitiba & 49 (Incl. Seitiba) & $\begin{array}{c}\text { Juana de Avalos } \\
\text { Marín }\end{array}$ \\
\hline Boavita & 81 (Incl. Cusaguey) & $\begin{array}{l}\text { Pedro Niño } \\
\text { Zambrano }\end{array}$ \\
\hline Bombaza & 82 & $\begin{array}{l}\text { Pedro Daza y } \\
\text { Olarte }\end{array}$ \\
\hline Bonza & 49 & $\begin{array}{l}\text { Fernando de } \\
\text { Orellana } \\
\text { Sandoval }\end{array}$ \\
\hline Boyacá & 128 & Juan de Osa \\
\hline Boyacá- Cap. García & 25 & $\begin{array}{l}\text { Martín Patiño de } \\
\text { Haro }\end{array}$ \\
\hline Buisa & 20 & $\begin{array}{c}\text { Diego Paredes } \\
\text { Calderón }\end{array}$ \\
\hline Busbanza & $\begin{array}{l}79 \text { (Incl. Tobon \& } \\
\text { Pirasira) }\end{array}$ & $\begin{array}{l}\text { Diego Ventura } \\
\text { Rincón }\end{array}$ \\
\hline Cavita & 38 (Incl. Cupiagua) & $\begin{array}{l}\text { Ana Ordoñez y } \\
\text { Valdelomar }\end{array}$ \\
\hline Ceitiba & 49 (Incl. Beteitiba) & $\begin{array}{c}\text { Juana de Avalos } \\
\text { Marín }\end{array}$ \\
\hline Ceniza & 154 & Juan de Poveda \\
\hline Chaine & 28 & $\begin{array}{c}\text { Juan de Zarate } \\
\text { Chacón }\end{array}$ \\
\hline Chameza & 49 & $\begin{array}{l}\text { Miguel Holguín } \\
\text { de Figueroa }\end{array}$ \\
\hline Chameza & 28 & $\begin{array}{l}\text { Pedro Daza y } \\
\text { Olarte }\end{array}$ \\
\hline Chausa & 99 (Incl. Sasa) & $\begin{array}{l}\text { Antonio Patiño } \\
\text { de Haro }\end{array}$ \\
\hline Cheva & $\begin{array}{c}105 \text { (Incl. Ura \& } \\
\text { Ogamora) }\end{array}$ & $\begin{array}{l}\text { Sebastián de } \\
\text { Velandia }\end{array}$ \\
\hline Chibaba & 95 (Incl. Tijo) & $\begin{array}{l}\text { Bartolomé } \\
\text { Bermúdez }\end{array}$ \\
\hline Chibatá & 141 & $\begin{array}{c}\text { Encomienda de } \\
\text { la Corona }\end{array}$ \\
\hline Chibatá & 67 & $\begin{array}{l}\text { Bartolomé } \\
\text { Bermúdez }\end{array}$ \\
\hline Chicamocha & 15 & $\begin{array}{l}\text { Antonio de } \\
\text { Enciso }\end{array}$ \\
\hline Chicuasa & 24 (Incl. Tutasa) & Juan de Borja \\
\hline Chinata & $\begin{array}{c}87 \text { (Incl. Ocusa \& } \\
\text { Timisa) }\end{array}$ & $\begin{array}{l}\text { Martín Niño } \\
\text { Rojas }\end{array}$ \\
\hline Chipatá & $\begin{array}{l}137 \text { (Incl. Topaga, } \\
\text { Gomato \& Satoba) }\end{array}$ & $\begin{array}{c}\text { Pedro Bravo } \\
\text { Bezerra }\end{array}$ \\
\hline Chiquinquirá & 55 & $\begin{array}{l}\text { Pedro Merchán } \\
\text { de Monsalve }\end{array}$ \\
\hline Chiquisa & 65 & $\begin{array}{c}\text { Pedro Merchán } \\
\text { de Velasco }\end{array}$ \\
\hline Chiramita & 17 & $\begin{array}{c}\text { Bartolomé } \\
\text { Velosa y Castro }\end{array}$ \\
\hline Chiscas & 43 & $\begin{array}{l}\text { Miguel Suárez } \\
\text { de Figueroa }\end{array}$ \\
\hline Chita & 181 & $\begin{array}{l}\text { Martín de } \\
\text { Mendoza y } \\
\text { Berrio }\end{array}$ \\
\hline Chitagoto & 47 & $\begin{array}{c}\text { Diego de } \\
\text { Carvajal } \\
\text { Manrique }\end{array}$ \\
\hline Chusbitá & 56 (Incl. Sagra) & $\begin{array}{l}\text { Fernando de } \\
\text { Rivera }\end{array}$ \\
\hline Ciénega & 38 & $\begin{array}{l}\text { Diego Paredes } \\
\text { Calderón }\end{array}$ \\
\hline Citaquezipa & 60 & $\begin{array}{l}\text { Pedro Merchán } \\
\text { de Velasco }\end{array}$ \\
\hline Coasa & 36 & $\begin{array}{c}\text { Miguel de } \\
\text { Fonseca }\end{array}$ \\
\hline
\end{tabular}

\begin{tabular}{|c|c|c|}
\hline Encomiendas & Indios Tributarios & Encomenderos \\
\hline Cochavita & 14 & Pedro Núñez Cabrera \\
\hline Cocuy & 71 & Pedro Núñez Cabrera \\
\hline Combita & 66 & Pedro Niño Zambrano \\
\hline Comeza & $\begin{array}{l}113 \text { (Incl. } \\
\text { Cosquetibá) }\end{array}$ & Gregorio Suárez de Novoa \\
\hline Coromoro & 42 & Pedro Ordoñez y Vargas \\
\hline Cosquetibá & 113 (Incl. Comeza) & Gregorio Suárez de Novoa \\
\hline Crabos & 30 & Encomienda de la Corona \\
\hline Cuuitivá & 83 & Magdalena de Gaviria \\
\hline Cupasayna & 8 & Francisco Cerón \\
\hline Cupiagua & 38 (Incl. Cavita) & Ana Ordoñez y Valdelomar \\
\hline Cuqueita & 107 (Incl. Meoca) & Gregorio Suárez de Novoa \\
\hline Cusaguey & 22 & Diego Carvajal \\
\hline Cusiana & 23 & Pedro Daza y Olarte \\
\hline Duitama & 168 & Encomienda de la Corona \\
\hline Firavitoba & 148 & Sebastián de Velandia \\
\hline Foacá & 36 & Fernando Albino de Rojas \\
\hline Furaquirá & 46 & Pedro Arias Maldonado \\
\hline Furaquirá & 58 (Incl. Gacha) & Juan de Osa \\
\hline Gacha & 58 (Incl. Furaquirá) & Juan de Osa \\
\hline Gameza & 135 (Incl. Sotaquirá) & Juan de Vargas Hermoso \\
\hline Gameza & 61 & Fernando Alvino de Rojas \\
\hline Garagoa & 38 & Andrés Bautista de los Reyes \\
\hline Gotamo & $\begin{array}{l}137 \text { (Incl. Topaga, } \\
\text { Chipata \& Satova) }\end{array}$ & Pedro Bravo Bezerra \\
\hline Guacamayas & 22 & $\begin{array}{c}\text { Sebastián de Cifuentes } \\
\text { Monsalve }\end{array}$ \\
\hline Guacha & 44 (Incl. Sumita) & Juan Durán de la Parra \\
\hline Guachetá & 189 & Félix de la Serna Mojica \\
\hline Guaneca & 3 & Miguel Suárez de Figueroa \\
\hline Guaquirá & 44 & Juan de Torres Contreras \\
\hline Guaravitebas & 35 & $\begin{array}{l}\text { Sebastián de Cifuentes } \\
\text { Monsalve }\end{array}$ \\
\hline Guaravitebas & 5 & Antonio de Cifuentes Angulo \\
\hline Guatatibe & 5 & Gregorio Suárez de Novoa \\
\hline Guatecha & 54 & Pedro Bravo Bezerra \\
\hline Guatenzana & 18 & Martín de Mendoza y Berrio \\
\hline Guateque & 38 & Juan de Velasco Vallejo \\
\hline Icabuco & 238 (Incl. Chiribí) & Miguel Suárez de Figueroa \\
\hline
\end{tabular}

71 
Anexo 6: Cifras de población 1634 continuación

\begin{tabular}{|c|c|c|}
\hline Encomiendas & Indios Tributarios & Encomenderos \\
\hline Icaga & 26 & $\begin{array}{l}\text { Sebastián de } \\
\text { Cifuentes } \\
\text { Monsalve }\end{array}$ \\
\hline Iguaque & 99 & Pedro Vanegas \\
\hline Iza & 83 & $\begin{array}{l}\text { Sebastián de } \\
\text { Velandia }\end{array}$ \\
\hline Labranza Grande & 44 & $\begin{array}{c}\text { Encomienda de } \\
\text { la Corona }\end{array}$ \\
\hline Lenguasaque & 125 & Francisco Cerón \\
\hline Lengupa & 13 & $\begin{array}{c}\text { Laureano de la } \\
\text { Parra }\end{array}$ \\
\hline Meoaca & 107 (Incl. Cuqueita) & $\begin{array}{c}\text { Gregorio Suárez } \\
\text { de Novoa }\end{array}$ \\
\hline Monga & 95 & $\begin{array}{l}\text { Encomienda de } \\
\text { la Corona }\end{array}$ \\
\hline Monguí & 97 (Incl. Tutasa) & $\begin{array}{l}\text { Encomienda de } \\
\text { la Corona }\end{array}$ \\
\hline Moniquirá & 8 & María de la Peña \\
\hline Moniquirá & 68 (Incl. Saquncipá) & $\begin{array}{c}\text { Felix de la Serna } \\
\text { Mojica }\end{array}$ \\
\hline Moniquirá & $\begin{array}{l}294 \text { (Incl. Sogamoso \& } \\
\text { Tiren) }\end{array}$ & $\begin{array}{l}\text { Encomienda de } \\
\text { la Corona }\end{array}$ \\
\hline Moquecha & 53 & $\begin{array}{c}\text { Martín de } \\
\text { Mendoza y } \\
\text { Berrio }\end{array}$ \\
\hline Morcote & 116 & $\begin{array}{l}\text { Pedro Niño } \\
\text { Zambrano }\end{array}$ \\
\hline Motavita & 87 & Francisco Cerón \\
\hline Motavita & 31 & $\begin{array}{l}\text { Andrés Bautista } \\
\text { de los Reyes }\end{array}$ \\
\hline Muecha & 2 & $\begin{array}{l}\text { Laureano de la } \\
\text { Parra }\end{array}$ \\
\hline Neacacha & 13 & $\begin{array}{l}\text { Martín Niño } \\
\text { Rojas }\end{array}$ \\
\hline Nemusa & 138 (Incl. Oicatá) & $\begin{array}{l}\text { Miguel Ruíz } \\
\text { Corredor }\end{array}$ \\
\hline Nobsa & 56 & $\begin{array}{c}\text { Miguel Holguín } \\
\text { de Figueroa }\end{array}$ \\
\hline Ocavita & 29 & $\begin{array}{l}\text { Jacinto de } \\
\text { Lisarazo }\end{array}$ \\
\hline Ochica & 73 & Juan de Borja \\
\hline Ocusa & $\begin{array}{c}87 \text { (Incl. Timisa \& } \\
\text { Chinata) }\end{array}$ & $\begin{array}{l}\text { Martín Niño } \\
\text { Rojas }\end{array}$ \\
\hline Ogamora & 105 (Incl. Ura \& Cheva) & $\begin{array}{c}\text { Sebastián de } \\
\text { Velandia }\end{array}$ \\
\hline Oicatá & 138 (Incl. Nemusa) & $\begin{array}{l}\text { Miguel Ruíz } \\
\text { Corredor }\end{array}$ \\
\hline Onzaga & 83 & María de la Peña \\
\hline Pachaquirá & 29 & $\begin{array}{c}\text { Alonso de Llano } \\
\text { Valdes }\end{array}$ \\
\hline Paipa & 195 & $\begin{array}{c}\text { Francisco de } \\
\text { Cifuentes } \\
\text { Monsalve }\end{array}$ \\
\hline Panqueba & 75 & $\begin{array}{l}\text { Diego Paredes } \\
\text { Calderón }\end{array}$ \\
\hline Pesca & 78 & $\begin{array}{c}\text { Pedro Daza y } \\
\text { Olarte }\end{array}$ \\
\hline Pirasira & $\begin{array}{l}79 \text { (Incl. Busbanza \& } \\
\text { Tobon ) }\end{array}$ & $\begin{array}{l}\text { Diego Ventura } \\
\text { Rincón }\end{array}$ \\
\hline Pisba & 81 & Juan de Borja \\
\hline Pueblo de La Sal & 58 & $\begin{array}{l}\text { Martín de } \\
\text { Mendoza y } \\
\text { Berrio }\end{array}$ \\
\hline Ramiriquí & 34 & $\begin{array}{l}\text { Pedro Arias } \\
\text { Maldonado }\end{array}$ \\
\hline Ráquira & 45 & $\begin{array}{c}\text { Eugenia Alfonso } \\
\text { de los Angeles }\end{array}$ \\
\hline
\end{tabular}

\begin{tabular}{|c|c|c|}
\hline Encomiendas & Indios Tributarios & Encomenderos \\
\hline Rasgón & 6 & $\begin{array}{l}\text { Sebastián de Cifuentes } \\
\text { Monsalve }\end{array}$ \\
\hline Sáchica & 142 & Juan Pérez de Salazar \\
\hline Sagra & 56 (Incl. Chusbitá) & Fernado de Rivera \\
\hline Samaca & 43 & Encomienda de la Corona \\
\hline Saquencipá & 68 (Incl. Moniquirá) & Félix de la Serna Mojica \\
\hline Sasa & 99 (Incl. Chausa) & Antonio Patiño de Haro \\
\hline $\begin{array}{l}\text { Sátiva } \\
\end{array}$ & $\begin{array}{l}60 \text { (Incl. Ocusa, } \\
\text { Timisa \& Chinata) }\end{array}$ & Martín Niño y Rojas \\
\hline Sátiva & 35 & Diego de Carvajal Manrique \\
\hline Satoba & $\begin{array}{c}137 \text { (Incl. Topoga, } \\
\text { Chipata \& Gotamo) }\end{array}$ & Pedro Bravo Bezerra \\
\hline Siachoque & 86 & Juan de Otálora \\
\hline Soacá & 55 & Francisco Rodríguez Melgarejo \\
\hline Soatá & 69 & Alonso de Llano Valdes \\
\hline Soatá & 57 & Encomienda de la Corona \\
\hline Socha & $\begin{array}{c}109 \text { (Incl. Tasco \& } \\
\text { Tobasía) }\end{array}$ & Diego de Carvajal \\
\hline Soconsaque & 6 & Pedro Arias Maldonado \\
\hline Soconsuco & 37 & $\begin{array}{c}\text { Sebastián de Cifuentes } \\
\text { Monsalve }\end{array}$ \\
\hline Socotá & 46 & Diego de Carvajal \\
\hline Sogamoso & $\begin{array}{c}294 \text { (Incl. Moniquirá } \\
\text { \& Tiren) }\end{array}$ & Encomienda de la Corona \\
\hline Somondoco & 71 & Alonso de Olalla Vasconcelos \\
\hline Sora & 99 & Pedro Vanegas \\
\hline Soraca & 77 & Juan de Enciso y Cárdenas \\
\hline Sotaquirá & 135 (Incl. Gameza) & Juan de Vargas Hermoso \\
\hline Sumita & 44 (Incl. Guacha) & Juan Durán de la Parra \\
\hline Sunuba & 26 & $\begin{array}{l}\text { Diego de Estupiñan Cabeza de } \\
\text { Vaca }\end{array}$ \\
\hline 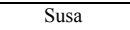 & 247 & Pedro Suárez Lanchero \\
\hline Susa & 51 & Fernando de Orellana Sandoval \\
\hline Susacón & 29 & Pedro Bravo Bezerra \\
\hline Susbaque & 21 & Diego de Paredes Calderón \\
\hline Suta & 100 & Pedro Merchán de Velasco \\
\hline Suta & 47 & Martín Niño Rojas \\
\hline Sutamanga & 21 (Incl. Baganique) & Laureano de la Parra \\
\hline $\begin{array}{l}\text { Sutatenza } \\
\text { Sul }\end{array}$ & 69 & $\begin{array}{l}\text { Juan de Zarate y María Arias } \\
\text { de Ugarte }\end{array}$ \\
\hline Tamara & 341 & Martín de Mendoza y Berrio \\
\hline Tasco & $\begin{array}{c}109 \text { (Incl. Socha \& } \\
\text { Tobasía) }\end{array}$ & Diego de Carvajal \\
\hline Teguas & 71 & Alonso de Olalla Vasconcelos \\
\hline Teguas & 57 & Andrés Bautista de los Reyes \\
\hline
\end{tabular}




\section{Anexo 6: Cifras de población 1634 continuación}

\begin{tabular}{|c|c|c|}
\hline Encomiendas & Indios Tributarios & Encomenderos \\
\hline Teguas & 19 & Juan de Zarate \\
\hline Tenza & 86 & Juan de Zarate \\
\hline Tequía & 61 & $\begin{array}{l}\text { Antonio de } \\
\text { Enciso }\end{array}$ \\
\hline Tibana & 106 & $\begin{array}{l}\text { Miguel Suárez } \\
\text { de Figueroa }\end{array}$ \\
\hline Tibaquirá & 8 & Diego Carvajal \\
\hline Tibasosa & 100 & $\begin{array}{l}\text { Miguel Holguín } \\
\text { de Figueroa }\end{array}$ \\
\hline Tijo & 95 (Incl. Chibaba) & $\begin{array}{c}\text { Bartolomé } \\
\text { Bermúdez de } \\
\text { Olarte }\end{array}$ \\
\hline Timisa & $87 \begin{array}{c}\text { (Incl. Ocusa \& } \\
\text { Chinata) }\end{array}$ & $\begin{array}{l}\text { Martín Niño y } \\
\text { Rojas }\end{array}$ \\
\hline Tinjaca & 246 & $\begin{array}{c}\text { Juan de } \\
\text { Avendaño } \\
\text { Maldonado }\end{array}$ \\
\hline Tiren & $\begin{array}{l}294 \text { (Incl. Sogamoso \& } \\
\text { Moniquirá) }\end{array}$ & $\begin{array}{c}\text { Encomienda de } \\
\text { la Corona }\end{array}$ \\
\hline Tobasía & 27 & Juan de Borja \\
\hline Tobon & $\begin{array}{c}109 \text { (Incl. Socha \& } \\
\text { Tasco) }\end{array}$ & $\begin{array}{l}\text { Diego de } \\
\text { Carvajal }\end{array}$ \\
\hline Toca & 176 & $\begin{array}{l}\text { Felipe de Rojas } \\
\text { Montalvo }\end{array}$ \\
\hline Topaga & $\begin{array}{l}137 \text { (Incl. Chipata, } \\
\text { Sátova \& Gotamo) }\end{array}$ & $\begin{array}{l}\text { Pedro Bravo } \\
\text { Bezerra }\end{array}$ \\
\hline Topía & 51 & $\begin{array}{c}\text { Magdalena de } \\
\text { Gaviria }\end{array}$ \\
\hline Toquecha & 62 (Incl. Moquecha) & Pedro Alarcón \\
\hline Toquilla & 9 & $\begin{array}{l}\text { Diego Patiño de } \\
\text { Argumedo }\end{array}$ \\
\hline Tota & 71 & $\begin{array}{c}\text { Pedro Ordoñez y } \\
\text { Vargas }\end{array}$ \\
\hline Tunebas & 34 & $\begin{array}{c}\text { Martín de } \\
\text { Mendoza y } \\
\text { Berrio }\end{array}$ \\
\hline Tunebas & 30 & $\begin{array}{l}\text { Diego Paredes } \\
\text { Calderón }\end{array}$ \\
\hline Tunebas & 17 & $\begin{array}{l}\text { Sebastián de } \\
\text { Cifuentes } \\
\text { Monsalve }\end{array}$ \\
\hline Tupachoque & 18 & $\begin{array}{l}\text { Andrés Bautista } \\
\text { de los Reyes }\end{array}$ \\
\hline Turga & 44 & $\begin{array}{l}\text { Pedro Bravo } \\
\text { Bezerra }\end{array}$ \\
\hline Turmequé & 357 & $\begin{array}{c}\text { Encomienda de } \\
\text { la Corona }\end{array}$ \\
\hline Tuta & 159 & $\begin{array}{l}\text { Francisco Félix } \\
\text { de Caicedo }\end{array}$ \\
\hline Tutasa & 24 (Incl. Chiquesa) & Juan de Borja \\
\hline Tutasa & $\begin{array}{l}97 \text { (Incl. Monguí \& } \\
\text { Tiren) }\end{array}$ & $\begin{array}{c}\text { Encomienda de } \\
\text { la Corona }\end{array}$ \\
\hline Ubeita & 7 & Juan de Zarate \\
\hline Ura & $\begin{array}{c}105 \text { (Incl. Cheva \& } \\
\text { Ogamora) }\end{array}$ & $\begin{array}{l}\text { Sebastián de } \\
\text { Velandia }\end{array}$ \\
\hline Viracacha & 37 & $\begin{array}{l}\text { Gregorio Suárez } \\
\text { de Novoa }\end{array}$ \\
\hline Viracusa & 11 & $\begin{array}{l}\text { Juan Encisco y } \\
\text { Cárdenas }\end{array}$ \\
\hline Viracusa & 5 & $\begin{array}{l}\text { Antonio de } \\
\text { Enciso }\end{array}$ \\
\hline \multicolumn{3}{|l|}{ Totales } \\
\hline Encomiendas & 178 & \\
\hline Indios encomendados & 10.144 & \\
\hline Encomenderos & 62 & \\
\hline Encomiendas de la Corona & 13 & \\
\hline
\end{tabular}

Fuente: AGN, Bogotá, Visitas de Boyacá, 11. 


\section{Bibliografía}

\section{A. Fuentes primarias}

Archivo General de Indias, Sevilla

Audiencia de Santafé

Archivo General de la Nación, Bogotá

Caciques e Indios

Miscelánea

Visitas de Boyacá

Archivo Regional de Boyacá, Tunja

Archivo Histórico

\section{B. Fuentes secundarias}

Aguado, Pedro. Recopilación historial. 4 tomos. Bogotá: Biblioteca de la Presidencia de Colombia, 1956.

Brothwell, Don. "On Biological Exchanges between the Two Worlds". En The Meeting of Two Worlds, Warwick Bray ed. Oxford: Oxford University Press, 1993.

Colmenares, Germán. Encomienda y población en la provincia de Pamplona, 1549-1650. Bogotá: Universidad de los Andes, 1969.

. La provincia de Tunja en el Nuevo Reino de Granada. Bogotá: Universidad de los Andes, 1970.

. Historia económica y social de Colombia, 1537-1719. Medellín: Editorial La Carreta, 1975.

Cook, Noble David. Demographic Collapse: Indian Peru, 1520-1620. Cambridge: Cambridge University Press, 1981.

Cook, Noble David y W. George Lovell, eds. Secret Judgments of God: Old World Disease in Colonial Spanish America. Norman: University of Oklahoma Press, 1992.

Cook, Sherburne y Woodrow Borah. The Indian Population of Central Mexico, 1531-1610. Berkeley: University of California Press, Ibero-Americana, 1960. The Aboriginal Population of Mexico on the Eve of the Spanish Conquest. Berkeley: University of California Press, Ibero-Americana, 1963. The Population of the Mixtec Alta, 1520-1960. Berkeley: University of California Press, 1968.

. Essays in Population History. Berkeley: University of California Press, 1971.

Crosby Alfred W., The Columbian Exchange: Biological and Cultural Consequences of 1492. Westport: Greenwood Press, 1972.

Denevan, William M. ed. The Native Population of the Americas in 1492. Madison: University of Wisconsin Press, 1976. 
Dobyns, Henry. "Estimating Aboriginal American Population: An Appraisal of Techniques with a New Hemispheric estimate", Current Anthropology 7 (1966), 395-449.

Eidt, Robert C. "Aboriginal Chibcha Settlement in Colombia", Annals of the American Association of Geographers 49 (diciembre, 1959).

Elliot, J.H. Spain and its World 1500-1700: Selected Essays. New Haven: Yale University Press, 1989.

Farris, Nancy. Maya Society Under Colonial Rule: The Collective Enterprise of Survival. Princeton: Princeton University Press, 1984.

Friede, Juan. Documentos inéditos para la historia de Colombia. Bogotá: Academia Colombiana de Historia, 1955. . Fuentes documentales para la historia del Nuevo Reino de Granada. Bogotá: Banco Popular, 1960.

"Algunas consideraciones sobre la evolución demográfica en la Provincia de Tunja", Anuario Colombiano de Historia Social y de la Cultura 2, no.3 (1965).

Gálvez Piñal, Esperanza. La Visita de Monzón y Prieto de Orellana a Nuevo Reino de Granada. Sevilla: Escuela de Estudios Hispano-Americanos, 1974.

Gibson, Charles. "Writings on Colonial México", Hispanic American Historical Review 55, no.2 (1975).

Groot, José Manuel. Historia eclesiástica y civil del Nuevo Reino de Granada. Bogotá, 1953.

Hansen, Caroline Anne. Conquest and Colonization in the Colombian Chocó, 1510-1740. Tesis doctoral.Warwick: University of Warwick, 1991.

Hernández Rodríguez, Guillermo. De los chibchas a la colonia y a la república. Bogotá: Universidad Nacional de Colombia, 1949.

Jaramillo Uribe, Jaime. "La población indígena de Colombia en el momento de la conquista y sus transformaciones posteriores", Anuario Colombiano de Historia Social y de la Cultura 1, no.2 (1964).

. Ensayos sobre historia social colombiana. Bogotá: Universitaria de Cultura Colombiana, 1968.

Kroeber, A.L. "The Chibcha". En Handbook of South American Indians, Julian H. Steward ed. Tomo 2. New York: Cooper Square Publishers Inc., 1963.

Langebaek, Carl Henrik. From Hunters and Gatherers to Muiscas, Campesinos and Hacendados in the Eastern Highlands of Colombia. An Archaeological Survey in the Valles de Fúquene and Susa. Disertación doctoral no publicada. Pittsburg: Universidad de Pittsburg, 1993.

López de Velasco, Juan. "Geografía y descripción universal de las Indias". En Biblioteca de Autores Españoles, Don Marcos Jiménez de la Espada ed., N.248. Madrid: Ediciones Atlas, 1971.

Lovell, W. George. Conquest and Survival in Colonial Guatemala: A Historical Geography of the Cuchumatán Highlands, 1500-1821, edición revisada. Montreal y Kingston: McGill-Queen's University Press, 1992.

McFarlane, Anthony. Colombia Before Independence: Economy, Society and Politics Under Bourbon Rule. Cambridge: Cambridge University Press, 1993.

Melo, Jorge Orlando. Historia de Colombia. Bogotá: La Carreta, 1978. 
Newson, Linda A. "Demographic Collapse of Native Peoples of the Americas, 1492-1650". En The Meeting of Two Worlds: Europe and the Americas, 1492-1650, Warwick Bray, ed. Oxford: Oxford University Press, 1993.

. Life and Death in Early Colonial Ecuador. Norman: University of Oklahoma Press, 1995.

Powers, Karen. Andean Journeys: Migration, Ethnogenesis, and the State in Colonial Quito. Albuquerque: University of New Mexico Press, 1995.

Reichel-Dolmatoff, Gerardo. "Colombia indígena". En Manual de Historia de Colombia. Bogotá: Instituto Colombiano de Cultura, 1984.

Robinson, David ed. Migration in Colonial Spanish America. Cambridge: Cambridge University Press, 1990.

Rowe, John. "Inca Culture at the Time of the Spanish Conquest". En Handbook of South American Indians, Julian H. Steward, ed., 2:183-330. Washington: Bureau of American Ethnology Bulletins, 1946-1959.

Ruíz Rivera, Julián. Encomienda y mita en Nueva Granada en el siglo XVII. Sevilla: Escuela de Estudios Hispano Americanos de Sevilla, 1975.

Simón, Pedro. Noticias historiales de las conquistas de tierra firme en las Indias Occidentales. Bogotá: Banco Popular, 1981.

Smith, C.T. "Depopulation of the Central Andes in the $16^{\text {th }}$ Century", Current Anthropology 11 (1970).

Suescún Monroy, Armando. La economía chibcha. Bogotá: Ediciones Tercer Mundo, 1987.

Todorov, Tzvetan. The Conquest of America. New York: Harper \& Row, 1934.

Torres de Mendoza, Juan. Colección de documentos inéditos relativos al descubrimiento, conquista y organización de las antiguas posesiones españolas de América y Oceanía. Madrid: Imprenta de Frías y Compañía, 1868.

Tovar Pinzón, Hermes. "Estado actual de los estudios de demografía histórica en Colombia", Anuario Colombiano de Historia Social y de la Cultura, no. 5 (1970): 65-140. . No hay caciques ni señores. Barcelona: Sendai Ediciones, 1988.

Villamarín, Juan A. Encomenderos and Indians in the formation of Colonial Society in the Sabana de Bogotá, Colombia -1537 to 1740-. Tesis doctoral. Brandeis: Brandeis University, 1972.

Wachtel, Nathan. Vision of the Vanquished: The Spanish Conquest of Peru Through Indian Eyes. Hassocks, Sussex: Harvester Press, 1977. 